University of San Diego

Digital USD

1989

\title{
The Labyrinth of Challenge to Change: An Analysis of Community College Leaders' Thinking Styles and Behavioral Practices in the Current Environment
}

Mary Elizabeth Scott EdD

University of San Diego

Follow this and additional works at: https://digital.sandiego.edu/dissertations

Part of the Leadership Studies Commons

\section{Digital USD Citation}

Scott, Mary Elizabeth EdD, "The Labyrinth of Challenge to Change: An Analysis of Community College Leaders' Thinking Styles and Behavioral Practices in the Current Environment" (1989). Dissertations. 530. https://digital.sandiego.edu/dissertations/530

This Dissertation: Open Access is brought to you for free and open access by the Theses and Dissertations at Digital USD. It has been accepted for inclusion in Dissertations by an authorized administrator of Digital USD. For more information, please contact digital@sandiego.edu. 
THE LABYRINTH OF CHALLENGE. TO CHANGE:

AN ANALYSIS OF COMMUNITY COLLEGE LEADERS' THINKING STYLES AND BEHAVIORAL PRACTICES IN THE CURRENT ENVIRONMENT

by

Mary Elizabeth Scott

A dissertation submitted in partial fulfillment of the requirements for the degree of

Doctor of Education

University of San Diego

1989

Dissertation '́ommittee

Edward Kujawa, Ph.D., Director

Patricia Anderson, Ph.D.

William Foster, Ed.D. 


\section{ABSTRACT OF THE DISSERTATION}

The Labyrinth of Challenge to Change:

An Analysis of Community College Leaders' Thinking Styles and Behavioral Practices in the Current Environment

The present research addressed a concern of both urgent and profound dimensions in the modern world: the current and compelling need for a radically different kind of leadership to meet the challenge of turbulent change. This need has been crystallized by a new and emerging paradigm shift which at once reflects, confronts and shapes the realities experienced today.

This study sought to set in relief the current thinking styles of nominated California community college leaders and to see if and how these correlated with their leadership behavioral practices. The Human Information Processing Survey (HIPS) and the Leadership Practices Inventory-Self (LPI-S) and other (LPI-0) were the survey instruments used. Responses were seen by both sets of authors to have direct implications for effectively meeting the challenges of innovative and adaptive change. Four research questions and five research hypotheses were developed to focus and examine the topic. 
The research indicated that, unlike previous related educational and business studies where the dominant left or right mode prevailed, this population of nominated California community college leaders fell primarily in the mixed and integrated thinking styles. Both the HIPS composite and Tactic profile scores reflected this with the former being predominantly mixed, and the latter mainly integrated. This demonstrates a facility for a large percent of the sample (74\%) to use either the left or right modes separately or simultaneously. There is a substantial complementary interaction between both modes. According to the rationale presented, this whole-brain processing provides the most pregnant possibilities for both innovative and adaptive change.

The largest number of respondents (51\%) fell in the moderate usage range of the five LPI-S leadership practices. Thirty percent perceived themselves in the high range, and $19 \%$ in the low. Several possible reasons were proferred for this result, none conclusive. High ratings, as shown by the combined two top scorings' summary, related to the practices of "enabling others to act", "modeling the way", and "challenging the process". The sample means reflected the following ranking: "enabling others to act", "encouraging the heart", "challenging the process", "modeling the way", and "inspiring a shared vision". There were, however, no 
correlations of statistical significance (.05) found between the thinking styles and leadership behavioral practices nor for any of the research hypotheses. The composite LPI-0 responses were comparable to those of the LPI-S; no differences of significance were notad. 
Copyright 1989

by

Mary Elizabeth Scott

All rights reserved 


\section{ACKNOWLEDGEMENTS}

Gratitude and appreciation are extended to the following:

... To Alice Opolay, Dennis Murphy, and Dr. Pat Anderson, who were very helpful with the data and statistical aspects of the study.

... To Joyce Standish and Kathie Schmit, who served as the typists for my dissertation project.

... To my dissertation committee, Drs. Ed Kujawa, Bill Foster, and Pat Anderson who offered advice, practical support, and encouragement.

... To the University of San Diego for its strong commitment to human and ethical values.

Thank you, all. 
Abstract. . . . . . . . . . . . . . . . . . $i i$

Acknowledgements. . . . . . . . . . . . . . . . vi

List of Tables. . . . . . . . . . . . . . . . . . xi

List of Figures . . . . . . . . . . . . . . . . . xiii

Chapter

I STATEMENT OF THE ISSUE . . . . . . . . . . . 1

Background. . . . . . . . . . . . 1

A Related Community College Issue . . . . . 4

Challenge to Leadership . . . . . . . 6

Relationship of Present to Previous

Research ........... . . 14

Purpose of the study. . . . . . . . . 15

Definition of Terms . . . . . . . . 15

Research Questions and Hypotheses . . . . 16

Significance of the study . . . . . . . 20

Summary . . . . . . . . . . . . 22

II REVIEW OF THE IITERATURE . . . . . . . . . . 24

Introduction. . . . . . . . . . 24

Implications for Leadership . . . . . . 28

Contribution to Previous Research . . . . 37

Summary . . . . . . . . . . . . 38

III RESEARCH DESIGN. . . . . . . . . . 40

Introduction. ........... . 40

vii 
Methodology . . . . . . . . . . 40

Instruments . . . . . . . . . . . . 45

Statistical Analysis. . . . . . . . . 50

Assumptions . . . . . . . . . . 50

Limitations of the study. . . . . . . 51

Summary . . . . . . . . . . . 51

IV. ANALYSIS OF THE DATA . . . . . . . . . . 54

Introduction .. . . . . . . . . . 54

Demographic Profile . . . . . . . . 54

The Human Information Processing

Questionnaire. . . . . . . . 55

The Leadership Practices Inventory

Self and other . . . . . . . 69

Research Hypotheses . . . . . . . . 84

Summary .. . . . . . . . . . . 90

V. DISCUSSION OF FINDINGS, CONCLUSIONS, AND

RECOMMENDATIONS • . . . . . . . . 96

Nature and Purpose of the Study . . . . 96

Discussion of Findings. . . . . . . . . 98

Conclusions . . . . . . . . . . 102

Implications of the Study . . . . . . 103

Recommendations for Future Studies. . . . 107

REFERENCES. . . . . . . . . . . . . . . . 110

viii 
Page

APPENDICES. . . . . . . . . . . . . . . . . 119

A: Paradigm Shift . . . . . . . . . . . 120

B: America's Future Labor Force . . . . . . . 123

c: Problem-Solving styles: systematic and Intuitive Thinkers . . . . . . . . . . 125

D: A Comparison of Left-Mode and Right-Mode Characteristics. . . . . . . . . 127

E: Letter to Presidents . . . . . . . . 129

F: Leadership Criteria. . . . . . . . . 131

G: Presidents' Nominations Form . . . . . . . 133

H: Reasons for Non-Participation. . . . . . 135

I: Follow-up Letter to Presidents . . . . . . 137

$J$ : Requests for Presidents' Reasons for Non-Participation . . . . . . . . 139

K: Letter to Nominated Leader . . . . . . . 141

L: Research Subjects' Consent Form. . . . . . 143

M: Demographic Questionnaire. . . . . . . . 145

$\mathrm{N}$ : Letter from Scholastic Testing Service, Inc. • 147

O: Leadership Practices Inventory-Self. . . . 149

P: Letter to Designated Observers . . . . . . 153

Q: Leadership Practices Inventory-other . . . 155

R: Follow-up Letter to Leaders. . . . . . . 159

S: Follow-up Letter to Observers. . . . . . . 161

T: HIPS Histograms. . . . . . . . . . . 163

$$
\text { ix }
$$


Page

U. IPI-S Percentile Rankings for Linear Averages. 167

V. LPI-S Percentile Ranking . . . . . . . . 169

W. LPI-S Histograms . . . . . . . . . . 171

X. Clustering of Questions for LPI-S Behavioral

Practices . . . . . . . . . 177

Y. Selected Examples of LPI-S and LPI-O

Differences ........... . . 180 
LIST OF TABLES

Table

Page

1. Summary of HIPS Composite Scores by

Dominant Mode . . . . . . . . . . . . . .

2. Summary of HIPS Tactics Profile by

Dominant Mode . . . . . . . . . . . . . .

3. HIPS Tactics Profile Report

for Nominated Community College Leaders . . . .

4. Number of HIPS Questions Most Often Answered Similarly by Percentage of Community College

Leaders . . . . . . . . . . . . . . . . .

5. Comparison of HIPS Composite and HIPS Tactics

Modes for Nominated Community College Leaders . .

6. Summary of Average Ranges of IPI-S Leadership Behavioral Practices for Nominated Community College Leaders . . . . . . . . . . . . . .

7. Sample Mean Scores of the Five Individual

Leadership Behavioral Practices for Community

College Leaders . . . . . . . . . . . . .

8. Means and Standard Deviations for the LPI-S

for Kouzes and Posner's Sample Population I . .

9. Means and Standard Deviations for the LPI-S

for Kouzes and Posner's Sample Population II. . .

10. Summary of Combined Two Top scorings, "Fairly

often" and "Very Frequently, for Each LPI-S

Behavioral Practice for Nominated Community

College Leaders. . . . . . . . . . . . . .

11. Summary of HIPS Composite Modes and IPI-Self

Average Composite Ranges for Nominated Community

College Leaders. . . . . . . . . . . . . .

12. Correspondence of HIPS Composite Modes and Ranges of Individual LPI-S Behavioral Practices for Nominated Community College Leaders . . . . . . 
Page

13. Correspondence of Designated LPI-S Ranges and Dominant HIPS Modes for Nominated Community

College Leaders . . . . . . . . . . . . . .

14. Comparison of LPI-S and LPI-O Behavioral Practice Means for Community College Leaders and Observers . . . . . . . . . . . . . 85

15. Comparison of Leaders' and Observers' Scores. . . 86

16. Correspondence of Designated LPI-S Ranges and Dominant HIPS Modes for Nominated Community College Leaders . . . . . . . . . . . .

xii 


\section{IIST OF FIGURES}

Figure

Page

1. Leaders Scoring at or above the 90th

Percentile on the HIPS Survey . . . . . . 60

2. Number of HIPS Questions Most Often Answered

Similarly by Percentage of Community

College Leaders. . . . . . . . . . 64

3. Summary of Combined Two Top Scorings for Each

LPI-S Behavioral Practice . . . . . . .

xiii 
CHAPTER I

STATEMENT OF THE ISSUE

\section{Background}

In the modern world leaders face a labyrinth of considerations in their efforts to meet the challenge to change. The underlying reason for this centers on the emerging paradigm shift in how people view the world. John Naisbitt (1982) spoke about our nation being caught in a "time of parenthesis, a time between eras" (p. 249), a time of challenges, possibilities, and questions. "We have not quite left behind the either/or America of the past -centralized, industrialized, and economically self-contained - . . But we have not embraced the future either" (p. 249). He outlines and discusses ten megatrends, new directions, impacting the lives of Americans. These are the movement from an industrial to an informational society, from forced technology to high tech/high touch, from a national to a world economy, from short-term focus to longterm, from centralization to decentralization, from institutional help to self-help, from a representative to a participatory democracy, from hierarchies to networking, from the North to the South and from an either/or perspective to multiple options.

on the international level, indicators which speak to a similar evolving shift abound. Examples of travel, communications, and business involvements are among the 
shift's catalysts. Several authors have discerned related short- and long-term implications for the future. In the field of education, Ernest Boyer (1985), former President of the Carnegie Foundation for the Advancement of Teaching, identifies today's primary educational goal as the "achievement of perspective": international, national, ecological, peace-related, because "the simple reality of existence [is] . . . while we are all alone, we are also all together . . while we are independent, we are all at the same time interdependent on each other." His sense of weightiness and urgency stems from his perception of the "dangerous, interdependent world we will inhabit" (Boyer, 1985). In the field of business, Naisbitt (1982) posits that "The two most important things to remember about world economics are that yesterday is over and that we must now adjust to living in a world of interdependent communities" (p. 55). Peters (1987) concludes a recent article with "going international has never been more important" (p. E1). Lamy (1987), Director of the Center for Public Education in International Affairs at the University of Southern California, clusters three areas of the challenge: political, economic and humanitarian (CCID Paper). Akers (1987) names the needed perspective for the future "glocal." organizationally, numerous authors have dealt with themes signaling major new perceptions. Deal and Kennedy (1982) discuss the emerging emphasis on organizational culture with its corresponding values, heroes, rites, 
rituals, and means of communication. Peters and Waterman (1982) identify nine core practices of excellence characteristic of successfully-managed companies, but frequently absent from others. These core practices encompass managing ambiguity and paradox, exhibiting a bias for action, keeping close to the customer, fostering autonomy and entrepreneurship, achieving productivity through people, performing hands-on and value driven activities, sticking to the knitting, maintaining a simple form, lean staff, and balancing simultaneously loose and tight properties. Schein (1985) presents the model of cultural artifacts, values and basic assumptions of organizations. Weick (1984) proffers his insights with his descriptions of "loosely-coupled systems" (pp. 375-408). others deal with the interface of all three: Harrison (1983) with his strategies of alignment and attunement for a new age; Motamedi (1985) with his study of adaptability and copability; Smith (1982) with his discussion of boundaries and turbulence in thinking about change; and Terreberry (1984) with her description of how organizational environments evolve in a turbulent world.

From these national, international, and organizational examples, an emerging sense of a profound change in the world-view is evident. This change affects such core assumptions as one's perception and understanding of the nature of reality, knowing, authority, organizations, change, decision-making, conflict, values, resources, of the 
possibility of generalizability and of the process of development. Allen, Chrispeels, Fink and Tan (1988) yielded a description of the paradigm shift currently underway (see Appendix A). The paradigm describes some fundamentally new and different perceptions which at once reflect and shape the realities shifting in today's environment. This overview is crucial in considering the challenges before leadership in the 1990's.

\section{A Related Community College Issue}

Numerous researchers have explicitly discussed broad as well as more detailed scenarios of several possible futures: Harmon (1976), Pluimer (1984), Hughes (1985), and Cetron, Rocha, and Luckins (1988). Davenport (1989) outlines a specific critical contemporary issue impacting future efforts and directions of community colleges. Since this study dealt with community college leaders, it seems apropos to include it as one related example.

Davenport explores the projected United States' work force of the 21 st century and the challenges that it will provide to chief executive officers in community colleges across the states. He describes four key trends: (a) a relatively healthy pace for the growing economy, (b) the increase of service industry jobs, (c) the changing demography of the work force, and (d) the demand for higher level skills. He discusses several major pressing policy issues: (a) the stimulation of a balanced world growth, (b) the acceleration of productivity in the service world, 
(c) the maintaining of vitality in an aging work force,

(d) the achieving of adequate harmony among the conflicting demands of woman, work, and families, (e) the integration of primary minorities into the economy, and (f) the improvement of educational preparation for the work force. He suggests fewer people in the workplace, a shorter average work week and more part-time employees.

Davenport provides a comparison of the current workforce (1985) with that of the new entrants for the next 15 years (1985-2000) (see Appendix B). The percentages below reflect significant shifts in composition:

1985

Current Labor Force

White men

White women

Non-white men

Non-white women

Immigrant men

Immigrant women $3 \%$
1985-2000

New Entrants

$15 \%$

$42 \%$

$7 \%$

$13 \%$

$13 \%$

$9 \%$

(Davenport, 1989, p. 24)

Davenport (1989) recommends the adoption of several. practices which may address some of these concerns. For example, the classroom must be brought to the worker; course scheduling must be arranged to reflect students' child care concerns; highly aducated and technologically trained retirees could be enlisted as instructors and administrators; and industry employees must be encouraged to 
serve as instructors in these endeavors. He then concludes his article with the following statement: "The innovation and adaptability that have historically characterized community, technical, and junior colleges will enable these institutions to play a leadership role in meeting the needs of the new economy" (p. 27).

The work force is just one of numerous major areas experiencing radical changes which impact the individual and society's institutions. The challenge to community college leaders is profound. As will be shown later, the focus of this study lays the foundation for an integral and balanced approach to grasping and to acting toward the preferred future.

\section{Challenge to Leadership}

The labyrinth of change will require a different type of leadership, having elements of those types described by people like Burns (1978), Foster (1988), Hagberg (1984), Hendrickson (1988), Kouzes and Posner (1987), Rost (1985, 1988) and zurcher (1977). New models of leadership must include a discussion of three major components: the human dynamic, sometimes referred to as the process; the change dynamic, sometimes called the product or outcome; and the environmental contribution and impact. Before describing this new leadership, a review of prior models is in order.

Former models. The management model of leadership is part of the declining paradigm. A primary reason is because it is based on an authoritarian or one-directional 
perspective toward persons, change and the environment. The model's premises are predicated on control, manipulation and predictability. Its emphases on conformity, rationality, reliability and impersonality as described by weber (1964) and Burns (1978) no longer fit. These emphases parallel many aspects of Kirscht and Dillehay's (1967) discussion of authoritarianism where conventionalism, submission, aggression, anti-intraception, superstition and stereotypy, power and toughness, destructiveness and cynicism are inherent characteristics (cited in scott, 1976).

Played out to their extremes, practices rooted in this management model lead to the "bureaucratized individuals" and "emotivism" of MacIntyre (1984), the "atomized society" and modern liberalism of Sullivan (1986), the ineffective "efficiency" of Taylor (cited in Hunt, 1984), the disjointed economic focus of Hughes (1985), the petrified bureaucracies of Weber (cited in Hunt, 1984), the despotism of Tocqueville (Bellah, 1985), the ethnocentric "racism" of Alderfer (1984) and the distorted "escalation and commitment" of staw (1982).

Rost (1985a) posits these focuses which differentiate this management from leadership: its emphasis on position, authority relationships, limited competition for followers, organizational as opposed to personal motivation, specific and narrow problem-solving concerns, products, modal values, procedure and regulations, maintenance of the status quo, low risk-taking practices, particular and discrete conflict 
resolution, present focus, predictability, the organizational thrust over the individual, practical operations, and an external locus of control. These characteristics comprise an antithesis of the demands made on leadership in the current turbulent environment. other earlier understandings of leadership initiated the attempts to enumerate a series of traits which individuals ought to possess. Hunt (1984) summarizes Jago's traits list to include the following: activity/energy, appearance/grooming, cooperativeness, height, initiative, intelligence, judgement, self-confidence, sociability, tact, talkativeness and weight. Other writers have more recently listed the fatal flaws of potential or aspiring leaders, another attempt to arrive at the same understanding, but from the shadow or opposite side. McCall and Lombardo (1983) distilled 65 possible derailing factors to ten categories: (a) insensitivity to others: abrasive, intimidating, bullying style; (b) coolness, aloofness, arrogance; (c) betrayal of trust; (d) overly ambitious attitude: thinking of the next job, playing politics; (e) specific performance problems with the business; (f) overmanaging: unable to delegate or build a team; ( $g$ ) inability to staff effectively; (h) inability to think strategically; (i) inability to adapt to a boss with a different style; and (j) overdependence on an advocate or mentor. 
Simple listing of traits or common pitfall categories does not provide a perspective of leadership which addresses today's understandings and needs. Such a listing is too simplistic and unilateral as was the "great man" theory which held that certain individual men such as churchill, Gandhi, and Napoleon do make history, that "the causes of real, intended social change can be traced back to the purposes and decisions of the most visible actors on the political stage" (Burns, 1978, p. 51). This theory, however, eschews the complex and sometimes obscure causal factors which underlie events. Indeed, it is also too one-sided and therefore inadequate, particularly in today's more comprehensive view of leadership.

Still others have based their explanations about leadership on contingency theory. Three basic explanations dominate this perspective of leadership. Fiedler (1967) believes that the best leadership style for group effectiveness, either relationship-motivated or taskmotivated, depends on the amount of control permitted by the leader. If a harmonious match exists between style and control, the results will be positive. House (1971) advocates that the leader should complement the subordinates' place of work with needed equipment, furnishings, etc. so that the individual will be more motivated and satisfied with his/her work. He suggests a leader may be directive, supportive, achievement-oriented, or participative in dealing with subordinate traits and work 
setting environments. The emphasis here still reflects secondary or superficial approaches. Vroom and Yetton (1973) present the use of authoritarian, consultative or group consensus leadership along with the promotion of effective decision-making through problem-solving. Examples of questions reviewed in this method are: "Is there a quality requirement such that one solution is likely to be more rational than another?" and "Do subordinates share the organizational goals to be obtained in solving this problem?" (Hunt, 1984, pp. 14-15). Few decisions are primarily or exclusively rational (Allison, 1973) and personal goals also need consideration today. Again this theory narrows the focus and scope of the leadership discussion so as to make this view untenable today.

More recent models. Many more recent writers have superseded these types of leadership explanations. Burns (1978) launched a new era in leadership discussion and understanding in his presentation of both transactional and transformational leadership. The first implies a rather short-term, off-again, on-again, reciprocal exchange of goods. The second describes a more relational interaction which occurs:

when one or more persons engage with others in such a way that leaders and followers raise one another to a higher level of motivation and morality. Their purposes become fused... Power bases are linked... as mutual support for common purpose.... [It] 
ultimately becomes moral in that it raises the level of human conduct and ethical aspiration of both leaders and the led,...thereby creating new cadres of leaders (Burns, 1978, p. 20). Burns also insists on pursuit of real, intended change. Rost $(1985,1988)$ summarizes the dimensions of leadership as mutual interaction toward real, mutuallypurposeful and substantive change achieved together in an ethical and generative process.

Hagberg (1984) characterizes this type of a more personalized role of leadership through reflection, purpose and Gestalt as breaking through the expected or ascribed role behaviors of submission or powerlessness, association and symbols. Zurcher (1977) also captures the dimension of personal development of the leader. He believes it is at the level of the mutable self that "process, change, flexibility, autonomy, tolerance and openness" (p. 446) work together in the person of the leader. Grob (1985) similarly grapples with a Socratic leadership model emanating from the "being" level.

What these last three writers are dealing with is an attempt to touch more deeply into the personal/interpersonal element of leadership. It is more than an ascribed role for the leader and the follower, more than a superficial relationship between them. True leadership touches into the holographic interpersonal level described by Lawler (1987), a level which encompasses both the conscious and unconscious 
complexities of human persons. All three of these develop a particular part of Burn's model, but only a part.

Current models. Notably three explicitly conscious focuses signal the credible current models: concern for the human, the change and the environmental dimensions of leadership. Foster (1988) describes four criteria which are essential in the newest definition and the practice of leadership. Such leadership must be critical: examining and evaluating the status quo; transformative: raising consciousness and concurrently changing social conditions; educative: "showing new social arrangements while still demonstrating a continuity with the past" (pp. 15-16); and ethical: providing the possibility, the foundation and the continuity of a community living its communal life.

Foster deals with challenging the status quo, with personal and group dimensions of relationship and commitment, and with personal and environmental change, all partially though as yet inadequately applied for the preferred future. His description captures an essence which parallels the predominant descriptors of the new paradigm: interactive, dialectical, contextual, dynamic, transforming and connective.

Hendrickson (1988) also captures the three major components of today's leadership stated earlier: a holistic concern for human, change and environmental dimensions. Perhaps for the purposes of this research, a synthesis of his new model would serve best. It understands leadership 
holistically, as essentially an interpersonal and a cultural phenomenon. It includes minimally at least these following components:

1. Meeting mutual wants and needs of both leaders and followers.

2. Being transformational, affirming change that is directed by purpose and vision and that adapts to changing environments.

3. Being resourceful, using influence through power, technology, and economic resources to achieve goals.

4. Being collective, building on shared understandings and group development.

5. Being meaningful and purposeful, centering on the creation of structures that express shared meanings and purposes among leaders and followers.

6. Using the linguistic and symbolic, creating sophisticated cultural communication and learning systems.

7. Being ethical, transforming people to higher levels of moral behavior and affirming personal and social progress.

8. Being generative, caring about cultural, organizational and individual maturation and development. For the researcher this definition explicitly highlights the necessary three dimensions for today's leaders stated previously - attention to the human, to change, and to the external and internal environment. Environmental concerns 
considering the degree and rapidity of change today merge as an added core element in any discussion of leadership.

with such leadership and followership, moving through today's interpersonal and environmental challenge to real intended substantive change will be within reach; moving beyond the probable and the possible to the preferred future will then be more readily attainable (Toffler, 1970).

\section{Relationship of Present to Previous Research}

The present research grapples with leadership within this new perspective. It moves forward the discussion on leaders' thinking styles as related to their effectiveness, an effectiveness necessarily resonant in actual behavioral practices. Thinking style is related to modes of change addressing the status quo and moving toward the preferred environment.

Previous research dealt with comparisons of thinking style alone in different populations, such as those of school superintendents and business chief executive officers, superintendents, principals and supervisors, elementary and secondary principals. These studies dealt with the relationship of thinking styles to leadership styles in the individual or as compared also to those of mentors, and the correlation of decision-making styles with key factors of responsibility and leadership effectiveness. 
Purpose of the study

Within this discussion of leadership, the purpose of this study is twofold: to assess the thinking styles and the behavioral practices of selected community college individuals regarded as leaders by the college community and to examine the interrelationship of these styles and practices. The community college by its very definition is immersed in the environmental aspect of leadership. It is the most dynamic, interactive, connective, changing, contextual of higher education institutions (Boyer, 1985). The study posits quantitative research in the larger qualitative context described previously and to be further described. That context includes the contemporary bombardment of change in all levels of the environment as well as the recently-articulated role of leadership in that process. Through the instruments selected, this dissertation also looks at the projected future effectiveness of leaders in the task of meeting this challenge and of deriving the maximum advantage from change given their proactive and reactive stances.

\section{Definition of Terms}

A series of definitions of terms will focus the meaning of key concepts to be used in the study:

Leadership. Refers to Kouzes and Posner's (1987) model which includes five essential leadership behavioral practices: (a) challenging the process, (b) inspiring a shared vision, (c) 
enabling others to act, (d) modeling the way, and (e) encouraging the heart (p. 8).

Left Mode Thinking style. Refers to a human information processing which is active, verbal and logical.

Right Mode Thinking Sty?e. Refers to a humán information processing which is receptive, spatial and intuitive.

Integrated Mode Thinking style. Refers to the use of right and left modes simultaneously. It combines both in appropriate proportions with the ability to see clearly the linkages between the two.

Mixed Mode Thinking style. Refers to the use of either right or left mode at any given time (Taggart, 1984, pp. 10-11).

Behavioral practices. Are commitments based on values and expressed in action and which are therefore observable by others (Kouzes \& Posner, 1987).

\section{Research Questions and Hypotheses}

The research questions to be addressed in the study are:

1. Among the population to be surveyed, nominated community college leaders, is there a greater tendency to have one dominant thinking style over another? 
2. To what degree are the leadership behavioral practices described by Kouzes and Posner found in the nominated community college leaders surveyed by the LPI-Self and LPI-Other?

3. Is there a significant correlation between thinking styles as measured by the Human Information Processing Survey (HIPS) and leadership behavioral practices as defined by the Leadership Practices Inventory-Self $(\mathrm{LPI}-\mathrm{S})$ ?

4. Are the leaders' perceptions of their own behaviors consistent with those of their designated close observers?

The research hypotheses are these:

1. There is no significant correlation between high scores on the first LPI Leadership Practice, "challenging the process", and the right or integrated thinking styles.

2. There is no significant correlation between high scores on the second LPI Leadership Practice, "inspiring a shared vision", and the right mode thinking style.

3. There is no significant correlation between high scores on the third LPI Leadership Practice, "enabling others to act", and the right mode thinking style.

4. There is no significant correlation between high scores on the fourth LPI Leadership Practice, "modeling the way", and the integrated thinking style. 
5. There is no significant correlation between high scores on the fifth IPI Leadership Practice, "encouraging the heart", and the right mode thinking style.

In an interview with Taggart (Personal Interview, October 14,1988$)$, these hypotheses were mutually generated related to a new HIPS Survey under preparation by him. Taggart expects to describe the rational left mode as dealing with planning, logic, and ritual and the intuitive right mode as dealing with vision, insight and feeling. He believes it is necessary to refine further and more explicitly certain practices related to leadership.

By extension and with the approbation of the HIPS Survey author, the left- and right-mode's more recent definition holds a much deeper meaning. It also has entered newer spirals of insight. Looking at each one closely will be beneficial to more comprehensive and profound realizations.

The left-mode uses words to name, describe and define while the right-mode is aware of things with minimal connection with words: verbal as compared to non-verbal. The left figures things out step-by-step and part-by-part while the right puts them together to form wholes: analytic versus synthetic. The first uses symbols to stand for something while the second relates to things as they are, at the present moment: symbolic as different from concrete. The left takes out a small bit of information and uses it to represent the whole while the right sees likenesses between 
things and understands metamorphic connections: abstract compared to analogic. The former keeps track of time, lining up one thing after another, doing things in order while the latter is without a sense of time: temporal rather than nontemporal. L-mode draws conclusions from reason and facts while R-mode doesn't require that basis and is willing to suspend judgement: rational as different from nonrational. The left mode sees numbers as in counting while the right sees things in relationship to other things and in how they form a whole: digital versus spatial. The left draws conclusions from logic, one thing following another in order while the right makes leaps of insight, often based on incomplete patterns, hunches, feelings or visual images: logical as compared to intuitive. The leftmode links ideas sequentially, leading to a convergent conclusion while the right mode sees whole things all at once, their patterns and structures, often leading to divergent conclusions: linear as different from holistic (Edwards, 1979).

It is important to note that the two modes, left and right, ideally are interactive. Taggart (1984), for example, explains that straightforward instances of each respectively would be balancing a checkbook and picking out a new outfit. These are rather simple tasks, however. As situations or problems become more complicated, it is more likely that a mixed or integrated style will be useful because they may require left and right hemisphere 
functioning. Taggart uses the purchase of a new car as such a case. In the following chapter, the Review of the Literature, the interrelationship of the left and right modes will be further discussed.

The more recent definition and description of the thinking styles mentioned previously adds further meaning to this study's probe of the potential relationship between processing modes and leadership effectiveness with the latter's current focus on the human, change and environmental perspectives.

\section{Significance of the study}

This study will contribute to the understanding and the sense of urgency surrounding the need for effective leaders in all societal areas and to the emerging focus of writing in this area. The significance of the subject is evident as concern about leadership arises on several fronts. Burns (1978) has called the hunger for compelling and creative leadership "one of the most universal cravings of our time" (p. 1). This concern is reflected in our nation's schools. The Nation at Risk Report (1983) and others have challenged leadership at all educational levels to confront the declining level of student achievement. Elliott and Sergiovanni (1975) have spoken about the imperative for administrators to prepare our youth for a society which requires the ability to deal with a breadth of areas, such as "rapid change, expanding technology, urbanization, 
polarized society, and increased interpersonal and personal tensions" (p. 4).

Current American business concerns likewise are expressed in such articles as the recent one entitled "B-School Blues." Deutsch's (1983) thesis revolves around the following realities:

Corporate managers charge that MBAs have learned to crunch numbers in lieu of how to manage people; they have mastered the art of figuring annual paybacks on projects without learning to sense what sorts of products will make it in the marketplace; that they have studied the ins and outs of the stock market at the expense of learning how to compete in any international arena; and overall, that they are prone to taking a well-focused view of short-term results without really learning how to take risks for the future (p. 20).

The same concern is expressed in American publications such as Pascale and Athos' (1981) The Art of Japanese Management which advocates United States' attention to such Japanese considerations as the "Soft s's": skills, staff, leadership style, superordinate goals as well as the more typically American emphasis on the "Hard S's": structure, strategy and systems.

Even recent management textbooks such as Management for Productivity have sections which address the need for creativity and innovation as well as the leader's decision- 
making styles: systematic and/or intuitive (Schermerhorn, 1984) (see Appendix C). Studies will continue to grapple with the interconnections of brain hemisphericity, effective leadership behaviors and their potential resultant interaction with change.

This study will contribute to leadership expertise by clarifying concepts regarding thinking styles and their relationship to interpersonal interaction, tasks, and either innovative or adaptive change, and by explicating their relevance to behavioral commitments.

Because leadership, as defined previously, is qualitative in nature, there is a basic research inadequacy in attempting to capture it with quantitative tools. However, any quantitative study would have this limitation. The instruments selected for this study, the researcher feels, best identify, focus and hone the habitual practices of the currently needed leadership as described in this work.

\section{Summary}

This study addresses a concern of both urgent and profound dimensions in the modern world. A newly-emerging paradigm shift becoming apparent on international, national and organizational levels at once reflects, confronts, and shapes the realities present in the turbulent environment of today. This labyrinth of change lays bare the current and compelling need for a radically different description and 
experience of leadership in order to meet the challenge of this era of history.

Such leadership must respect followers holistically, as persons and as partners in common endeavors toward change and a preferred future. It must be contextual, transformational, resourceful, effectively communicative, mutually purposeful, ethical, connective and generative. The purpose of this study is to set in relief the current thinking styles of nominated community college leaders and to examine if and how these interrelate with their leadership behavioral practices. These thinking styles and practices have direct implications for effectively meeting the challenges of innovative and adaptive change. 
CHAPTER II

REVIEW OF THE LITERATURE

\section{Introduction}

The statement of the issue discusses an emerging sense of a profound change in world view on the national, international, and organizational levels. This paradigm shift will challenge leadership in the 1990's in new and significant ways. Can awareness, understanding, and strategies be generated which support the development of competency in the face of such a turbulent environment?

Before proceeding to the specific review of the literature, it is necessary to set out the broader context of current theory and relevant research in which this study is posited. Since the pioneering work of Sperry (1968), much work on brain hemispheres has been done to try to understand the realities surrounding them. ornstein, following sperry, defined the distinct functions of the areas of the brain: "In right-handed individuals, the left side of the brain controls analytic, language and math[ematic] skills, while the right side of the brain controls holistic patterns, spatial concepts, and imagery" (cited in Reitz, 1986, p. 30).

Herrmann (1982), in his discussion of lateralization, extended the concepts:

For a great majority of people, the left brain is far better at performing logical, analytic, mathematic 
tasks; particularly those involving linear and sequential processing. In distinct contrast, the right brain is much better at nonverbal ideation, intuition, holistic and synthesizing activities and tasks; particularly those involving spatial, visual, and simultaneous processing. In other words, the left brain does good [sic] at language, does well at arithmetic, and can plan and schedule and organize events very precisely. The right brain is musical and artistic, sees the forest instead of the trees, helps us drive cars and ski without cracking up, and is amazingly good at hunches and 'intuitive' flashes ( $p$. 31).

According to Taggart and Torrance (1984), the flexible, whole-brain information processor is, the most creative. creativity is traditionally associated with right hemisphere behavior. This is a Iimited view. Accomplishing work requires nonconforming individuals inventing sometning new combined with conforming people with an eye toward improving something. Indeed, there is a left dominant mode of creativity as well as a right dominant mode. The person who has developed a flexible processing style exhibits the characteristics of what has been referred to as innovators (right dominant) and adaptors (left dominant) (p. 11). 
Torrance and Rockenstein (1987) confirmed that although the processing styles and strategies may differ in individuals, creativity is maximized through the use of the fully functioning hemispheres. They extend and further explain the previous quotation in the following way: Left Dominant Creativity You tend to be a conforming person who prefers structured assignments in which you can discover systematically by recalling verbal material in order to look for specific facts which will sequence ideas in the form of an outline from which you can draw conclusions to solve problems logically so that you can improve something. Right Dominant Creativity You tend to be a nonconforming person who prefers openended assignments in which you can discover through exploration by recalling spatial imagery in order to look for main ideas which will show relationships in the form of a summary from which you can produce ideas to solve problems intuitively so that you can invent something new (p. 38)

As people seek opportunities to explicitly use a complementary approach in problem-solving, they can become more integrated, thereby promoting flexibility. With ongoing awareness, change can come. Specific efforts and 
programs can then be designed to challenge this personal and indirectly, collective growth.

The effort required must be a serious one, however. Short-term training or practice was not shown to affect the learning styles of 73 students participating in a study done by Masten and Morse (1987) at Mississippi State University. Some examples of such potential efforts are suggested by Torrance and Rockenstein (1987): providing adequate interest, concern and time for randomizing and original thinking, improvising with improbable situations, devising scenarios and doing problem-solving related to the future, and in general combining the creative, affective and cognitive aspects of learning activities simultaneously. Edwards (1986) has extended and synthesized the interaction of the right- and left-brain modes of information processing. Her emphasis is on the dynamic of creativity. She posits five stages of the creativity process and attributes hemisphericity to each: (a) First Insight, mainly R-mode; (b) Saturation, mainly L-mode; (c) Incubation, mainly R-mode; (d) Illumination, mainly R-mode; and (e) Verification, mainly L-mode. It is obvious from her description that both hemispheres have a vital and ongoing part in the rhythm of creativity. In her use of the word "mainly", she has avoided an earlier tendency to dichotomize the left and right modes as if they functioned quite separately. 
Numerous implications for the educational process of teaching/learning have been described by researchers such as Debono (1970), Edwards (1979) (see Appendix D), Galyean (1981), and Nancy and Martin Kane (1979) as related to general understanding and the need to challenge both sides of the brain, the theory's processes and impact in the field of art, the need for broader related curriculum development, and implications for the gifted child respectively.

\section{Implications for Leadership}

Education. Along with these developments, the area of educational leadership has come into focus. Coulson and Strickland (1983) contrasted 23 school superintendents in the Northeast with 21 executive officers from businesses across the country. In this important work they stated: our findings reveal some striking differences between the thinking styles of superintendents and C.E.O.s: Superintendents prefer left-mode thinking styles; that is, they're reasoners and analyzers. C.E.O.s, by comparison, tend to be right-mode thinkers--innovators, experimenters.... Superintendents tend to be more rational, cognitive, and quantitative than do C.E.O.s, as well as more controlled, structured, and conservative. C.E.O.s, on the other hand, tend to be more emotional, expressive, and personal than superintendents do, as well as more creative, innovative, and experimental.... The reasons for these 
differences, we believe, lie largely in each group's training and measures of success ( $p .22)$.

The word, "creative", is used differently by various writers. For purposes of this study the explanations of Taggart and Torrance (1984) and Edwards (1986) are embraced. Further work by Norris in 1984 dealt with the connection between leadership effectiveness and thinking styles. Her hypotheses were five: (a) that educational leadership was predominantly left-brain in orientation, (b) that the higher up in position leaders moved, the more narrowly left-brained their focus became, (c) that women were more whole-brained in orientation than men, (d) that supervisors whose tasks were more staff in nature had a better balance in hemisphere dominance, and (e) that conceptual skill was less prevalent at the higher educational administrative levels.

A Tennessee panel of experts nominated the effective leaders group used by Norris (1984). Using the same tool as Coulson and Strickland (1983), the Herrmann Brain Dominance Instrument, Norris added also the Katz's ranking of management skills as human, conceptual and/or technical, and a researcher-designed questionnaire measuring perceived innovation displayed by each leader. Norris drew composite leadership profiles at the respective administrative levels. Her population included some 115 subjects: superintendents, principals and supervisors. 
Norris (1984) concluded:

the highest level of educational leadership is

dominated by individuals whose cognitive style is ineffective for conceptualizing the future . . that many superintendents have difficulty moving beyond the analytical and technical aspects of their positions. (These administrator characteristics contrast with the leadership qualities identified in the literature as effective) . . that principals and supervisors showed a better balance with principals scoring the highest . . . that women showed a better balance than men (pp. 56-58). The significance of the Norris study is that it identified and focused a major current and threatening future leadership crisis related to the one-sided use of brain function. It challenged educational administrators to develop a new balance. This balance could enable them to forge a visionary perspective oriented to dealing with the challenges of today and tomorrow, a perspective oriented to building human potential.

Spruill (1986) also addressed cerebral laterality and leadership in her work. She defined two purposes for her research: (a) to determine if a relationship existed between the cerebral dominance of principals and their leadership styles, and (b) to ascertain any related difference between elementary and secondary principals. She 
used Your style of Learning and Thinking, Form C (SOLAT), developed by Torrance, to address the first and the climate Impact Profile (CIP) for the second. The first part of her results reflected the following: 58\% of the virginia principals sampled had left-brain thinking styles, $32 \%$ integrated ones, and $10 \%$ right-brain styles. The left mode dominated, claiming almost $60 \%$ of the sample.

The second part, the CIP, used six impact modes: (a) information, (b) magnetic, (c) position, (d) affiliation, (e) coercive, and (f) tactical. Through self-rating and the use of the Pearson Product Moment Correlation, the following results emerged: (a) the right-brain thinking style correlated significantly in a positive direction with the affiliation mode and negatively with position, (b) the leftbrain style correlated significantly in a positive direction with the position mode and negatively with the affiliation and magnetic modes, and (c) the integrated style correlated significantly in a positive direction with the information leadership style and negatively with position. A second finding was that elementary principals had significantly higher scores on the magnetic and affiliation styles. The relevance of this study is that spruill (1986) confirmed the concern regarding one-sided, limiting, leftbrain dominance among the majority of administrators. It is not stated nor researched if one mode is valued more highly for effectiveness than any other. The researcher may have made that assumption. 
For the purposes of this study, Spruill (1986), through the correlation of results of two test instruments administered to Virginia principals, broadened the base of understanding through her discussion of the six impact modes. She also raised the question of whether persons of other contrasting styles could acquire the necessary attributes to be effective leaders and in what environment that would be true.

Owen (1986) investigated the relationships among brain dominance of elementary principals, their leadership style, the length of their administrative experience and the difference of their leadership style and that of their mentors. The SOLAT, Form B, and a General Information Questionnaire were sent to 176 Texas participants. Multiple regression, Pearson Product Moment and Analysis of Variance were used to analyze the data. She concluded the following: (a) the left-brain dominant principal had an initiating structure leadership style, (b) the right-brain, a consideration style, (c) the mentor with a consideration style did not have a significant influence on the mentee, but the opposite one did, and (d) length of service did not seem to influence leadership style. This study validates the previous patterns mentioned regarding the task and human processes aspects of brain dominance. It does not, however, correlate these to any discussion of leadership effectiveness in a designated place and time. 
Reitz (1986) designed his research to analyze thinking styles of selected school administrators and to relate these to leadership effectiveness. He used HIPS to assess the left, right, and integrated preferred styles and the Tennessee Administrator Career Ladder Program to obtain the measure of effectiveness. The latter's five areas of competence included instructional leadership, organizational management, communication and interpersonal relations, professional growth and leadership, and a screening of basic communication skills. Using these measures and demographic categories as the independent variables, analysis of variance tests (ANOVA) were computed for each of the grouped scores and chi-square tests were calculated for overall thinking styles for each classification. Reitz concluded that there are no significant thinking style differences among demographic groupings and no correlation between thinking style and leadership effectiveness.

Business. The previous examples have been from the area of education. Since this is a new subject in research, it will be helpful to look also to the field of business. Hines (1987), for example, reviewed related research and dismissed any hemisphere differences as mythology. Several other researchers took a different stance.

Some of these signal recent developments in business which are a reaction to the kind of feedback provided by Coulson and strickland regarding right-mode C.E.O.'s as contrasted with left-mode school superintendents. 
Cultivation of more innovators, more experimenters, are encouraged by such well-knowned national spokespersons as Peters and waterman (1982). In their research of excellent companies, they discuss corporate "skunk works" where rich support networks are set up and maintained so the company pioneers will flourish, so that champion innovators are created. 3M Company (Minnesota Mining and Manufacturing), for example, developed the Post-It, a phenomenal success, as a result of a climate which fosters the entrepreneurial spirit. Peters and Waterman describe at length this major case in point, a case which reflects various right-mode thinking styles.

A related type of activity in the field of business is the increased awareness regarding entrepreneurial characteristics in C.E.O.'s and others. These include the ability to create a vision, to innovate, to challenge the established processes, to work off of hunches and intuition. Joseph Mancuso, president of the Center for Entrepreneurial Management, published a questionnaire in 1983 which he tested with 1,500 entrepreneurs. Its purpose is to measure the degree of one's entrepreneurial potential, a potential with right-mode connectedness.

Hurst (1984) described a specific desperate corporate scenario and how executives turned that situation around. He discussed the development of a "soft," intuitive framework where roles were the counterpart of tasks, where groups replaced structure, where networks operated instead 
of information systems, where rewards were so aligned, and where people were seen as social rather than rational beings. The significance of the Hurst presentation is that trust, a common purpose, fluidity, immersion in the mission, and caring played important roles. These aspects, from the above research, infer right brain dominance.

Hodgson (1987) dealt with managing optimal performance. He felt that managers who developed their analytic powers to a great degree may have by default omitted a comparable right-mode maturation. Therefore their creativity would be hampered and their achievements also somewhat limited. He believes that the left-mode problem solvers need also to push their horizons to opportunity seeking. They must also ask "why" more frequently in order to balance off the "hows". He advocates a regular personal "commitment check" to raise one's consciousness and effectiveness.

Friend (1982) outlined common roadblocks which check creativity and innovations in organizations. They are the following: (a) an excessive focus on order, (b) penalties for failure, (c) resources myopia, (d) signs of prejudice, and (e) discouragment of free expression. He also suggests how to move beyond them and install positive energy flows: (a) identify creative individuals, (b) define the goals and objectives, (c) emphasize the importance of the group, (d) recognize the importance of mentors, (e) set up in-house seminars and discussions, (f) analyze the communication system, (g) avoid the velvet rut, (h) aramatize problems to 
be solved, and (i) emphasize the long-term nature of the creative approach. Numerous connections with the previous hemisphere discussion are obvious.

The major research in business was done by Mann (1982) at the University of Southern California. Mann recognized the need for conceptual fluency and thinking in determining managerial effectiveness. He set out to investigate two groups of corporate planners: financial and strategic, as well as four related key factors: environmental focus, task requirements, structure formality and cognitive decision style. Mann used the Rowe Cognitive Contingency Model as operationalized in the Decision Style Inventory (DSI); the latter combines cognitive style, leadership style, leftbrain/right-brain, and thinking/feeling functions. The emphasis of the research was on cognitive decision style rather than on overall behavioral or leadership focuses. Mann's (1982) hypotheses stated that financial planners would be stronger with an analytical/directive (AD) decision style, certainty in the environment, formality in the structure and quantitative thinking as opposed to strategic planners who would be more effective with a conceptual/ analytical (CA) style, uncertainty in the environment, informality in the structure, and qualitative analysis. Seven of the eight hypotheses were significant. In fact, decision style alone accounted for as much, or more, of the difference in effectiveness than a combination of the remaining factors. The relevance of this study is that it 
identified the impact of decision style encompassing the brain dominance concept on specific types of leadership effectiveness. Its confidence level at $99 \%$ reflects a major contribution to the field and enhances the significance of related study.

\section{Contribution to Previous Research}

As is evident from the former review, there are only limited contributions in this field to date. The new dimension of this research is the correlation of thinking styles directly to leadership practices. Adequate instruments have been and are available regarding the first part. In addition to the Human Information Processing Survey used in this study, there is also, for example, the Herrmann Brain Dominance Instrument. Its design is structured to measure dominance in the separate hemispheres along two different planes:

Left: Cerebral - the analytical, logical, problemsolving person.

Left: Lower - the reliable, organized, controlling, conservative person.

Right: Cerebral the creative, conceptual, synthesizing person.

Right: Lower - the interpersonal, emotional, sensitive, musical person (cited in Norris, 1984). Each quadrant receives a three-tiered dominance score.

A new tool, the IPI-Self and other (Kouzes and Posner, 1987), identifies behavioral practices and facilitates this 
study by providing the possibility of measuring specific behaviors which reflect personal lived value commitments.

\section{Summary}

It is clear from the review of the literature that various measures are being used to assess the distinct functions of areas of the brain and that the results of these measures have significant implications for the type of leadership needed in the present and future. The review of the literature looks at attempts to understand how the particular assets of the left brain: analysis, language, mathematical, and sequential functioning, can be fruitfully balanced with those of the right brain: holistic and spatial patterns, musical, artistic and intuitive processing. It relates such whole-brain processing to modes of creativity as evidenced in innovative and adaptive efforts.

Such efforts are integral to meeting the challenges of the emerging paradigm shift becoming visible in many levels of the current turbulent environment. For education, the leadership implications are crucial if superintendents and other administrators are to forge a visionary perspective which deals with necessary response to change and with the building of human potential. This is true for the previously discussed elementary and secondary school level as well as for community college leaders. Long-term success in the world of business can also be affected by insights about brain lateralization and its connection to cognitive decision styles. 
Researchers in Tennessee, Virginia, Texas and California have alerted the intellectual world to new awareness and understanding. The present research complements these endeavors and extends them to a deeper level of understanding and to the leadership behavioral practices for today's changing environment. 
CHAPTER III

RESEARCH DESIGN

\section{Introduction}

In Chapters I and II, the purpose of the study was stated, the research questions and hypotheses were identified, and the pertinent research literature was reviewed in order to provide a foundation for this research effort. As was mentioned earlier, the turbulent environment of today's world requires a different type of leadership to meet the challenges at all levels of the emerging paradigm shift. This study addresses the concern for understanding and for experiencing the dynamics of an effective and holistic leadership. Its results contribute to the literature which specifically correlates thinking style to leadership behavioral commitments.

The design and methodology which were used to achieve this objective are described in chapter III. Specifically, the design, sample, procedure, instrumentation, statistical analysis, assumptions and limitations are discussed in that sequence.

\section{Methodology}

Design. This study is correlational in nature. The two primary instruments are the Human Information Processing Survey (HIPS) and the Leadership Practices Inventory-Self 
(IPI-S). Another secondary survey tool is the Leadership

Practices Inventory-other (LPI-O).

Sample. The sample consisted of two individuals, administrative or full-time faculty, from each of the participating California community colleges. These persons were nominated as leaders by their respective college presidents based on the specific criteria provided (see Appendices $F \& G)$. The presidents also nominated observers. Altogether 48 community college presidents responded positively out of a possible 107 (45\%). The total number of leader and observer responses received included 360 from 576 distinct addressees (63\%). Of these, 347 (60\%) agreed to participate in the study and 13 (2\%) declined explicitly in writing. Of 96 possible leader responses (two from each participating community college), 84 were received with 70 complete and therefore usable (73\%); of 480 potential observers (three to five for each leader), 273 were returned with 214 complete and therefore usable (45\%) in the study. These latter comprised 56 complete sets. It was not necessary for leaders to have a set of observers in order to be included in the sample because a correlation of the perceptions of these two groups was only a secondary consideration in this research.

It was anticipated that the response rate would be high because of the timeliness and interest surrounding the topic. Just recently, for example, a major series of articles in the Community, Technical and Junior College 
Journal reported on a national study which assessed the status of community college presidents as transformational leaders (Roueche, Baker \& Rose, 1988a). According to work done by Heberlein and Baumgartner (1978), for studies salient to the participants, the return rate averaged 77 percent. For studies possibly salient 66 percent responded and for those which were not perceived as salient only 42 percent. In this study, the leaders (73\%) and observers (59\%) appeared to fall near the first and second categories while the presidents (45\%) appeared to fall in the third. Several additional presidents, 38 (35\%), however, did respond explaining why they chose not to be involved. The main reasons given by those community college presidents choosing not to participate included newness in the position and current heavy job demands. Primary reasons given by the nominees and/or observers were current heavy job demands and inadequate familiarity with the nominee. A breakdown of total set of reasons proffered is in Appendix $\mathrm{H}$.

An additional external reason may have been a recent survey of community college chief executive officers done by Roueche et al. (1988b) as a publication of the American Association of Community and Junior Colleges. Their recently announced book is entitled shared Vision: Transformational Leadership in American Community colleges. The authors attempt to identify the qualities and attributes of such leaders, examine the achievements of some of the 
most successful and account for their impact on the growth of the community college in American higher education. The degree of sample overlap within the state of California directly includes 29 of this study's potential nominees, 6 of whom appear on the final "Blue Chippers" list.

Procedure. A timeline was determined for the initial mailing requesting the names of nominees from the community college presidents, subsequent mailing of the questionnaires to the designees and respective observers, follow-up mailings, response deadlines, and additional procedures for conducting the survey. The researcher decided against using pre-contact telephone calls which according to Fowler (1988) has been found to be very effective. Specifically, telephone calls aid in identifying the investigator, in discussing the purpose of the study and in requesting the respondents' cooperation. However, both cost and time factors made this procedure seem less feasible for the current study of community college leaders.

College presidents were requested by mail to submit the names of two leaders regarded as such by the college community. Criteria to be used for selection were provided by the researcher. It consisted of the leadership characteristics listed as fundamental by Kouzes and Posner (1987). The presidents were also requested to name five close observers from administrative and full-time faculty groups for each of their designees. A range of three to five respondents was deemed adequate for the correlation of 
leader and observer data. Kouzes and Posner indicated that there were "approximately three subordinate-respondents (IPI-O) for each managerial subject" for the sample used for the current version of the Leadership Practices Inventory. A follow-up letter was also sent (see Appendices I \& J). Upon receiving the nominations, the HIPS Survey and the IPI-Self were sent to the nominees who were assured that they would receive a copy of the results of the study upon its completion. The LPI-other was concurrently sent to the five observers to complete and return to the researcher also. This was the number selected because procedurally, Kouzes and Posner (1987) indicate that four or five other people familiar with the LPI-S candidate are asked to complete the LPI-O.

Five hundred and seventy-six packets were prepared for these two different groups. The first set contained a letter to each leader-nominee (see Appendix K), a consent form (see Appendix L), a demographic questionnaire (see Appendix M), two survey questionnaires (Appendices $N \& 0$ ), and a self-addressed return envelope. The second set included a letter to each respective observer (see Appendix P), the same consent form, one questionnaire (see Appendix Q) and a self-addressed return envelope. Anonymity was guaranteed to all participants, as was confidentiality regarding responses.

spproximately two weeks after the initial mailing, a follow-up letter (see Appendices $R \& S$ ) was sent in each 
case to those who had not responded. In the second mailing, only potentially valuable responses were requested. These included those from leaders themselves and from observers who would make up an adequate number for a complete set of LPI-O data, that is, bring the minimum number to at least three persons. Second mailings are recommended as an effective means of augmenting return rates (Dillman, 1978). In fact, this was the case in this study. Twelve additional leader responses were received boosting the total to $70(73 \%$ of the participating colleges' nominees). The observersubmitted surveys moved the return rate up by 39 for a total of $214(45 \%)$. This completed ten more sets of observers although one group did not have a corresponding leader so the questionnaires were unusable.

The consent form discussed above was required by the University of San Diego Protection of Human Subjects Committee. The underlying purpose in requiring a consent form is to insure that ethical considerations are met during the investigation. Since participation in this study was voluntary and the risk in completing the questionnaire was negligible, it was unlikely that any violation of mental, physical or social rights would have occurred.

\section{Instruments}

Human Information Processing survey. The current research used two instruments to ascertain the correlation of thinking styles and behavioral practices. The first, the Human Information Processing Survey (HIPS), was developed by 
Taggart and Torrance (1984) (see Appendix N). They defined four approaches in human information processing as follows: Left: active, verbal, logical

Right: receptive, spatial, intuitive Integrated: right and left simultaneously. The integrated style combines left and right in appropriate proportions with the ability to clearly see the linkages between the two.

Mixed: either right or left. A person with a mixed strategy tends to look at left dominant elements in isolation from the right dominant and vice versa (pp. 1011).

The measure of this test reflected overall hemisphere dominance. It consisted of 40 sets of choices from three possible responses. Its internal reliability had been set at the following:

$$
\begin{aligned}
& \text { Right Hemisphere Scales }=.84 \\
& \text { Left Hemisphere Scales }=.86 \\
& \text { Integrated Style Scales }=.82 \\
& \text { (Taggart \& Torrance, 1984, p. 28). }
\end{aligned}
$$

This reliability is based on Pearson Product-Moment coefficients of correlation between the HIP Survey and Form A of SOLAT. The former is in reality form $c$ of SOLAT. No alpha coefficient is provided for the scales shown above. 
A particular section of the Tactics Profile served another function. The authors believe that "flexibility represents the ideal profile," that the "flexible, wholebrained person uses his or her biocomputer to its best advantage in all problem-solving situations, calling on the strategy and tactics that are most appropriate for a given problem" (p. 11). This is because some problems require a left or right brain approach; others, particularly as situations become more complicated, require a mixed or integrated one.

Leadership practices inventory. The second instrument, the Leadership Practices Inventory-Self and Others, developed by Kouzes and Posner (1987), centered on five practices common to most extraordinary leadership achievements (see Appendices $O \& Q$ ). These five practices relate to transformational leadership as described by James McGregor Burns (1978) in his seminal work on that topic. Kouzes and Posner (1987) are dealing with patterns of behavior that people used to "lead and to achieve extraordinary results" (p. 6).

Unlike an earlier study by Norris (1984) which measured quantitative change, acknowledged by the author as a weakness of the study, Kouzes and Posner (1987) have concentrated on qualitative "behavioral commitments" (p. 13). The choice of this term is significant. Commitments are based on values and are expressed in action; they can be observed by others. The key point is that they 
include the value base and thereby elude the pitfalls of a non-integral leadership description.

Kouzes and Posner's (1987) original research questions reflected the mind set of the authors regarding the relationship of leadership to change. It included such questions as:

Who initiated the project? What made you believe you could accomplish the results you sought? What special, if any, techniques or strategies did you use to get other people involved in the project? Did you do anything to mark the completion of the project at the end or along the way? What did you learn most from this experience? What key lessons would you share with another person about leadership from this experience? (pp. 309-310)

Five fundamental practices were discovered by Kouzes and Posner (1987), practices which enabled these "leaders to get extraordinary things done" (p. 7): (a) challenging the process, (b) inspiring a shared vision, (c) enabling others to act, (d) modeling the way, and (e) encouraging the heart. Two related behavioral activities fit under each of the five mentioned above, respectively: (al) Search for opportunities, (a2) experiment and take risks, (b1) envision the future, (b2) enlist others, (c1) foster collaboration, (c2) strengthen others, (d1) set the example, (d2) plan small wins, (el) recognize individual contribution, and (e2) celebrate accomplishments. The focus on the human, on 
substantive change and on interaction with the environment is clearly evident here.

The instrument was developed over a 5 year period during which literally hundreds of managers were asked to describe a "personal best," an experience in which they felt that "they led, not managed, their projects to plateaus beyond traditional expectations" (p. 309). Leadership effectiveness was assessed in two ways: (a) by the individual leaders, and (b) by their group of subordinates.

The LPI-Self had 30 behaviorally-based sets of statements with responses given on a five-point Likert Scale. Its partner instrument, the LPI-other, had the same format with voluntary and confidential responses given by three to five individuals close enough to the leader to observe behaviors well. These observers returned their forms directly to the researcher.

Internal reliabilities for the LPI-Self ranged from .69 to .85 , and for the LPI-Other from .78 to .90 . Test-retest reliability was verified at better than the .93 level (Kouzes \& Posner, 1987). The original long LPI form was scaled down for broader use through factor analysis.

The particular significance of Kouzes and Posner's (1987) research was that more than $70 \%$ of the behaviors and strategies described can be "accounted for by these factors" (p. 310). It was an important step in pushing ahead the conceptual understanding of leadership. It synthesized and reported in a quantitative fashion an integrative 
qualitative approach which transcended such leadership theories as trait, great man, and contingency.

Using these instruments, the current research pushed forward the attempt to correlate thinking styles and leadership behavior in a different dimension.

\section{Statistical Analysis}

Data were processed using SPSS-X (1988) and with a dBASE (DBXL) (1989) program. HIPS data were generated using raw, standard and percentile scores. A composite score and a Tactics Profile score were obtained for each leader. Composite LPI-S and LPI-O as well as individual behavorial practices scores were also produced. These descriptive statistics were computed for the variables discussed in Research Questions 2, 3. and 4. Correlation coefficients were obtained to assess statistical significance for correlations among the pertinent variables in Research Question 3 and for each of the five Research Hypotheses. The narrative, tables and figures in Chapter IV will present and address these.

\section{Assumptions}

There are three underlying research assumptions of this study:

1. The selected instruments do yield accurate information regarding brain dominance and leadership behavior. 
2. The community college presidents have pivotal positions from which to make credible recommendations.

3. There will be sufficient interest on the part of both leaders and observers to realize a strong response rate.

\section{Limitations of the Study}

One limitation of the study was in the level of responses providing names of nominees. In order to ascertain effective leaders, it was important to ask persons who stand in pivotal positions and who have adequate longevity in order to make recommendations. It was determined that the college presidents were the best choice. These same individuals however were among the busiest in any college. A second limitation was that all the nominations were made solely by the community college presidents. This was deemed necessary for the reliability and best success of the study. It was so limited because of an indirect leverage and motivation which the presidents' involvement was expected to provide. A third limitation was that the LPI instruments to date have been used primarily with noneducational populations. This may have had an impact on the final results.

\section{Summary}

In summary, the survey questionnaire method was determined appropriate for this particular study because it has historically proven effective in gathering information 
about a given area of research, identifying related issues, and obtaining data on which to base further investigations (Borg \& Gall, 1983).

The process of the research design utilized three instruments, the first two completed by the nominated leaders and the third by the corresponding observers. The first mailing to community college presidents requested the nominations of two persons regarded as leaders by the college community. The second mailing was sent to these leaders and to the respective observers. Second reminder letters were forwarded where suitable.

Regarding the first mailing to 107 community college presidents, 48 of them (45\%) nominated leaders and observers in response to the researcher's request. Another 38 (35\%) responded providing reasons why they preferred not to be involved in the study at this time. Only $21(20 \%)$ of 107 presidents did not reply at all.

Regarding the second major mailing, the first to leaders and observers, results included 360 responses from 576 distinct addressees (63\%), 347 (60\%) agreeing to participate and $13(2 \%)$ declining in writing. Not all mailings from those wanting to participate, however, became part of the sample. Of 96 possible leader responses, 70 complete sets were received (73\%); of 480 potential observers, 214 (45\%) were returned and were usable, making up 56 complete sets. A total of 284 responses out of a possible 576 then were actually included in the study (49\%). 
Sixty-three leader and observer replies were not usable (11\%). From this second mailing, 13 other individuals (3\%) declined in writing to participate. Two hundred sixteen persons out of $576(37 \%)$ in this mailing never replied. The data collected during this study are reported and analyzed in Chapter IV. In addition, the project's overall results are addressed. 
CHAPTER IV

ANALYSIS OF THE DATA

Introduction

In the former chapters, the researcher discussed the statement of the issue, the review of the literature, and the research design. These sections have laid the groundwork for the current analysis of the data collected. For this study, two survey instruments, one measuring thinking styles and the other ascertaining leadership behavioral practices, were completed by 70 California community college leaders, individuals regarded as such by their college communities. In addition, 56 sets of observers (a total of 214 individuals) completed a parallel survey related to these persons.

\section{Demographic Profile}

The demographics of the leader sample showed that 42 $(60 \%)$ were men and $28(40 \%)$ were women. of the total number of leaders nominated, $44(63 \%)$ were currently in administrative positions while 26 (37\%) were faculty. The largest number, almost $40 \%$, fell in the age category between 46 to 50. Almost $60 \%$ had a Master's degree as their highest earned degree while approximately $40 \%$ had doctorates. Nearly $60 \%$ had been in education for over 20 years. Twenty percent had served as administrators for 6 to 10 years and another $20 \%$ for 11 to 15 years. The largest single number, 
30\%, had been in administrative positions between 1 to 5 years. Almost $30 \%$ had been at the current place of employment between 11 and 15 years.

\section{The Human Information Processing Questionnaire}

The Human Information Processing Survey identifies and categorizes thinking styles of individuals. As stated by the authors, Taggart and Torrance (1984), this questionnaire yields a dominant mode of left, integrated or right as well as a Tactics Profile which is designed to correlate to profile strategies used in one's approach to change. If no dominant mode is ascertained, that is, if no standard score is equal to or greater than 120 , the person is classified as having a mixed strategy (Taggart \& Torrance, 1984).

There are four points of discussion relevant to the HIPS questionnaire. The first is the sample's composite scores which will provide an overview of the dominant modes of the nominated community college leaders. The second is the strength of these scores reflected in the number of leaders who scored at or above the 90 th percentile of the total HIPS normed survey pool. The third is the sample's Tactics Profile scores which were generated from a subset of the whole HIPS survey. This score relates in a specific way to one's approach to change. The fourth is a summary of the questions most often answered similarly by the respondents. This point of discussion will give the reader a sense of the type of questions on the survey as well as an understanding of responses viewed as important by the group as a whole. 
Composite scores. HIPS composite scores designate the dominant mode of each leader. The term "composite score" is used to distinguish the overall HIPS test results from a second test result called the Tactics Profile. This latter profile is obtained from the last 10 items of the survey instrument only and will be discussed later in this chapter.

Each respondent's composite score was ascertained from the 40 survey items in order to address Research Question 1: Among the population to be surveyed, nominated community college leaders, is there a greater tendency to have one dominant thinking style over another? (see Table 1). The largest number of composite scores, 35 (50\%), falls into the mixed category. This is consistent with the number normally found in the general population, a number which Taggart posits at 50\% (Personal Interview, October 14, 1988). The integrated category has the second largest number 17 (24\%), with the left- and right-modes each having $9(13 \%)$. The general population's percentages are reversed with the integrated measuring $10 \%$ and left and right $20 \%$ each. The sample's combined integrated and mixed categories comprise $74 \%$ of the total while the general population includes $60 \%$. Various implications will be discussed later. If one were to consider only the three standard survey scores which would preclude the mixed category, a consideration which Taggart confirmed is possible (Personal Interview, July 6, 1989), the predominance of integrated scores is even higher. of the 70 leaders in the sample, 17 


\begin{tabular}{|c|c|c|c|c|c|c|c|c|}
\hline $86^{\circ} t$ & $90 \cdot 8 \mathrm{I}$ & $6 S \cdot 5$ & $9 \tau \cdot 0 \tau$ & $69^{\circ} \sigma$ & $\angle \sigma^{\circ} I T$ & $(0 \cdot 00 \tau)$ & $O L$ & โе70匹 \\
\hline $\begin{array}{l}96^{*} z \\
90^{*} Z \\
\varepsilon \varepsilon \cdot \tau \\
50^{\circ} \cdot z\end{array}$ & 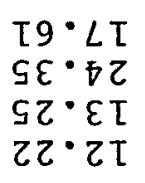 & $\begin{array}{l}\mathrm{T} \tau \cdot \varepsilon \\
\tau \tau \cdot \tau \\
\mathrm{T} \mathrm{S}^{\circ} \cdot \tau \\
\mathrm{T} 8 \cdot \tau\end{array}$ & $\begin{array}{l}\tau T \cdot T I \\
L D \cdot 9 \\
00 \cdot 6 T \\
8 L \cdot L\end{array}$ & $\begin{array}{l}\angle 0^{\circ} \varepsilon \\
89^{\circ} Z \\
\angle T \cdot \tau \\
9 T^{\circ} \cdot \varepsilon\end{array}$ & $\begin{array}{l}S Z \cdot T \tau \\
8 \tau \cdot \sigma \\
S L \cdot L \\
00 \cdot 0 Z\end{array}$ & $\begin{array}{l}(\delta \cdot \tau S) \\
(\varepsilon \cdot \tau \tau) \\
(\delta \cdot T \tau) \\
(\sigma \cdot \tau T)\end{array}$ & $\begin{array}{l}9 \varepsilon \\
\angle I \\
8 \\
6\end{array}$ & 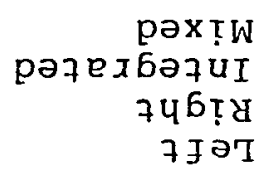 \\
\hline as & ue әу & as & ue әw & as & ue әW & & & \\
\hline \multicolumn{2}{|c|}{ 4709 } & \multicolumn{2}{|c|}{ 7Чбт़प } & \multicolumn{2}{|c|}{ ҰЈ } & & & \\
\hline
\end{tabular}

วpoW queuṭurod $K q$ saxoss

I әтqе山 
(24\%) are left mode, 38 (54\%) are integrated, and 15 (21\%) are right (see Appendix $\mathrm{T}$ for related histograms). The researcher determined to use the four categories of dominance rather than three because that would better distinguish the thinking modes under consideration. With no mixed category, the difference of a single raw score may cause a shift in mode.

Compared to previous educational studies, this research reflects a different pattern, albeit the current one includes faculty rather than exclusively administrators. Administrative jobs have been the topic of discussion because of the types of demands and rewards connected with them and because of the impact they have on the institution and on change. For example, coulson and strickland (1983) found that northeastern school superintendents prefer leftmode thinking styles: Norris (1984) showed that Tennessee superintendencies are dominated by the left-mode while principals and supervisors show a better balance. Spruill (1986) reported Virginia elementary and secondary principals as having $58 \%$ left-brain thinking styles, $32 \%$ integrated, and $10 \%$ right. The mixed mode is not considered in her work using Torrance's Your style of Learning and Thinking, Form $C$ (SOLAT). Table 2 gives a summary of the HIPS Tactics Profile by dominant mode. It mirrors Table 1.

Leaders' scores over the 90th Percentile. It will be beneficial to review the strength of the scores discussed in the previous section. Of the total sample, 22 (31\%) scored 
Table 2

Summary of HIPS Tactics Profile by Dominant Mode

Mode N ( 8$)$ Raw Tactics profile scores

\begin{tabular}{|c|c|c|c|c|c|c|c|c|}
\hline & & & \multicolumn{2}{|c|}{ Left Score } & \multicolumn{2}{|c|}{ Right Score } & \multicolumn{2}{|c|}{ Integrated Score } \\
\hline & & & Mean & SD & Mean & SD & Mean & SD \\
\hline $\begin{array}{l}\text { Left } \\
\text { Right } \\
\text { Integrated } \\
\text { Mixed }\end{array}$ & $\begin{array}{r}9 \\
8 \\
17 \\
36\end{array}$ & $\begin{array}{l}(12.9) \\
(11.4) \\
(24.3) \\
(51.4)\end{array}$ & $\begin{array}{l}4.67 \\
1.00 \\
1.29 \\
2.44\end{array}$ & $\begin{array}{r}2.06 \\
1.41 . \\
.85 \\
1.61\end{array}$ & $\begin{array}{r}1.22 \\
5.50 \\
.94 \\
2.47\end{array}$ & $\begin{array}{r}83 \\
1.41 \\
.97 \\
1.44\end{array}$ & $\begin{array}{l}4.11 \\
3.50 \\
7.77 \\
5.08\end{array}$ & $\begin{array}{l}1.90 \\
1.93 \\
1.03 \\
1.75\end{array}$ \\
\hline Total & 70 & $(100.0)$ & 2.29 & 1.84 & 2.29 & 1.84 & 5.43 & 2.16 \\
\hline
\end{tabular}


at or above the 90 th percentile or had a standard score of 126 or better for the left, integrated or right mode. The standard score is computed from the test's raw scores and is given a percentile ranking relative to the general HIPS survey pool. Eleven leaders were at or above the 90 th percentile for the integrated mode. Seven were at or above the goth percentile for the left mode, and four for the right mode. Two respondents in the left mode category were at the 100th percentile. Each of these 22 nominated college leaders $(31 \%)$ selected more responses from their dominant category than $90 \%$ plus of the total survey pool. This outcome of the community college sample, therefore, shows a number (31\%) of strongly dominant scores (see Figure 1).

Figure 1

Leaders Scoring at or above the 90th percentile on the HIPS Survey

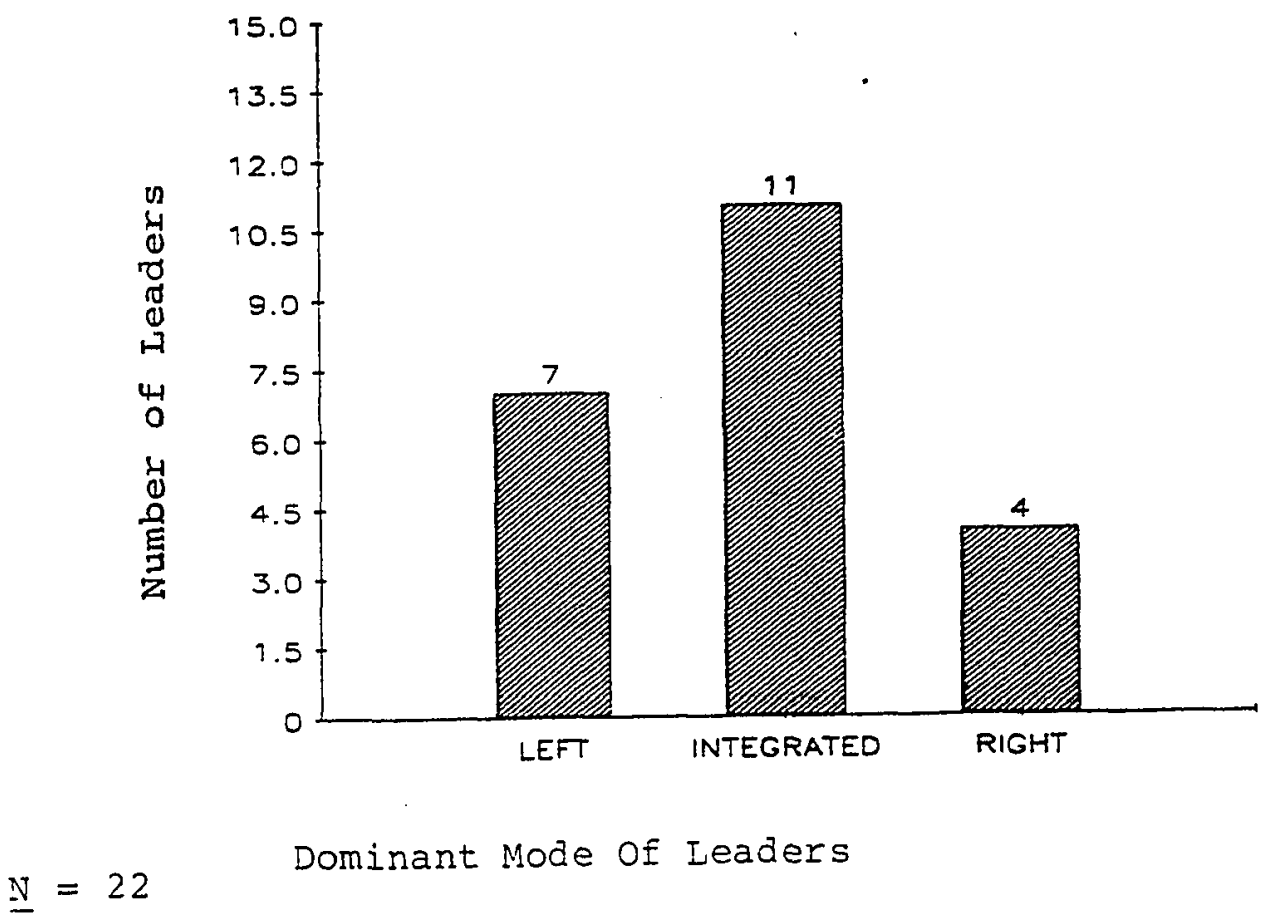


Relationship to change. In order to understand the impact of the HIPS instrument related to change, it is necessary to provide a framework. The best overall indication of how a person approaches change is the individual's composite survey score. A second source is the Tactics Profile proper, made up of the last ten items of the HIPS instrument.

The first 30 questions on the HIPS Survey are more generic in nature and are believed by Taggart (Personal Interview, May 31, 1989) to represent more directly the inner, true, personal self. The last ten items are more specific and are potentially more work-related. In general, the higher the number of similar left or right answers for Tactics score, the more clear-cut, less flexible one's approach to change. It is relevant to note that Taggart and Torrance (1984) have provided no separate reliability and validity documentation for this subset of the HIPS survey. As was mentioned earlier, a left dominant composite score would suggest an adaptive approach to change while a right-mode would correlate with an innovative one. The definition of an integrated style, as previously stated, combines the left and the right in appropriate proportions with the ability to clearly see the linkages (italics) between the two (Taggart \& Torrance, 1984). The mixed implies distinct uses of left- and right-mode. In the Tactics profile, the mixed requires the closest possible split of the other three: $4,3,3$ or any combination thereof. 
In Taggart's judgment, a mixed score suggests a broader but less penetrating approach to change as contrasted with an integrated one which indicates a vivid understanding of different perspectives and alternatives (Personal Interview, May 31, 1989).

Tactics Profile. Change strategies are an important focus of this study. By extension then, a second aspect of Research Question 1 regarding the sample's tendency toward a particular mode must deal with the subset of the HIPS Survey called the Tactics Profile. Considering only the responses from that portion which refer specifically to one's approach to change, Table 3 yields the following data:

Table 3

HIPS Tactics Profile Report for Nominated Community College Leaders Number

Percent

Left

Integrated

Right

Mixed

Dual Primaries:

$\begin{array}{rr}8 & 11 \\ 44 & 63 \\ 8 & 11 \\ 2 & 3\end{array}$

Left/Right

Integrated/Left

1

5

Integrated/Right

Total

$\underline{N}=70$ 
Clarifications are needed for the two categories entitled mixed and dual primaries. First, the mixed scores are obtained by the formula for conversion provided previously by Taggart (Personal Interview, June 3, 1989), one of the authors of the instrument. A mixed profile derived from the last ten items of the survey requires the following breakout of the number of scores, left, integrated and right in any combination thereof $(4,3,3)$. Secondly, the category called dual primaries is included for the Tactics Profile because of the limited number of questions within this subset of the HIPS instrument. It indicates that the two top scores came up equally high and had minimal or no third mode responses. These clusters, therefore, are classified in this different manner according to the survey author.

The significance of this particular table is that it ties directly to one's approach to change. As was stated earlier, the left dominant tactics mode relates to an adaptive style of change while the right indicates an innovative style. The integrated reflects the capacity for both simultaneously while the mixed indicates the same capacity but in distinct rhythms. It is of note that the mixed category looks substantially different from Table 1, and the integrated one has by far the highest percentage with the left and right responses remaining similar to Table 1 . It is not possible to consider only the raw and standard scores for determining the mode on the Tactics Profile. A mixed 
category must be included if the degree of preference is to be adequately distinguished in the view of this researcher. More will be said of this later in looking at the projected future effectiveness of the sample of this study, community college leaders. For now, it will be helpful to look at the modes of the HIPS questions most often answered similarly.

Clustering of Similar HIPS Responses. Twenty survey questions had a predominance of the same thinking style responses. The purpose of this table is to show the reader which questions were most often answered similarly and which responses, therefore, were important for a majority of the sample as a group. The HIPS instrument has 40 questions. As is shown on Table 4, 20 questions, 50\% of the total number, were answered as follows: 13 in the integrated mode, 3 in the left and 4 in the right. of these same 20 questions, 4 (20\%) had responses at the 70th percentile or better, all with integrated scores (see Figure 2).

Figure 2

Number of HIPS Questions Most often Answered Similarly by Percentage of Community College Leaders




Table 4

Number of HIPS Questions Most Often Answered Similarly by Percentage of Community College Leaders

\begin{tabular}{lccccc}
\hline Mode & $\frac{50-59 \%}{2}$ & $\frac{60-69 \%}{20 \%-O v e r}$ & $\begin{array}{c}\text { Total No. } \\
\text { of Questions }\end{array}$ \\
$\mathrm{I}$ & 2 & 1 & 0 & 3 \\
$\mathrm{R}$ & 5 & 4 & 4 & 13 \\
$\mathrm{M}$ & 3 & 1 & 0 & 4 \\
& $\mathrm{n} / \mathrm{a}$ & $\mathrm{n} / \mathrm{a}$ & $\mathrm{n} / \mathrm{a}$ & $\mathrm{n} / \mathrm{a}$ \\
$\mathrm{N}=70$ & & & Total & 20 \\
\hline
\end{tabular}

It may appear that these questions are neutral. However, their responses may in fact be due to various factors, such as, one's own thinking style, one's experience, and the prevailing cultural awareness about the topics. Specific examples may be helpful at this point. The integrated answers are as follows:

1. "equally fun to dream or plan realistically" (question 3).

2. "could probably be hypnotized but it would be difficult" (question 8).

3. "have few mood changes" (question 14).

4. "can clown or be serious depending upon the occasion"* (question 17).

* Responses at the 70th percentile or better. 
5. "occasionally absent-minded" (question 18).

6. "when viewing advertisements, am most often influenced by the information on the quality of the product" (question 19).

7. "equally valuable to tell stories and to act out stories" (question 22).

8. "equal preference for thinking while lying down or sitting up straight" (question 26).

9. "conforming or nonconforming depending on the situation"* (question 31).

10. "equally skilled in sequencing (ideas) and showing relations"* (question 36).

11. "producing ideas and drawing conclusions are equally enjoyable" (question 38).

12. "equally skilled in solving problems intuitively and logically" (question 39).

13. "just as exciting to me to improve something as to invent something new"* (question 40).

Examples of the left-mode responses were these:

1. "if seeking mental health counseling, would prefer the confidentiality of individual counseling" (question 6).

2. "more valuable to discuss stories read" (question 21).

3. "can control attention during verbal explanations" (question 29). 
Examples of the right-mode answers were as follows:

1. "enjoy drawing my own images and ideas" (question 7).

2. "prefers demonstration (over verbal instructions)" (question 20).

3. "enjoy interacting affectively with others" (question 25).

4. "would like to be a music composer [over a music critic]" (question 27).

These specific examples provide a sense of the meaning and implications from Table 4. The number of integrated answers (13 out of 40 questions -- 33\%) again reinforces the use of this mode among the nominated leaders.

Comparison of composite and Tactics scores. Since the HIPS Composite and Tactics scores have bearing on the question of change to be discussed in the next chapter, a comparison of these would also be important at this juncture. Compared with the dominant composite thinking styles, the Tactics responses of the leaders show several differences. Categorization of scores have been assigned as was discussed in the previous section on the Tactics Profile (see Table 5) .

of those nine left-mode composite scores, five (56\%) were the same as the Tactics; four (44\%) were different. of the nine right-mode scores, six (67\%) were the same; three (33\%) were dissimilar. of the integrated scores, 17 (100\%) 


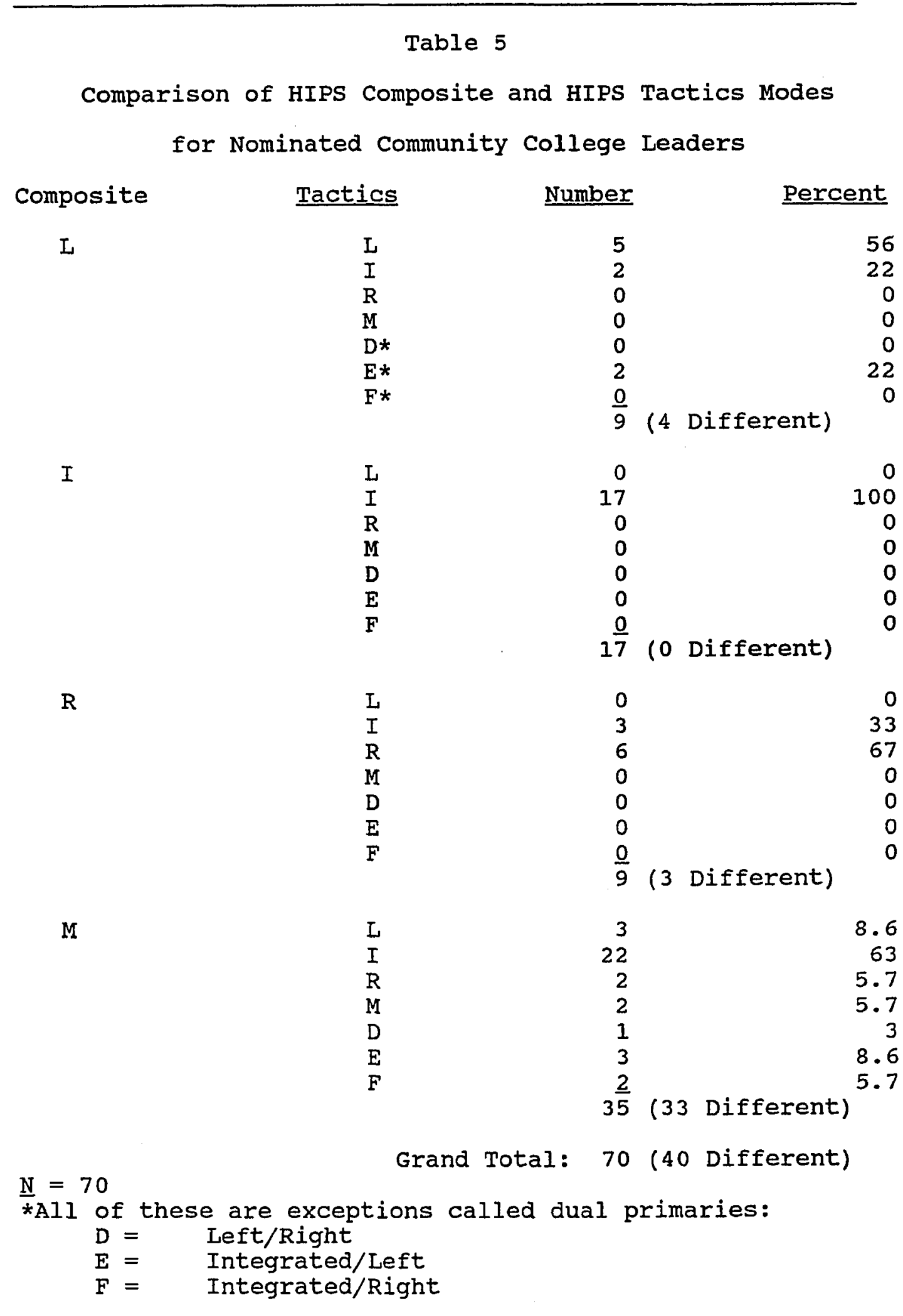


were alike; and of the mixed, 33 (94\%) were different and two (6\%) were not. The totals indicate 30 (43\%) similar and 40 (57\%) different. In each category, the integrated score is of particular note, holding either the largest or next to largest number. This may be in part attributable to the educational and administrative experience as well as to the age of the sample.

\section{The Leadership Practices Inventory Self and other}

Self. The Leadership Practices Inventory-Self according to authors Kouzes and Posner (1987) clusters five currently espoused essential leadership behavioral practices from its 30 item survey. These practices are evaluated and reflected on three ranges: high, moderate and low. These three ranges are ascertained through the scoring on a fivepoint Likert scale of how often each practice is used: rarely, (b) once in a while, (c) sometimes, (d) fairly often, and (e) very frequently. A linear average for each community college leader was derived from the ranges of each of the five individual behavioral practices. It was based on five raw scores which were converted to percentile rankings (see Appendix $U$ ) and then averaged. Each percentile ranking falls within one of the three ranges below. Table 6 exhibits the summary of these data in response to the first part of Research Question 2: "To what degree are the leadership behavioral practices described by Kouzes and Posner found in the nominated community college leaders surveyed by the LPI-S?" (see Table 6). 


$$
\begin{gathered}
\text { Table } 6 \\
\text { Summary of Average Ranges of } \\
\text { LPI-S Leadership Behavioral Practices } \\
\text { for Nominated Community College Leaders }
\end{gathered}
$$

$\begin{array}{lcc}\text { Range of Usage } & \text { Number } & \text { Percent } \\ \text { High }(70 \%-99 \%) & 21 & 30 \\ \text { Moderate }(30 \%-69 \%) & 36 & 51 \\ \text { Low (5\%-29\%) } & \underline{13} & \underline{19} \\ & 70 & 100 \\ \underline{N}=70 & & \end{array}$

The table shows that 21 individuals rated high, 36 persons rated moderate and the remaining 13 rated low in relation to the behavioral practices identified by the LPI-S. Comparison data of normed average ranges are not available from the authors' publications as was mentioned earlier. They did not develop a singular composite score for the whole test result. With their approval, this researcher did, however, prepare Table 6 using the conversion chart in Appendix U (Posner, Personal Interview, May 20, 1989). The breakpoint score between high and moderate was set at 25 test score points (70\%) and between the moderate and low at 21 test score points $(30 \%)$. These scores were derived by calculating the average of each of the five behavioral practice raw scores and percentiles. 
Further explanation and implications of this table will be discussed in the subsection entitled, "Correlation of the HIPS and the LPI-S Instruments."

It is also helpful to look at the sample means for each of the five separate LPI-S behavioral practices (see Table 7). All of these mean scores fall in the moderate usage range as described by Kouzes and Posner in the Leadership Practices Inventory Manual (1988) (see Appendix V).

Related LPI-S instrument norms prepared by Kouzes and Posner (1987) were based on a sample of 423 managers and executives from a full array of functional fields from both public and private sector organizations. The following means and standard deviations provide the profile (see Table 8). From Table 8 , it is evident that the normed sample's average means fell totally within the moderate range (see Appendix V) as did the nominated community college leaders of this study. Kouzes and Posner also report a second set of similar results, those from a population of 49 senior human resource management professionals (see Table 9). 
Table 7

Sample Mean Scores of the Five Individual

Leadership Behavioral Practices

for Community College Leaders

Practice
Challenging
Inspiring
Enabling
Modeling
Encouraging

\begin{tabular}{|c|c|}
\hline Mean & Range \\
\hline 23.13 & $M$ \\
\hline 22.13 & M \\
\hline 25.44 & M \\
\hline 22.71 & $M$ \\
\hline 23.47 & $\mathrm{M}$ \\
\hline
\end{tabular}

Standard Deviation
3.96
3.86
3.33
3.37
3.91

\begin{tabular}{c} 
Minimum/Maximum \\
Score \\
\hline $10 / 30$ \\
$11 / 30$ \\
$10 / 30$ \\
$8 / 28$ \\
$14 / 30$
\end{tabular}

$\underline{N}=70$ 


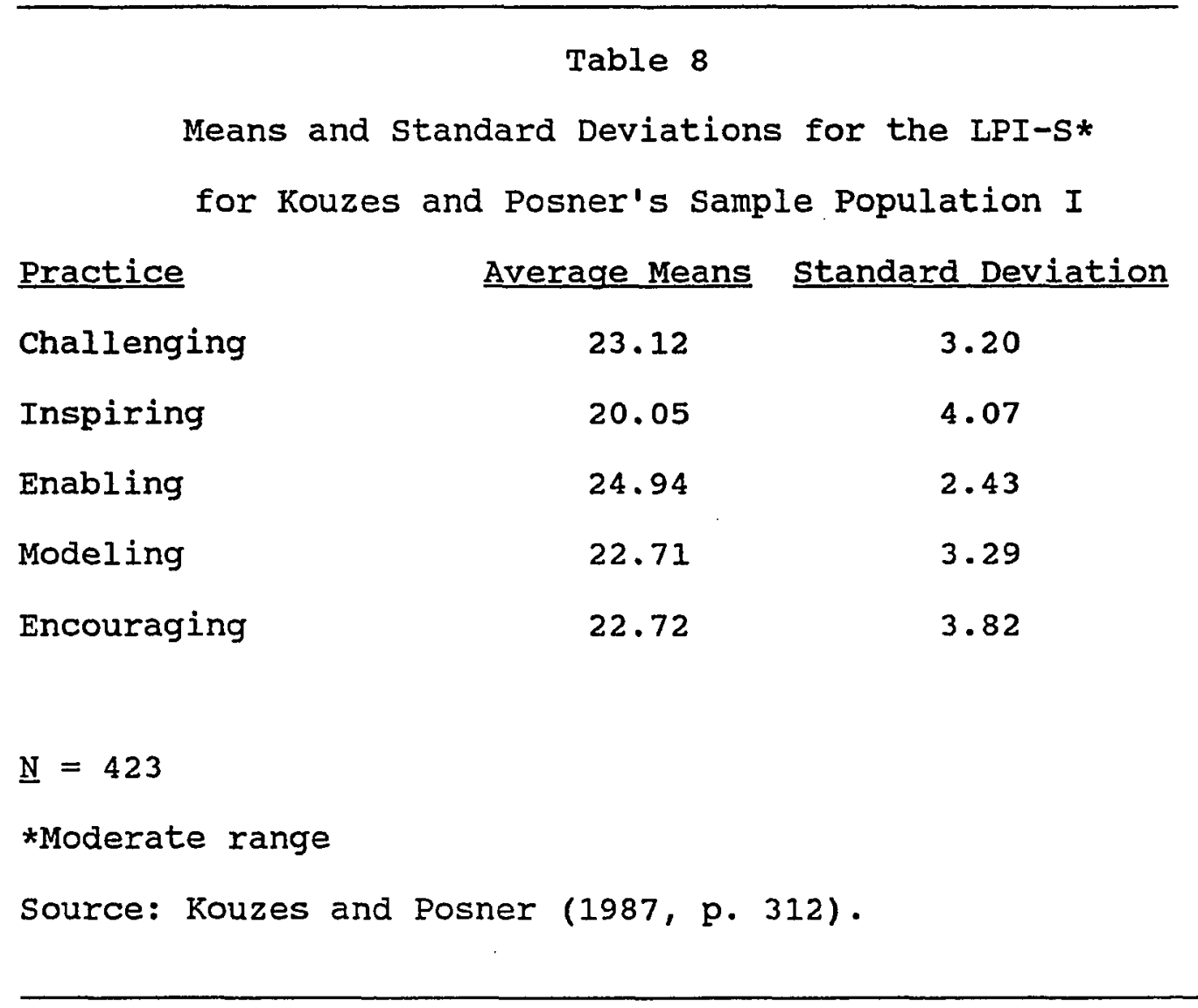




\section{Table 9}

Means and Standard Deviations for the LPI-S

for Kouzes and Posner's Sample Population II*

Practice

Challenging

Inspiring

Enabling

Modeling

Encouraging
Average Means Standard Deviation

24.35

22.98

26.63

23.94

23.22

2.61

3.19

2.17

2.66

$\underline{\mathrm{N}}=49$

*All moderate range except for "enabling" which is high. Source: Kouzes and Posner (1987, p. 315). 
Clusters of Highest LPI-S Answers. An LPI-S item analysis provides the percentage of the sample population which answered in each of the appropriate categories: "once in a while", "sometimes", "fairly often", and "very frequently". Additional insight about the nominated leaders as a group can be gleaned from ah overview of selected related data.

It is first important to explain that six LPI-S questions in each case pertained to one of the five behavioral practices: under "challenging the process," (questions $1,6,11,16,21 \& 26)$; "inspiring a shared vision" (questions 2, 7, 12, 17, 22 \& 27); "enabling others to act" (questions $3,8,13,18,23 \& 28$ ); "modeling the way" (questions 4,9,14, 19, $24 \& 29$ ); and "encouraging the heart" (questions 5, 10, 15, 20, 25 \& 30) (Kouzes \& Posner, 1988, pp. 12-13) (see Appendix X). It was possible then to cluster the responses into appropriate categories and to see where dominant patterns occurred.

Table 10 displays the percentages of the sample for which the five individual behavioral practices' scores clustered in the two top categories, "fairly often" and "very frequently", at a rate of $60 \%$ or above. Each instance was tallied and totaled for each practice.

The following figure presents the information graphically (see Figure 3 ). 
Table 10

Summary of Combined Two Top Scorings, "Fairly often" and "Very Frequently", for Each LPI-S Behavioral Practice for Nominated Community College Leaders

\begin{tabular}{|c|c|c|c|c|c|c|c|}
\hline $\begin{array}{l}\% \text { of } \\
\text { Sample }\end{array}$ & $\begin{array}{c}\text { Challeng- } \\
\text { ing }\end{array}$ & $\begin{array}{l}\text { Inspir- } \\
\text { ing. }\end{array}$ & $\begin{array}{l}\text { Enabl- } \\
\text { ing }\end{array}$ & $\begin{array}{l}\text { Model- } \\
\text { ing }\end{array}$ & \multicolumn{2}{|c|}{$\begin{array}{l}\text { Encour- } \\
\text { aging }\end{array}$} & Total \\
\hline Over $60 \%$ & 2 & 3 & 1 & 2 & & & 8 \\
\hline Over $70 \%$ & 3 & 0 & 0 & 1 & & & 5 \\
\hline Over $80 \%$ & 0 & 1 & 3 & 1 & & & 8 \\
\hline \multirow[t]{2}{*}{ Over $90 \%$} & $\underline{0}$ & $\underline{0}$ & $\underline{2}$ & 1 & & & 3 \\
\hline & $5(7 \%)$ & 4( & & $9 \%)$ & $5(7 \%)$ & $4(4 \%)$ & 24 \\
\hline$=70$ & & & & & & & \\
\hline
\end{tabular}




\section{Figure 3}

Summary of Combined Two Top Scorings for Each LPI-S

Behavioral Practice

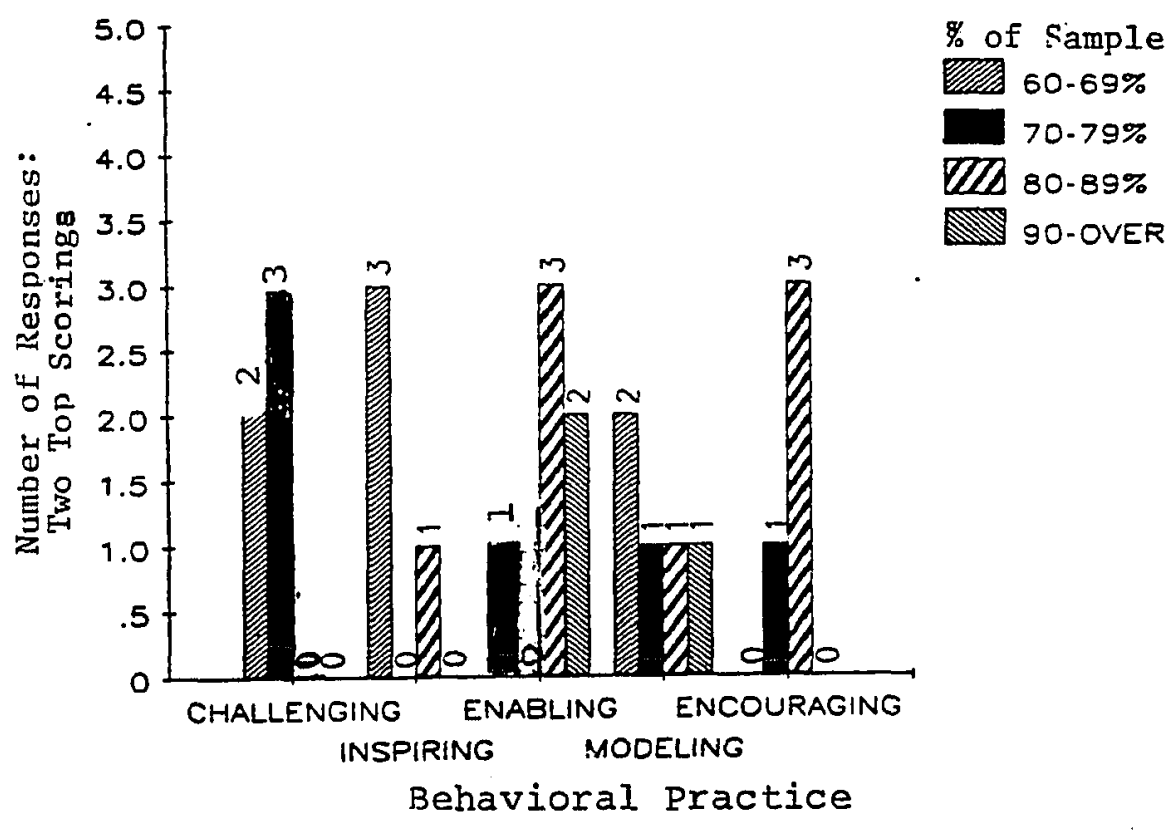

$\underline{N}=70 \quad$ Six Test Itens for Each Practice

The total number of answers falling in the two top categories at $60 \%$ or above was $24 \%$. There were 30 -item responses, six for each individual behavioral practice, which make the 24 equate to $80 \%$ of the instrument. As can be observed, the third practice had six possible responses (100\%) for that behavioral practice at the various percentages. "Modeling the way" and "challenging the process" had five responses or $83 \%$ of the possible six. The last two categories were that of "inspiring a shared vision" and "encouraging the heart" with four of six possible responses $(67 \%)$. 
Two behavioral practices had $90 \%+$ responses. Under the first, "enabling others to act", the two specific test item behavioral activities which received a $90 \%+$ rating were "treats others with respect" and "develops cooperative relationships". Under the second practice of "modeling the way", the specific test question activity was "practices what is espoused".

Correlation of the HIPS and the LPI-S Instruments. Research Question 3 will be discussed next: Is there a significant correlation between thinking styles as measured by the Human Information Processing survey (HIPS) and leadership behavioral practices as defined by the Leadership Practices Inventory-Self (LPI-S)?

The ranges of high, moderate and low for purposes of this question are calculated from a linear average of the individual survey scores. (The breakpoint score between high and moderate was set at 25 test score points and between moderate and low at 21 test score points.)

The linear average was calculated after discussion and approval from Posner, one of the authors of the instrument (Personal Interview, May 20, 1989). Kouzes and Posner (1987) had not used such a score in their work with the Leadership Practices Inventory because they chose to emphasize that each behavioral practice was interrelated. Posner affirmed also, however, that each of the practices stood on its own and had no problem with this researcher's focusing on both aspects. As will be evident, a linear 
average was necessary to address the correlation in the two different dimensions implied in Research Question 3, the IPI-S composite test score as well as the individual behavioral practices' score (see Table 11).

Table 11

Summary of HIPS Composite Modes and LPI-Self

Average Composite Ranges for Nominated Community college Leaders

\begin{tabular}{|c|c|c|c|c|}
\hline HIPS Composite & LPI-S Range & Number & $\%$ of Mode & of Tota \\
\hline Left & $\begin{array}{l}\mathrm{H} \\
\mathrm{M} \\
\mathrm{L}\end{array}$ & $\begin{array}{l}2 \\
6 \\
\frac{1}{9}\end{array}$ & $\begin{array}{r}22 \\
67 \\
11 \\
100\end{array}$ & $\begin{array}{r}3 \\
9 \\
\frac{1}{3}\end{array}$ \\
\hline Integrated & $\begin{array}{l}\mathrm{H} \\
\mathrm{M} \\
\mathrm{I}\end{array}$ & $\begin{array}{r}7 \\
7 \\
\frac{3}{7} \\
17\end{array}$ & $\begin{array}{r}41 \\
41 \\
18 \\
100\end{array}$ & $\begin{array}{r}10 \\
10 \\
4 \\
24\end{array}$ \\
\hline Right & $\begin{array}{l}\mathrm{H} \\
\mathrm{M} \\
\mathrm{L}\end{array}$ & $\begin{array}{l}3 \\
6 \\
\frac{0}{9}\end{array}$ & $\begin{array}{r}33 \\
67 \\
0 \\
100\end{array}$ & $\begin{array}{r}4 \\
9 \\
1 \frac{2}{3}\end{array}$ \\
\hline Mixed & $\begin{array}{l}\mathrm{H} \\
\mathrm{M} \\
\mathrm{L}\end{array}$ & $\begin{array}{r}9 \\
17 \\
9 \frac{9}{35} \\
\text { Total: }\end{array}$ & $\begin{array}{l}25.7 \\
49 \\
25.7 \\
100\end{array}$ & $\begin{array}{r}13 \\
24 \\
13 \\
50 \\
100\end{array}$ \\
\hline
\end{tabular}

overall, in every category except the integrated, the moderate range has the highest percentage of responses: $67 \%, 67 \%$, and $49 \%$, respectively. The integrated is equally split between the high and the moderate ranges. In all 
cases, no correspondence between the composite scores is significant.

An ANOVA on the HIPS dominant modes and the LPI-S average composite ranges $(\underline{N}=69)$ likewise reflects no evidence of mean scores being significantly different. The means of dominant modes for Groups $1(\underline{N}=9), 2(\underline{N}=17), 3$ $(\underline{\mathrm{N}}=8), 4(\underline{\mathrm{N}}=35)$, and at the total $(\underline{\mathrm{N}}=69)$ are 23.44, $23.96,24.78,22.83$, and 23.42 , respectively. A crosstabulation of dominant modes and LPI-S average composite ranges yielded a Chi-square value of 3.75 ( $\underline{\mathrm{f}}=6$, significance $=.710)$. An added consideration is that $53 \%$ of the cells, 7 out of 12 , have less than five entries. This could have the effect of inflating chi-square values.

Table 12 contains a summary of descriptive statistics for HIPS scores and Tactics Profile scores by dominant mode.

In addressing Research Question 3 more thoroughly, it will be beneficial to look at each of the behavioral practices individually (see Table 13). The score and range breakout is included in Appendix $\mathrm{V}$.

In analyzing the left mode responses, the largest number of them fall in the "inspiring a shared vision" category with $78 \%$ in the moderate range, that is, $10 \%$ of the total number of leaders surveyed. The next largest two numbers at $44 \%$ in the high range are in the columns "enabling others to act" and "modeling the way" $6 \%$ of the total sample). Two in the low range, also at $44 \%$, are under the heading "challenging the process" and "encouraging the 
Table 12

Sumary of Descriptive Statistics by Daninant Mode

\begin{tabular}{|c|c|c|c|c|c|c|c|c|c|c|c|c|c|c|c|}
\hline \multirow{3}{*}{ SelE Ratings LPI } & \multicolumn{3}{|c|}{ Left } & \multicolumn{3}{|c|}{ Right } & \multicolumn{3}{|c|}{ Integrated } & \multicolumn{3}{|c|}{ Mixed } & \multicolumn{3}{|c|}{ Total Sampl.e } \\
\hline & Mean & $\underline{S D}$ & $\underline{\mathbf{N}}$ & Mean & $\underline{\text { SD }}$ & $\underline{\mathbf{N}}$ & Mean & $\underline{S D}$ & $\underline{\mathbf{N}}$ & Mean & $\underline{\text { SD }}$ & $\underline{\mathbf{N}}$ & Mean & $\underline{S D}$ & $\underline{\mathbf{N}}$ \\
\hline & & & & & & & & & & & & & & & \\
\hline $\begin{array}{l}\text { Challenging } \\
\text { Inspiring } \\
\text { Enabling } \\
\text { Modeling } \\
\text { Encouraging }\end{array}$ & $\begin{array}{l}22.4 \\
21.8 \\
26.2 \\
23.9 \\
22.9\end{array}$ & $\begin{array}{l}3.4 \\
2.0 \\
2.4 \\
3.0 \\
4.2\end{array}$ & $\begin{array}{l}9 \\
9 \\
9 \\
9 \\
9\end{array}$ & $\begin{array}{l}24.9 \\
24.0 \\
25.8 \\
23.0 \\
26.3\end{array}$ & $\begin{array}{l}3.0 \\
4.0 \\
3.6 \\
3.3 \\
3.2\end{array}$ & $\begin{array}{l}8 \\
8 \\
8 \\
8 \\
8\end{array}$ & $\begin{array}{l}24.1 \\
22.5 \\
25.7 \\
23.6 \\
23.9\end{array}$ & $\begin{array}{l}2.9 \\
4.0 \\
2.6 \\
2.5 \\
4.1\end{array}$ & $\begin{array}{l}17 \\
17 \\
17 \\
17 \\
17\end{array}$ & $\begin{array}{l}22.6 \\
21.7 \\
25.0 \\
22.2 \\
22.7\end{array}$ & $\begin{array}{l}4.5 \\
4.1 \\
3.8 \\
3.7 \\
3.8\end{array}$ & $\begin{array}{l}35 \\
35 \\
35 \\
35 \\
35\end{array}$ & $\begin{array}{l}23.2 \\
22.1 \\
25.4 \\
22.9 \\
23.4\end{array}$ & $\begin{array}{l}4.0 \\
4.0 \\
3.4 \\
3.4 \\
4.0\end{array}$ & $\begin{array}{l}72 \\
72 \\
72 \\
72 \\
72\end{array}$ \\
\hline Linear Average 1 & 23.4 & 2.4 & 9 & 24.8 & 2.3 & $\mathbf{B}$ & 24.0 & 2.6 & 17 & 22.8 & 3.4 & 35 & 23.4 & 3.1 & 72 \\
\hline OUhers' Ratings LPI & & & & & & & & & & & & & & & \\
\hline $\begin{array}{l}\text { Cllatlenging } \\
\text { Inspiring } \\
\text { Finabling } \\
\text { Modeling } \\
\text { Encouraging }\end{array}$ & $\begin{array}{l}23.4 \\
21.8 \\
25.5 \\
24.9 \\
22.7\end{array}$ & $\begin{array}{l}1.9 \\
1.7 \\
2.7 \\
2.2 \\
2.8\end{array}$ & $\begin{array}{l}7 \\
7 \\
7 \\
7 \\
7\end{array}$ & $\begin{array}{l}23.6 \\
23.4 \\
24.6 \\
22.9 \\
23.6\end{array}$ & $\begin{array}{l}2.7 \\
2.7 \\
2.1 \\
2.8 \\
4.7\end{array}$ & $\begin{array}{l}7 \\
7 \\
7 \\
7 \\
7\end{array}$ & $\begin{array}{l}24.4 \\
23.5 \\
25.7 \\
24.3 \\
25.5\end{array}$ & $\begin{array}{l}3.3 \\
4.3 \\
3.0 \\
3.7 \\
3.6\end{array}$ & $\begin{array}{l}15 \\
15 \\
15 \\
15 \\
15\end{array}$ & $\begin{array}{l}22.5 \\
21.8 \\
25.0 \\
23.2 \\
23.5\end{array}$ & $\begin{array}{l}4.2 \\
3.9 \\
3.2 \\
3.3 \\
3.7\end{array}$ & $\begin{array}{l}27 \\
27 \\
27 \\
27 \\
27\end{array}$ & $\begin{array}{l}23.1 \\
22.3 \\
25.2 \\
23.5 \\
23.9\end{array}$ & $\begin{array}{l}3.7 \\
3.6 \\
3.1 \\
3.3 \\
3.8\end{array}$ & $\begin{array}{l}65 \\
65 \\
65 \\
65 \\
65\end{array}$ \\
\hline $\begin{array}{l}\text { Jinear Average }{ }^{2} \\
\text { III'S Scores }\end{array}$ & 23.7 & 1.8 & 7 & 23.6 & 2.7 & 7 & 24.7 & 3.3 & 15 & 23.2 & 3.2 & 27 & 23.6 & 3.1 & 65 \\
\hline $\begin{array}{l}\text { Left } \\
\text { llight } \\
\text { Intergrated }\end{array}$ & $\begin{array}{r}20.0 \\
7.8 \\
12.2\end{array}$ & $\begin{array}{l}3.5 \\
2.8 \\
2.0\end{array}$ & $\begin{array}{l}9 \\
9 \\
9\end{array}$ & $\begin{array}{r}7.8 \\
19.0 \\
13.3\end{array}$ & $\begin{array}{l}4.2 \\
1.5 \\
4.3\end{array}$ & $\begin{array}{l}8 \\
8 \\
8\end{array}$ & $\begin{array}{r}9.2 \\
6.5 \\
24.4\end{array}$ & $\begin{array}{l}2.7 \\
2.2 \\
2.1\end{array}$ & $\begin{array}{l}17 \\
17 \\
17\end{array}$ & $\begin{array}{l}11.3 \\
11.1 \\
17.6\end{array}$ & $\begin{array}{l}3.1 \\
3.2 \\
3.0\end{array}$ & $\begin{array}{l}36 \\
36 \\
36\end{array}$ & $\begin{array}{l}11.5 \\
10.5 \\
18.1\end{array}$ & $\begin{array}{l}4.7 \\
4.6 \\
5.0\end{array}$ & $\begin{array}{l}70 \\
70 \\
70\end{array}$ \\
\hline l'actics profile scor & & & & & & & & & & & & & & & \\
\hline $\begin{array}{l}\text { Left } \\
\text { Right } \\
\text { Integrated }\end{array}$ & $\begin{array}{l}4.7 \\
1.2 \\
4.1\end{array}$ & $\begin{array}{r}2.1 \\
.8 \\
1.9\end{array}$ & $\begin{array}{l}9 \\
9 \\
9\end{array}$ & $\begin{array}{l}1.0 \\
5.5 \\
3.5\end{array}$ & $\begin{array}{l}1.4 \\
1.4 \\
1.9\end{array}$ & $\begin{array}{l}8 \\
8 \\
8\end{array}$ & $\begin{array}{r}1.3 \\
.9 \\
7.8\end{array}$ & $\begin{array}{r}.8 \\
1.0 \\
1.0\end{array}$ & $\begin{array}{l}17 \\
17 \\
17\end{array}$ & $\begin{array}{l}2.4 \\
2.5 \\
5.1\end{array}$ & $\begin{array}{l}1.6 \\
1.4 \\
1.7\end{array}$ & $\begin{array}{l}36 \\
36 \\
36\end{array}$ & $\begin{array}{l}2.3 \\
2.3 \\
5.4\end{array}$ & $\begin{array}{l}1.8 \\
1.8 \\
2.2\end{array}$ & $\begin{array}{l}70 \\
70 \\
70\end{array}$ \\
\hline
\end{tabular}

$\frac{1}{2}$ OF 5 Behavioral Practices Raw Scores Means (Self Ratings)

2 OF 5 Belavioral practices Raw Scores Means (Others' Rating) 
Table 13

Correspondence of HIPS Composite Modes and Ranges of Individual LPI-S Behavioral Practices for Nominated Community College Leaders

Mode/R Challenging Inspiring Enabling Modeling Encouraging

$$
\begin{aligned}
& \mathrm{L}-\mathrm{H} \quad 2(22 \%) \quad 2(22 \%) \quad 4(44 \%) \quad 4(44 \%) \quad 3(33 \%) \\
& \text { M } 3(33 \%) \quad 7(78 \%) \quad 3(33 \%) \quad 3(33 \%) \quad 3(22 \%) \\
& \text { L } \quad 4(44 \%) \quad 0(0 \%) \quad 2(22 \%) \quad 2(22 \%) \quad 4 \quad(44 \%) \\
& \mathrm{I}-\mathrm{H} \quad 10(59 \%) \quad 7(41 \%) \quad 7(41 \%) \quad 6(35 \%) \quad 7(41 \%) \\
& \text { M } \quad 4(24 \%) \quad 7(41 \%) \quad 7(41 \%) \quad 8(47 \%) \quad 6(35 \%) \\
& \text { L } 3(18 \%) \quad 3(18 \%) \quad 3(18 \%) \quad 3(18 \%) \quad 4(24 \%) \\
& \mathrm{R}-\mathrm{H} \quad 4(44 \%) \quad 5(56 \%) \quad 4(44 \%) \quad 2(22 \%) \quad 5(56 \%) \\
& \text { M } \quad 5(56 \%) \quad 3(33 \%) \quad 3(33 \%) \quad 3(33 \%) \quad 4(44 \%) \\
& \text { I } \quad 0(0 \%) \quad 1(11 \%) \quad 2(22 \%) \quad 4(44 \%) \quad 0(0 \%) \\
& \mathrm{M}-\mathrm{H} \quad 11(31 \%) \quad 12(34 \%) \quad 14(40 \%) \quad 8 \quad(23 \%) \quad 10 \quad(29 \%) \\
& \text { M } 10(29 \%) \quad 15(43 \%) \quad 13(37 \%) \quad 14 \quad(40 \%) \quad 14 \quad(40 \%) \\
& \text { I } \quad 14(40 \%) \quad 8(23 \%) \quad 8(23 \%) \quad 13(37 \%) \quad 11(31 \%) \\
& \underline{\mathbf{N}}=70
\end{aligned}
$$


heart". Less than 25\% of the left mode participants fell in the low range for the second, third and fourth practices, the second one actually having $0 \%$.

The most notable obvious impression regarding the integrated mode is that the combinations of high and moderate ranges in each column produce between 13 and 14 of the total 17 in this mode, that is, $76-82 \%$ or about $20 \%$ of total responses. By contrast, the low range generally claims a small percentage of this mode, approximately $18 \%$, which equates to only $4 \%$ of the total survey responses. The largest single grouping is in the high range of the "challenging" practice at $59 \%$ and the second in the moderate range of "modeling" at $47 \%$. The last two percentages for this mode equate to $14 \%$ and $11 \%$ of the total group surveyed $(\underline{N}=70)$, respectively.

Regarding the right mode answers, again there is a clustering in the high and moderate range in four practices, with $100 \%$ of them there in "challenging" and "encouraging" columns. Only in the category of "modeling" is there a majority in the low range, $44 \%, 6 \%$ of the total sample surveyed. The largest three numbers are at 56\%, two in the high range of "inspiring" and "encouraging" and one in the moderate range of "challenging". Fifty-six percent of this mode converts to $7 \%$ of the total population.

The mixed mode shows the largest number, $43 \%(21 \%$ of the total), in the moderate "inspiring" range. This score plus two $40 \%$ ones in "modeling" and "encouraging" make the 
moderate range most prevalent for the mixed mode. Two other responses fall at the $40 \%$ level, one in the low "challenging" and one in the high "enabling" categories.

Overall, however, Table 13 does not reflect any significant correspondence between thinking style as measured by the HIPS instrument and leadership behavioral practices as defined by the IPI-S.

Chi-Square values were calculated between HIPS dominance and the LPI-S practice ranges likewise show no statistical significance at the .05 alpha level. For "challenging", "inspiring", "enabling", "modeling", and "encouraging", the Chi-Square values were 9.60 ( $\underline{N}=68)$, $6.36(\underline{\mathrm{N}}=68), 2.01(\underline{\mathrm{N}}=66), 2.86(\underline{\mathrm{N}}=67)$, and $6.94(\underline{\mathrm{N}}=$ 68), respectively. These are not statistically significant.

In the total sample, there are no correlation coefficients beyond the .10 level. However, as noted in Tables 14 and 15 , an examination of the correlation coefficients by dominant subgroups shows various statistically significant relationships between modes and behavioral practices.

\section{Research Hypotheses}

This study also explored five research hypotheses which posited specific correlations between behavioral practices and thinking styles (see Table 16). From this data it is readily apparent that there is not a high correspondence between the high responses of the 


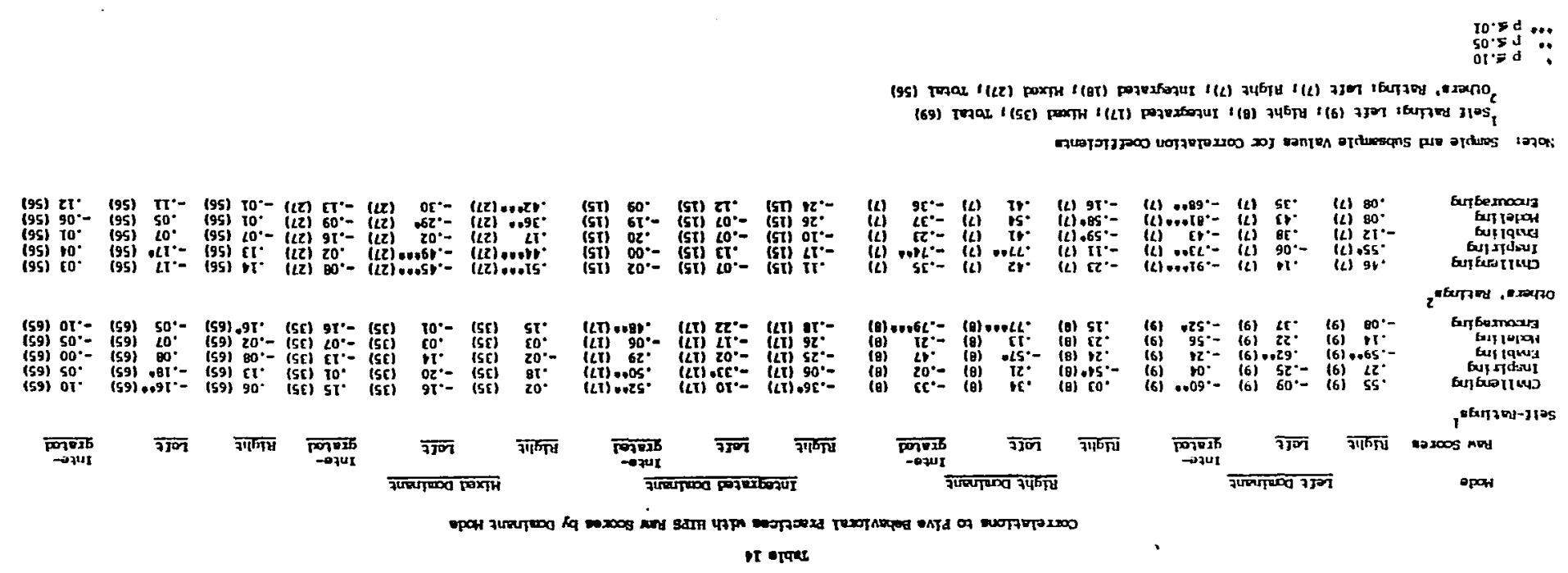


Table 15

Correlations of Five Behavioral Practices into Raw Tactics Score by Doninant Mode

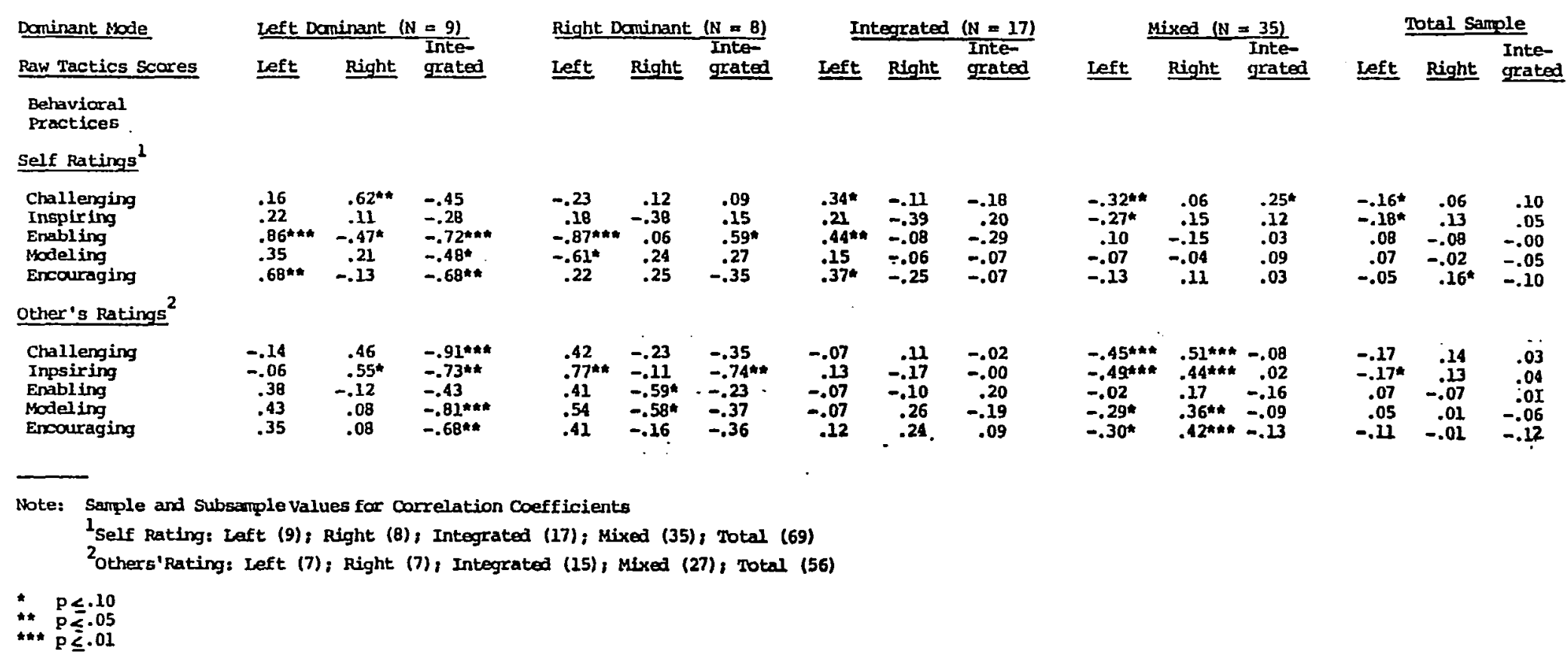

Note: Sample and Subsample values for correlation coefficients

1Self Rating: Laft (9); Right (8); Integrated (17); Mixed (35), Total (69)

Oothers'rating: Left (7); Right (7); Integrated (15); Mixed (27); Total (56)

$* \quad \mathrm{p} \leq .10$

*t** $\mathrm{p} \leq .01$ 
Table 16

Correspondence of DesIgnated LPI-S Ranges and Dominnnt IIIPS Modes for Nominated Connunity Callege Leaders

\begin{tabular}{|c|c|c|c|c|c|c|}
\hline $\begin{array}{c}\text { practice/ } \\
\text { Range } \\
\end{array}$ & Number & $\begin{array}{c}\text { Percent of } \\
\text { Total } \\
\end{array}$ & $\begin{array}{r}\text { L } \\
\text { No. (8) } \\
\end{array}$ & $\begin{array}{l}I \\
\text { No. }(8) \\
\end{array}$ & $\begin{array}{l}\text { R } \\
\text { No. (z) } \\
\end{array}$ & No. ${ }^{M}(z)$ \\
\hline Challeng ing/lligh & 27 & 39 & $2(78)$ & $1.0(378) \star$ & $4(158)^{*}$ & $11(418)$ \\
\hline Inspiring/ulgh & 26 & 37 & $2(88)$ & $7(278)$ & $5(398) *$ & $12(162)$ \\
\hline Enabling/uigh & 29 & 41 & $4(148)$ & $7(248)$ & $4(148) *$ & $14(488)$ \\
\hline $\begin{array}{l}\text { Modeling/ } \\
\text { Moderate/Low }\end{array}$ & 50 & 71 & $5(108)$ & $11(228) \star$ & $7(148)$ & $27(548)$ \\
\hline Encouraging/lligh & . 25 & 36 & $3(128)$ & $7(288)$ & $5(208)^{\star}$ & $10(408)$ \\
\hline$N=70$ & & & & & & \\
\hline
\end{tabular}


first behavioral practice and the integrated and right modes. Only $52 \%$ of the responses fall in these categories. This is true also of the high responses of the second, third or fifth practices where right mode is generally the third highest response at a percentage range between only 14 and $20 \%$. The moderate to low response range of the fourth practice is likewise not significant in that it shows only $22 \%$ of the responses in the integrated mode. None of the Research Hypotheses, therefore, is shown to be supported. A multinomial Chi-square test calculated for these same hypotheses also confirms no statistically significant relationship.

Other. The second part of Research question 2 and Research Question 4 address the responses of the LPI-Others and their correlation with the LPI-S: What are the leadership behavioral practices of the nominated community college leaders as identified by observers in the LPI-Other? Are the leaders' perceptions of their own behaviors consistent with those of their designated close observers? In ascertaining leadership effectiveness, Kouzes and Posner built in two levels of assessment: first, individual leaders and the second, their group of subordinates and peers. The same survey format and content is utilized by both groups (see Table 17). The composite ranking of leaders' and observers' perceptions did not reflect great inconsistency. Five t-tests show likewise no statistically significant differences between the LPI-S and LPI-O scores. 
Table 17

Comparison of LPI-S and LPI-0 Behavioral Practice Means

for Community College Leaders and Observers

\begin{tabular}{|c|c|c|c|c|c|}
\hline \multirow[t]{2}{*}{ Practice } & \multicolumn{2}{|c|}{ LPI-Self } & \multicolumn{2}{|c|}{ LPI-Other (Average)* } & \multirow[t]{2}{*}{ 2-Tailed probability } \\
\hline & Mean & $\underline{S D}$ & Mean & $\underline{\mathrm{SD}}$ & \\
\hline Challenging & 23.59 & 3.90 & 23.45 & 3.60 & .420 \\
\hline Inspiring & 22.38 & 3.92 & 22.48 & 3.65 & .811 \\
\hline Enabling & 25.36 & 3.53 & 25.29 & 2.96 & .618 \\
\hline Modeling & 22.75 & 3.40 & 23.77 & 3.30 & .149 \\
\hline Encouraging & 23.16 & 3.97 & 24.00 & 3.70 & .268 \\
\hline$N=58$ & & & & & \\
\hline
\end{tabular}


The $t$-values for each of the behavioral practices $(\underline{N}=58)$

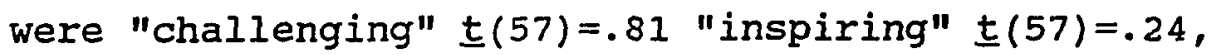
"enabling" $\underline{t}(57)=.50$, "modeling" $\underline{t}(57)=-1.46$, and "encouraging" $\underline{t}(57)=-1.12$. These values were not statistically significant.

However, in graphing and comparing the individually averaged survey scores, many differences were obvious. Selected examples are shown in Appendix $Y$. In each case, leaders' and others' scores were compared showing those greater than, equal to, less than the opposite (see Table 18).

These LPI-S and -0 findings do not in any way directly affect the earlier correspondence or correlation of the leaders' HIPS and LPI-S scores. They are a secondary consideration only, intended to gain a sense of the similarity of these perceptions only.

\section{Summary}

The findings of the study of designated California community college leaders suggest some interesting insights and relevant considerations:

\section{Findings related to the HIPS composite scores:}

1. The sample of nominated leaders doesn't necessarily follow the norms of the general population. While the mixed mode percentage of the two groups is consistent at $50 \%$, the community college sample's integrated mode is $24 \%$ while the general population's is $10 \%$. The community college population's left- and right-modes are $13 \%$ 
Table 18

Comparison of Leaders' and Observers' Scores

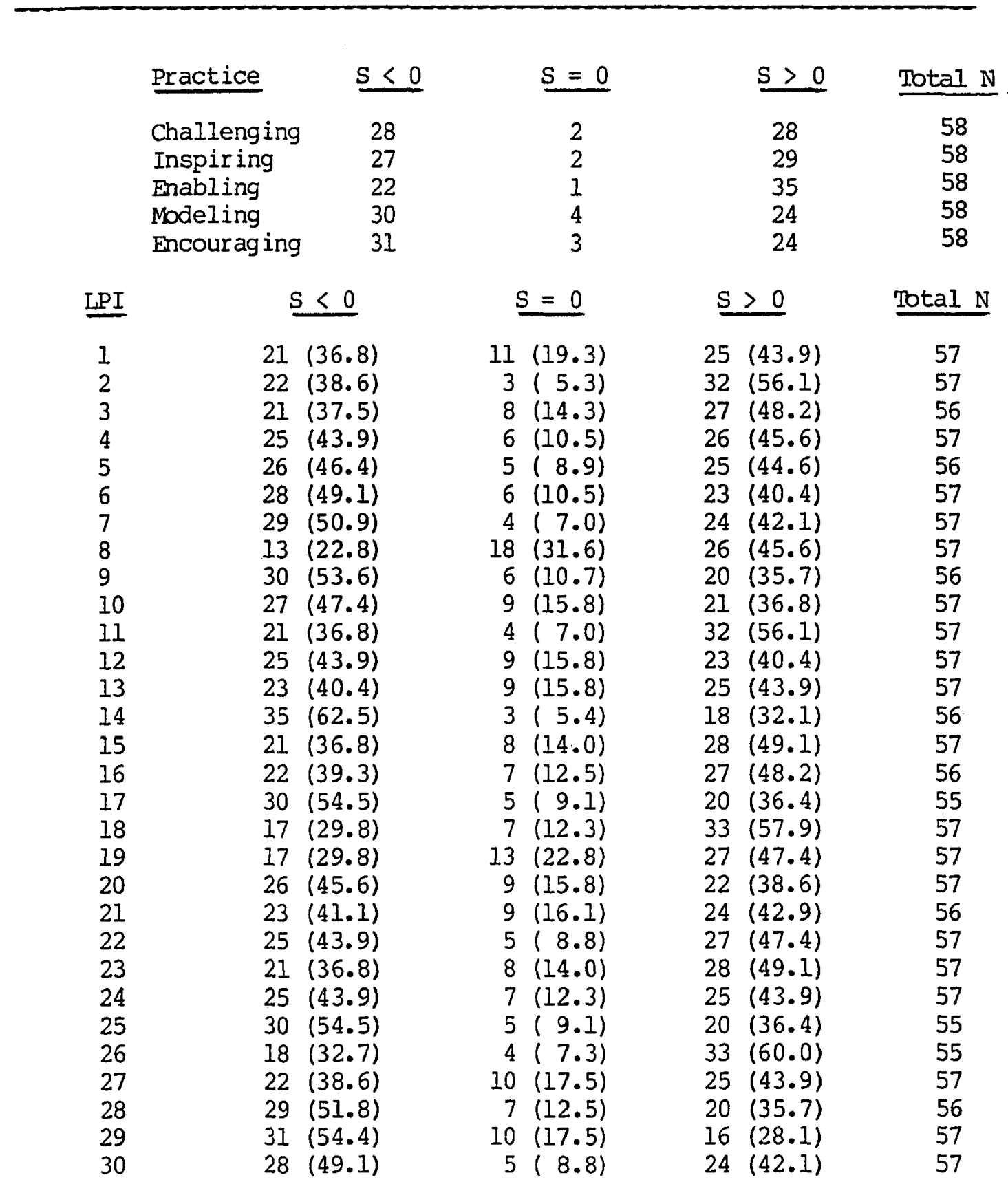


2. The combination of mixed and integrated scores in this study's sample is $74 \%$ while in the national norm it is $60 \%$.

3. Left-mode dominance prevailed in the previous educational studies of school officials, studies conducted by Coulson and Strickland (1983), Norris (1984) and Spruill (1986), but mixed at $50 \%$ and integrated at $24 \%$ were more prevalent in this study. A comparison of community college dominant modes from standard scores only, excluding the mixed category strongly affirms this difference. These results are 17 (24\%) are left mode, 38 (54\%) are integrated, and 15 (21\%) are right.

4. Thirty-one percent of the community college leaders fell in the 90th percentile of those internationally taking the normed HIPS Survey. About one-third of the group scored substantially higher than the general population.

5. Twenty specific questions, half of the test, were answered similarly by $50 \%$ or more of the sample. There are several possible reasons for this, cultural loading being one. Regardless, again there was a strong tendency toward the integrated category.

Findings related to the HIPS tactics profile:

1. There is a large shift from the composite mixed scores to the integrated mode when dealing with only the Tactics Profile portion of the test. The integrated information processing is preferred. 
2. Considerations related to change seem to force or encourage a concomitant use of left-and right-modes. Findings related to the LPI-S:

1. Fifty-one percent of the nominated community college leaders (36) perceived themselves as using moderately the leadership behavioral practices defined by Kouzes and Posner (1987). This may be attributable to high expectations of oneself or to a difference in the criteria applied to the understanding and evaluation of leadership, for example. Both educational and business sample populations scored similarly.

Another potentially important factor may be the interpretation of the word, "moderate". For some, the word is closer to "high" in meaning; for others, it is nearer to the category "low". In other words, its exact meaning may be skewed based on the understanding of the respondent.

2. A breakdown of the individual distinct behavioral practices were practically identical in that they were also moderate in range.

3. The summary of the two top scoring categories reflects higher ratings in the more commonly-espoused current desirable practices: "enabling others to act", "modeling the way", and "challenging the process". This preponderance with regard to certain practices may reflect cultural loading. The profile on "inspiring a shared vision" and "encouraging the heart" are only more recently 
being given consideration in some circles of leadership understanding.

Findings related to the relationship of HIPS to LPI-S:

1. Of those leaders sampled, the left, right and mixed mode individuals rated themselves most frequently in the moderate usage range. Only in the integrated mode responses did the high and moderate ranges tie. No correlations of statistical significance were evident, however, using the HIPS composite dominant score and the LPI-S linear average range.

2. The individual practices while showing more distinct clustering likewise did not reflect correlations of statistical significance between the composite dominant thinking styles and the individual leadership behavioral practices. While this was true for the correlation coefficients, beyond the .10 level for the total sample, there were statistically significant results among dominant mode subgroups of the whole HIPS survey as well as for the section called Tactics Profile.

\section{Findings related to the research hypotheses:}

1. None of the research hypotheses was confirmed by the studies as multinomial Chi-square test indicated.

2. The right or integrated HIPS composite dominant modes do not reflect a significant association with high LPI-S usage of the practice, "challenging the process".

3. The right HIPS composite dominant mode does not share a significant relationship with high LPI-S usage 
ranges on "inspiring a shared vision", "enabling others to act" and "encouraging the heart".

4. The integrated HIPS composite dominant thinking style does not relate significantly to the high LPI-s range for "encouraging the heart".

\section{Findings related to the LPI-S and LPI-O:}

1. The averaged scores of both tools evaluating nominated leaders are very similar. Five $\underline{\text {-tests }}$ demonstrated no statisically significant differences between LPI-S and LPI-O ratings for the averaged score on the individual behavioral practices.

2. Many differences between LPI-S and LPI-0 ratings were evident, however, for given examples of individual persons.

All research questions and research hypotheses have been addressed in chapter IV. Chapter V will contain a discussion and summarization of the findings of the study, the conclusions, and the recommendations for future research into this important theme. 


\section{CHAPTER V \\ DISCUSSION OF FINDINGS, CONCLUSIONS, AND RECOMMENDATIONS}

\section{Nature and Purpose of the study}

The present research set out to explore a concern of both urgent and profound dimensions in the modern world, the current and compelling need for a radically different kind of leadership to meet the challenge of turbulent change. This need has been crystallized by a new and emerging paradigm shift which at once reflects, confronts, and shapes the realities experienced today.

Such leadership must see followers holistically and holographically, as persons and as partners in mutual endeavors toward desired change. It must be contextual, transformational, resourceful, communicative, mutually purposeful, ethical, connective and generative. It must effectively address the three core awarenesses present in the discussion of today's leadership, the dimensions of the human, of change, and of the environment.

The purpose of the study was to set in relief the current thinking styles of nominated california community college leaders and to see if and how these correlated with designated desirable leadership behavioral practices. These thinking styles, as defined by the survey instrument's authors, have direct implications for constructively meeting the challenges of innovative and adaptive change. These 
behavioral practices have direct connection to effectively leading toward that change.

It was clear from the review of the literature that various measures have been used to ascertain brain hemisphere functions and that their results have important implications for the type of needed leadership described previously. It is the whole-brain processing which enables both innovative and adaptive efforts toward change. The left hemisphere abilities of analysis, language, mathematics and sequencing, for example, must interplay with the holistic and spatial patterning, the musical, artistic and intuitive processing of the right mode. Only then will both educational and business efforts forge a visionary perspective which is able to address change fruitfully in the long and short run and build human potential.

The present research complements these new understandings of hemispheric development and leadership. It extends them by relating the former to the leadership behavioral practices seen as crucial in today's changing environment. Two survey instruments, the Human Information Processing Survey developed by Taggart and Torrance (1984), and the Leadership Practices Inventory-Self prepared by Kouzes and Posner (1987), were employed in collecting data from 70 persons regarded as leaders on their California community college campuses. A companion questionnaire, the Leadership Practices Inventory-other, was also requested of 
70 sets of observers who were recommended as knowledgeable about the leaders' consistent behavioral stances.

\section{Discussion of Findings}

Findings related to the HIPS instrument. With respect to the HIPS survey, the leaders' ability to use in their modus operandi both hemispheres, either simultaneously (integrated mode) or separately (mixed mode), was much higher than that found in the general population. In the latter, $60 \%$ have these same thinking styles $110 \%$ and $50 \%$, respectively); in the study, $74 \%$ of the leaders do $(24 \%$ and $50 \%$, respectively). The mixed is consistent in both groups; the major difference is in the large number of integrated scores found in this sample population. If one were to take only the standard survey scores which preclude the mixed category, the evidence is even stronger in support of this contention. Of the 70 leaders in the sample, 17 (24\%) are left mode, 38 (54\%) are integrated, and 15 (21\%) are right. The strength of the left, integrated and right scores generally can be seen from the fact that 22 (31\%) leaders had a left, integrated or right score which fell in the goth percentile of the total normed HIPS survey pool. The largest part of these was integrated mode: 11 (50\%). Among the survey questions most often answered similarly, 20 in number, there was a strong tendency again (13 of the 20, or 65\%) toward the integrated category. The responses of the HIPS Tactics Profile also clustered in integrated mode. A larger number of leaders 
who were mixed in the composite score were integrated in this section. The HIPS Tactics Profile together with the Composite score reflects one's approach to change. It does this through the specific focus on problem-solving. Findings related to the LPI-S instrument. Over $50 \%$ of the nominated leaders perceived themselves as having moderate usage of the leadership behavioral practices identified by Kouzes and Posner (1987). This was true in the computation of the composite linear average as well as the individual behavioral practice scores. Both this sample and the Kouzes and Posner normed samples showed similar results.

Referring to the data provided in Table 10, one practice, "enabling others to act" emerged as the most used leadership behavior. "Modeling the way" and "challenging the process," were the next most used. This may reflect a more general awareness and consensus about the stances needed to confront the crisis that leadership faces today. The choices may signal some ways that current leaders perceive, initiate and attempt to shape the preferred future. The two categories of responses used least frequently were "inspiring and shared vision" and "encouraging the heart". Indeed, this result presents a real challenge for leaders who believe in the full set of five behavioral practices set forth by Kouzes and Posner (1987) as crucial for today's effective leaders. The sample's mean scores from highest to lowest for the LPI-S 
indicate this order: "enabling," "encouraging," "challenging," "modeling," and "inspiring" (see Table 7). Findings related to correlation of the two previous instruments: HIPS and LPI-S. No correlations of statistical significance $(.05)$ were evident in the data analyses done on the HIPS and the LPI-S. This was true for the composite HIPS and LPI-S results as well as for the breakout scorings, that is, the Tactics Profile section and the individual IPI-S behavioral practices. However, some significant correlations were evident when HIPS subgroups by dominance were compared with the IPI-S and LPI-O data.

Looking at the data from Table 14, the association between the specific HIPS mode information and the LPI-S practices for the total sample is negligible. It is possible, however, to observe the direction and strength of various relationships which are present in these self-rating examples.

1. For the integrated raw score of the left dominant mode, the correlation is -.60 for "challenging". This indicates that when the challenging score goes up, the integrated goes down.

2. For the right raw score of the left dominant mode, the correlation is -.59 for "enabling". This means that when the "enabling" score increases, the right one decreases. 
3. For the left raw score at the left dominant mode, the relationship .62 for "enabling". This indicates that when the "enabling" score goes up, the left one does also.

4. For the left raw score of the right mode, the correlation is .77 for "encouraging". This demonstrates that when the "encouraging" score increases, so does the left one.

5. For the integrated raw score of the right dominant mode, the association is -.79 for "encouraging". This suggests that when the "encouraging" score goes up, the integrated goes down.

Further analysis of this table and Table 15 could generate additional research hypotheses.

Findings related to the research hypotheses. None of the research hypotheses was confirmed. In the case of each of the five practices, the mixed mode claimed the highest percentage of responses, ranging from $40 \%$ to $54 \%$. If the mixed scores are removed from consideration for purposes of discussion, there would be two cases that have a higher percentage though not a significant one. The first, related to "challenging the process", puts 10 (37\%) of the 27 high responses in the hypothesized integrated mode and the second, related to "modeling the way", puts 11 (22\%) of the 50 moderate/low responses in the same hypothesized mode. 
Findings related to the LPI-S and LPI-0. The average linear scores and those clustered for each behavioral practice for both the LPI-S and LPI-O were similar. Examples of differences between nominated leaders and their observers were present, but no significant group differences were noted.

\section{Conclusion}

According to the most recent thinking on whole-brain processing as yielding the most creative fruits both innovation and adaptive in nature, the majority of this sample fares well. Generally, these individuals (74\%) are able to move between and to combine both left and right mode processing.

A reflection which emerged from the study is that, as a group, the nominated leaders do not perceive themselves as high on the leadership behavioral practice's range. Fifty-one percent rated themselves in the moderate range, $19 \%$ in the low range and $30 \%$ in the high. Kouzes and Posner (2987) believe firmly as a result of their research with the LPI-S instruments that leadership is inextricably connected with the process of innovation, of bringing new ideas, methods, or solutions into use. They agree the real result of the leaders with whom they worked was that the organization was substantially improved. There was a real difference that could be seen, felt, and measured. Increased awareness of these practices among the participants and readers of this study may lead to a 
stronger cultivation of them, if indeed people believe that they are essential today.

For purposes of this study, there is no correlation of statistical significance between the results of both survey instruments.

\section{Implications of the study}

The predominance of isolated left-mode functioning in the former educational studies of coulson and strickland (1983), Norris (1984) and Spruill (1986), and the similar perceived problem in business discussed by Hurst (1984) and Hodgson (1987) are not reflected in this sample. The needed balance in human information processing which these writers discuss is present in the majority of this sample of community college leaders.

Nor is the predominance of the singular right-mode processing seen in Coulson and Strickland's (1983) discussion of business C.E.O.s as well as implied in the Peters' (198) and Mancuso's (1989) entrepreneurial emphases found in this study's population. What is seen primarily is the joint interaction of left and right mode in both integrated and mixed fashions. If the pure standard scores which do not include a mixed category are examined alone, the following is the breakdown of the sample of 70 leaders: $17(24 \%)$ are left mode, $38(54 \%)$ are integrated, and 15 (21\%) are right. It is apparent then that the nominated California community college leaders are a different breed. 
The majority (74\%) of California community college leaders in this sample appear to exercise regularly the left dominant creativity and the right dominant creativity described previously by Torrance and Rockenstein (1987). They have been able to make both dimensions of Mann's study (1982) work for them, the analytical/directive (AD) decision style which prefers certainty in the environment, formality in structure and quantitative thinking as well as the conceptual/analytical style which capitalizes on uncertainty in the environment, informality in structure and qualitative thinking.

In those areas where this study's leaders have direct impact, they apparently have been able to move beyond the common roadblocks which check creativity and innovations in organizations, roadblocks discussed by Friend (1982). Using both the left initiating structure style and right consideration style of Owen (1986), they have effectively and constructively parlayed the results from both the process and human aspects of leadership.

Another underlying reason for their creative fluency may be in part the nature of the institution for which they work. The community college by definition is a dynamic institution mandated to serve the community in which it resides. Meeting its reason for being requires a contextual, interactive, dynamic stance which addresses the current and future needs of the community through ongoing dialogue with all related civic, business and educational 
entities. The United States future labor force issue discussed in Chapter I provides a clear example. It includes a shortfall in white male workers, the resultant projected shifting of the ethnic profile of the general workforce, the need to be aware of new technology and demands through interaction with the business community, and the need to educate these ethnic groups immediately.

A new iteration of this continuing core mission is apparent in the recent effort by the Board of Directors of the American Association of Community Junior Colleges. In 1988, it published recommendations to assist colleges' movement into the 2 lst century with wisdom and vitality. The theme selected after two years of review and assessment of the community college movement was "Building Communities". The document states:

The building of community, in its broadest and best sense, encompasses a concern for the whole, for integration and collaboration, for openness and integrity, for inclusiveness and self-renewal - . The college can, Gardner concludes, 'be an effective convener, a valuable forum, a meeting ground where the common good is discussed.' In such a spirit, community colleges can, we believe, become sources of educational, civic, and cultural renewal (p. 7). 
This effort held such importance to the community college leadership that it was prepared and broadcast nationally by satellite as the Fifth AACJC American Seminar.

The diversity of the community college population across this country as well as recent AACJC efforts to advocate and to make international connections (Reneau, 1989) continually challenge the awareness of different needs among the varied segments of the college population. Current community college national demographics give the following student profile as an example of the variation encountered. Women accounted for 53\% of all enrollees in fall 1987. The average age in the for-credit classes is 28 , with $58 \%$ of the students older than the traditional collegeage cohort (18 through 24 years). Community colleges in 1988 enrolled $57 \%$ of the Native American college students, $55 \%$ of all Hispanic, $43 \%$ of all Black, and $41 \%$ of all Asian college students (Palmer, 1988). These demographics highlight the need for an ongoing awareness and flexibility in dealing with today's kaleidoscopic changes whether they be in trends of community college or general populations or elsewhere.

By its initial mandate, the community college philosophy has traditionally and continues to encompass the concern for the human dimension, the change factor and the environmental realities in which it moves. In this writer's judgment, all of these are at the heart of leadership effectiveness today. Such a philosophy might be used where 
beneficial as a model by other institutions in order to free up the left and right modes of rhythmic interaction. This would be true particularly in places where unchanging bureaucratic structures are entrenched, where set procedures are routinized, and where impersonality prevails in decision-making and other processes. It would also apply where seniority reigns as the measure of success and achievement, where training's purpose is to usher employees into an established status quo, where minds and hearts are "petrified" or "in absentia" on the job.

Recommendations for Future studies

Additional analysis using correlations of the IPI-S

five behavioral practices with the HIPS raw scores by dominant mode as well as using further descriptive statistics would extend the results of this study. Specific other patterns of comparison may emerge.

Correlations of the particular demographic data similar to that collected during this survey could be made with each of the hemisphere modes and behavioral practices. Relationships between gender, age, degrees earned, years of educational and administrative experience, and the questions of this study might reveal some interesting patterns and/or trends.

A correlational study using the Herrmann Brain Dominance Instrument and the HIPS revised one would be useful. 
Development of or refinement of the LPI instrument specifically related to the University of San Diego Leadership and Administration Program could be done in future research.

Qualitative research involving interviews with selected nominated community college leaders may yield additional understanding of the dissertation themes, both of thinking styles and leadership behavioral practices. A researcher, for example, could take sets of the highest and/or lowest scores from each of the two major instruments of this study. similar studies as this one could be done using the same instruments but with other sample populations. For example, university and business C.E.O.s might reflect different conclusions. Retired leaders might display variations on percentages of dominant modes and on behavioral practice usage because of the influence of training, measures of success, and cultural loading. Nonpace-setting states might not demonstrate the same tendencies on either instrument. Intercultural and/or international populations might fare altogether differently because of educational, social, and cultural awareness.

Studies regarding the incorrect use of a given thinking style could be done. It would consider a poor or inappropriate application of an individual's human information processing to a given task. 
Finally, future studies might pursue these themes using newly-refined instruments which may be even more precise at identifying thinking styles and crucial behavioral practices for leadership of today and tomorrow. 
REFERENCES

Akers, D. (1987, February). Challenges of international education. Paper presented at the Community college for International Development Annual Winter Conference, Newport Beach, CA.

Alderfer, C. P. (1984). Problems of changing white males' behavior and beliefs concerning race relations. In P. S. Goodman \& Associates (Eds.), change in organizations (pp. 122-165). San Francisco: Jossey-Bass.

Allen, K., Chrispeels, J., Fink, B., \& Tan, H. (1988, July). Paradigm shift.

Bastick, T. (1982). Intuition-how we think and act. New York: John Wiley \& Sons.

Baumgartner, T. (1975). Measurement for evaluation in physical education. Boston: Houghton-Mifflin. Bedeian, A. (1986). Management. San Francisco: Dryden Press.

Bell, D. (1973). The coming of post-industrial society: A venture in social forecasting. New York: Basic Books. Bellah, R., Madsen, R., Sullivan, W., Swidler, A., \& Tipton, S. (1985). Habits of the heart. San Francisco: Harper \& Row, Publishers.

Borg, W. R., \& Gall, M.D. (1983). Educational research: An introduction (4th ed.). New York: Longman, Inc. 
Boyer, E. (1985, April). Community junior colleges'

leadership challenges. Paper presented at the American Association of Community and Junior Colleges Annual Conference, San Diego, CA.

Boyer, E., \& The Commission on the Future of Community Colleges. (1988). Building communities: A vision for a new century. Washington, DC: National Center for Higher Education.

Bronowski, J. (1973). The ascent of man. Boston: Little, Brown and company.

Burns, J. M. (1978). Leadership. New York: Harper and Row.

Cetron, M., Rocha, W., \& Luckins, R. (1988). Into the 21st century. The Futurist, $\operatorname{xXII}(4), 29-40$.

Coulson, L. T., \& Strickland, A. G. (1983). Your brain tells plenty about your management skills. The Executive Educator, $\underline{22}$,

Davenport, L. (1989). The role of the community college in meeting America's future labor force needs. Community, Technical, and Junior College Journal, 59(4), 23-27. dBASE (DBXI) . (1989). Los Angeles: CA: Wordteach Corporation.

Deal, T. E., \& Kennedy, A. A. (1982). Corporate cultures. Menlo Park, CA: Addison-Wesley Publishing Company. Debono, E. (1970). Lateral thinking. New York: Harper and Row. 
Deutsch, C. H. (1983, December). B-school blues. TWA Ambassador [publisher not noted].

Dillman, D. (1978). Mail and telephone surveys. New York: John wiley \& Sons.

Edwards, B. (1979). Drawing on the right side of the brain. Los Angeles: J.P. Tarcher, Inc.

Edwards, B. (1986). Drawing on the artist within. New York: Simon and Schuster.

Elliott, D. L., \& Sergiovanni, T. J. (1975). Educational and organizational leadership in elementary schools. Englewood Cliffs, NJ: Prentice-Hall, Inc.

Emrick, A. (1989). Cycle for excellence. Columbus, Ohio: Mount Carmel Health.

Fiedler, F. (1967). A theory of leadership effectiveness. New York: McGraw-Hill.

Foster, W. (1988). Toward a critical practice of leadership. In J. Smyth (Ed.), critical perspectives on educational leadership. New York: Falmer Press (In press).

Fowler, F. (1988). Survey research methods. San Mateo, CA: Sage Publications.

Friend, W. (1982). Be a creative leader. Association Management, $34(3), 54-57$.

Galyean, B. C. (1981). Guided imagery in the curriculum. Educational Leadership, $40(6), 54-58$. Grob, A. (1973). Philosophic mind. Athens, OH: University. 
Hagberg, J. (1984). Real power. Minneapolis, MN: Winston Press.

Harrison, R. (1983). Strategies for a new age. In W. G. Bennis, K. D. Benne, \& R. Chin (Eds.), The planning of change (pp. 128-149). New York: Holt, Rinehart \& winston.

Hendrickson, R. (1988, February). Relationships, organizations, and leadership in the future. Paper presented at the conference on the Way to 2019, Akron, $\mathrm{OH}$.

Herrmann, M. (1982). The creative brain. NASSP Bulletin, 66, 31-46.

Hines, T. (1987). Left brain-right brain mythology and implications for management and training. Academy of Management Review, 12, 600-607.

House, R. (1971). A path-goal theory of leader effectiveness. Administrative Science Quartery, 16, 321-338.

Hughes, B. B. (1985). World futures. Baltimore, MD: John Hopkins University Press.

Hunt, J. (1984). Leadership and managerial behavior. Chicago: Science Research Associates

Hurst, D. K. (1984). Of boxes, bubbles, and effective management. Harvard Business Review, 78, Kane, N., \& M. (1979). Comparison of right and left hemisphere functions. The Gifted Child Quarterly, $\underline{23}(1), \quad 157-167$. 
Kouzes, J. M., \& Posner, B. Z. (1987). The leadership challenge. San Francisco: Jossey-Bass, Inc.

Lamy, S. (1987, February). Internalizing the community college curriculum: A hands-on presentation. Paper presented at the community college for International Development Annual Winter Conference, New Port Beach, CA.

MacIntyre, A. (1984). After virtue. Notre Dame, IN: University of Notre Dame Press.

Mann, R. (1982). Relationships between the decision-making styles of corporate planners and other planning executives: Their environmental focus, organizational structure and task requirements. Dissertation Abstracts International, $43(06-\mathrm{A}), 2026$. Masten, W., \& Morse, D. (1987). Effects of training gifted children in creative imagination on your style of learning and thinking. Psychological Reports, 61(1), 107-109.

Mccall, M., \& Lombardo, M. (1983, February). What makes a top executive? Psychology Today, pp. 26-31.

Motamedi, K. K. (1985). Adaptability and capability: A study of social systems, their environment, and survival. In W. G. Bennis, K. D. Benne, \& R. Chin (Eds.), The planning of change (pp. 185-134), New York: Holt, Rinehart \& winston. Naisbitt, J. (1982). Megatrends. New York: Warner Books. 
Nelton, S. (1984). The people who take the plunge. Nation's Business, $\underline{72(6), 22-26 . ~}$ Norris, C. (1984). A discussion of brain hemisphere characteristics and creative leadership among selected educational administrators in Tennessee. Dissertation Abstracts International, $45(11-\mathrm{A})$, p. 3256.

ornstein, R. (1977). The psychology of consciousness (2nd ed. rev.). New York: Harcourt Brace Jovanovich. Ornstein, R., \& Sobel, D. (1987). The healing brain. New York: Simon and Schuster. Owen, G. B. (1986). The relationship of left/right brain dominance, administrative experience, and mentorship to the leadership style of elementary school principals. Dissertation Abstracts International, 47(04-A), 1142. Palmer, J. (1988). Where America goes to college. Washington, DC: National Center for Higher Education. Pascale, R. T., \& Athos, A.G. (1981). The art of Japanese management. New York: Simon and Schuster. Peters, T. (1987, october). To sell abroad, think global but tailor to the local trade. San Diego Union, pp. E$1 \& \mathrm{E}-2$.

Peters, T. J., \& Waterman, R. H., Jr. (1982). In search of excellence. New York: Harper \& Row.

Reitz, B. (1986). Thinking styles (right-left brain dominance) of school administrators and their relationship to leadership effectiveness. Unpublished Ph.D. dissertation, University of Nevada, Las Vegas. 
Reneau, S. (1989). Japanese and Americans work in

partnerships for education. Community, Technical, and Junior College Journal, $\underline{59}(6), 47$.

Rost, J. (1985a, October). Distinguishing leadership and management: A new consensus. Paper presented at the

O.D. Network National Conference, San Francisco, CA.

Rost, J. (1985b, November). Transforming leadership:

Shaping the school culture for educational excellence.

Paper presented at California Principals Conference, Anaheim, CA.

Rost, J. (1988, May). Generativity. Paper presented at the University of San Diego, San Diego, CA.

Roueche, J. E., Baker, G. A., \& Rose, R. R. (1988a). The community college president as transformational leader. Community, Technical, and Junior College Journal, $\underline{58}(5), 48-52$.

Roueche, J. E., Baker III, G. A., \& Rose, R. R. (1988b). Transformational leaders in the community college: The best of the best. Community, Technical, and Junior

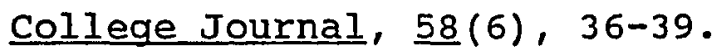

Roueche, J. E., Baker, III, G. A., \& Rose, R. R. (1989). Shared vision: Transformational leadership in American community colleges. Alexandria, VA: AACJC Publications.

Emrick, A. (1980). A theory-based curriculum in personhood development. New York: McGraw Hill. 
Schein, E. H. (1985). organizational culture and

leadership. San Francisco: Jossey-Bass.

Schermerhorn, J. R., Jr. (1984). Management for

productivity. New York: John Wiley and Sons.

Scott, M. E. (1976). The labyrinth of otherness: An essay

on authoritarian acquiescence in Mexico. Unpublished

Master's thesis, University of the Pacific, Stockton,

CA.

Smith, K. (1984). Philosophical problems in thinking about organizational change. In P. S. Goodman \& Associates (Ed.), Change in organizations (pp. 316-371). San Francisco: Jossey-Bass.

Sperry, R. W. (1968). Hemisphere disconnection and unity in conscious awareness. American Psychologist, 23, 723733.

Sperry, R. W., Gazzaniga, M. S., \& Bogen, J. E. (1969) . Interhemispheric relationships: The neocortical commissures; syndromes of hemisphere disconnection. In P. J. Vinken, \& G. W. Bruyn (Eds.), Handbook of clinical neurology (pp. 273-289). Amsterdam: NorthHolland Publishing Company.

Sperry, R. W. (1973). Lateral Specialization of cerebral function in the surgically separated hemispheres. In F. J. McGuigan \& R. A. Schoonover (Eds.), The psychophysiology of thinking (pp. 209-229). New York: Academic Press. 
Sperry, R. (1975). Iateral specialization in the surgical separated hemispheres. Hemispheric specialization and interaction. Cambridge, MA: MIT Press. Spruill, S. (1986). Cerebral laterality and leadership styles of principals. Dissertation Abstracts International, $48(02-\mathrm{A}), 278$.

SPSS, Inc. (1988). SPSS-X user's guide (3rd ed.). Chicago: SPSS, Inc.

Staw, B. M. (1982). Counterforces to change. In P. S. Goodman \& Associates (Eds.), Change in organizations (pp. 87-121). San Francisco: Jossey-Bass. Sullivan, W. M. (1986). Reconstructing public philosophy. Bereley, CA: University of California Press. Taggart, W., \& Torrance, E. P. (1984). Human information processing survey administrator's manual. Bensenville, IL: Scholastic Testing service, Inc. Terreberry, S. (1984). The evolution of organizational environments. In W. G. Bennis, K. D. Benne, \& R. Chin (Eds.), The planning of change (pp. 176-186). New York: Holt, Rinehart \& Winston. Toffler, A. (1970). Future shock. New York: Random House. Torrance, E. P., \& Rockenstein, Z. L. Styles of thinking and creativity. Gifted International, 4 (1), 37-49. U.S. Commission on Excellence in Education (1983). Nation at risk. Washington, DC: Superintendent of Documents. 


\section{APPENDICES}


APPENDIX A

PARADIGM SHIFT 


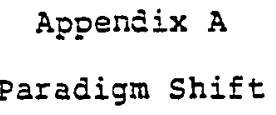

\begin{tabular}{|c|c|c|}
\hline 3xions & old Paradiom & New Paradigm \\
\hline Nature of reality & $\begin{array}{l}\text { single, tangible, } \\
\text { fragmentable, simple }\end{array}$ & $\begin{array}{l}\text { multiple, } \\
\text { constructed, } \\
\text { holistic, } \\
\text { complex }\end{array}$ \\
\hline $\begin{array}{l}\text { Relationship of the } \\
\text { knower and the known }\end{array}$ & independent, dualistic & $\begin{array}{l}\text { interactive, } \\
\text { interdependent }\end{array}$ \\
\hline $\begin{array}{l}\text { Possibility of causal } \\
\text { linkages }\end{array}$ & $\begin{array}{l}\text { real prior causes, } \\
\text { predictable effect, } \\
\text { linear causality }\end{array}$ & $\begin{array}{l}\text { all entities } \\
\text { mutually- } \\
\text { shaping. } \\
\text { urpre- } \\
\text { dictabilities }\end{array}$ \\
\hline $\begin{array}{l}\text { Notion of authority } \\
\text { and relatianships }\end{array}$ & $\begin{array}{l}\text { hierarchy, ranking, } \\
\text { outtrol, position } \\
\text { legitimacy }\end{array}$ & $\begin{array}{l}\text { heterarchy, } \\
\text { linking, fluid, } \\
\text { relatianship } \\
\text { legitimacy }\end{array}$ \\
\hline Nature of organizations & $\begin{array}{l}\text { fixed and tangible } \\
\text { boundaries } \\
\text { periods of calm } \\
\text { and butuilence }\end{array}$ & $\begin{array}{l}\text { fluid and less } \\
\text { tangible } \\
\text { boundaries, } \\
\text { turtoulent } \\
\text { field }\end{array}$ \\
\hline Nature of change & $\begin{array}{l}\text { planned and controlled } \\
\text { as evert, periods of } \\
\text { sporadic or no change }\end{array}$ & $\begin{array}{l}\text { an evolving, } \\
\text { process, change } \\
\text { constant }\end{array}$ \\
\hline Decision-making & $\begin{array}{l}\text { rational, linear } \\
\text { imposed, limited, } \\
\text { single constituency }\end{array}$ & $\begin{array}{l}\text { intuitive and } \\
\text { rational } \\
\text { multidimen- } \\
\text { sioral, } \\
\text { mutiple } \\
\text { constituency }\end{array}$ \\
\hline conflict & $\begin{array}{l}\text { control and linit, } \\
\text { negatively-peroeived } \\
\text { issue-related }\end{array}$ & $\begin{array}{l}\text { driver of } \\
\text { change } \\
\text { natural } \\
\text { process } \\
\text { positively- } \\
\text { viewed }\end{array}$ \\
\hline
\end{tabular}


Appencix A (continued)

\begin{tabular}{|c|c|c|}
\hline Axioms & old Paradiom & New paradign \\
\hline Values & value-free inquiry & value-laden \\
\hline Nature of resources & $\begin{array}{l}\text { finite, scarce, } \\
\text { tangible, canpetitive } \\
\text { struggle for external } \\
\text { goods, wir/lose }\end{array}$ & $\begin{array}{l}\text { infinite, } \\
\text { abundant, } \\
\text { intangible } \\
\text { intermal goods } \\
\text { win/win }\end{array}$ \\
\hline & goods, wir/lose & wirs/win \\
\hline $\begin{array}{l}\text { Possibility of } \\
\text { generalizability }\end{array}$ & $\begin{array}{l}\text { time and context-free, } \\
\text { focus on the sinilar }\end{array}$ & $\begin{array}{l}\text { time and } \\
\text { context-bound, } \\
\text { hypotheses } \\
\text { possible, } \\
\text { focus } \\
\text { on differences }\end{array}$ \\
\hline View of develogment & $\begin{array}{l}\text { fixed stages, } \\
\text { predictable, } \\
\text { additive, } \\
\text { orderly, } \\
\text { normal curve, } \\
\text { individuationy } \\
\text { segarateness } \\
\text { left brain } \\
\text { history shapes } \\
\text { incremental change } \\
\text { only, } \\
\text { insular }\end{array}$ & $\begin{array}{l}\text { unique } \\
\text { patterns } \\
\text { and themes, } \\
\text { individualized, } \\
\text { bi-directional, } \\
\text { fluid, evolving, } \\
\text { potentiality } \\
\text { unlimited, } \\
\text { identity, } \\
\text { attactunent and } \\
\text { canmunity. } \\
\text { left/right } \\
\text { brain, } \\
\text { dissipating } \\
\text { structures, } \\
\text { radical change } \\
\text { possible, } \\
\text { glocal }\end{array}$ \\
\hline
\end{tabular}


APPENDIX B AMERICA'S FUTURE IABOR FORCE 
APPENDIX B

AMERTCA'S FUTURE IABOR FORCE

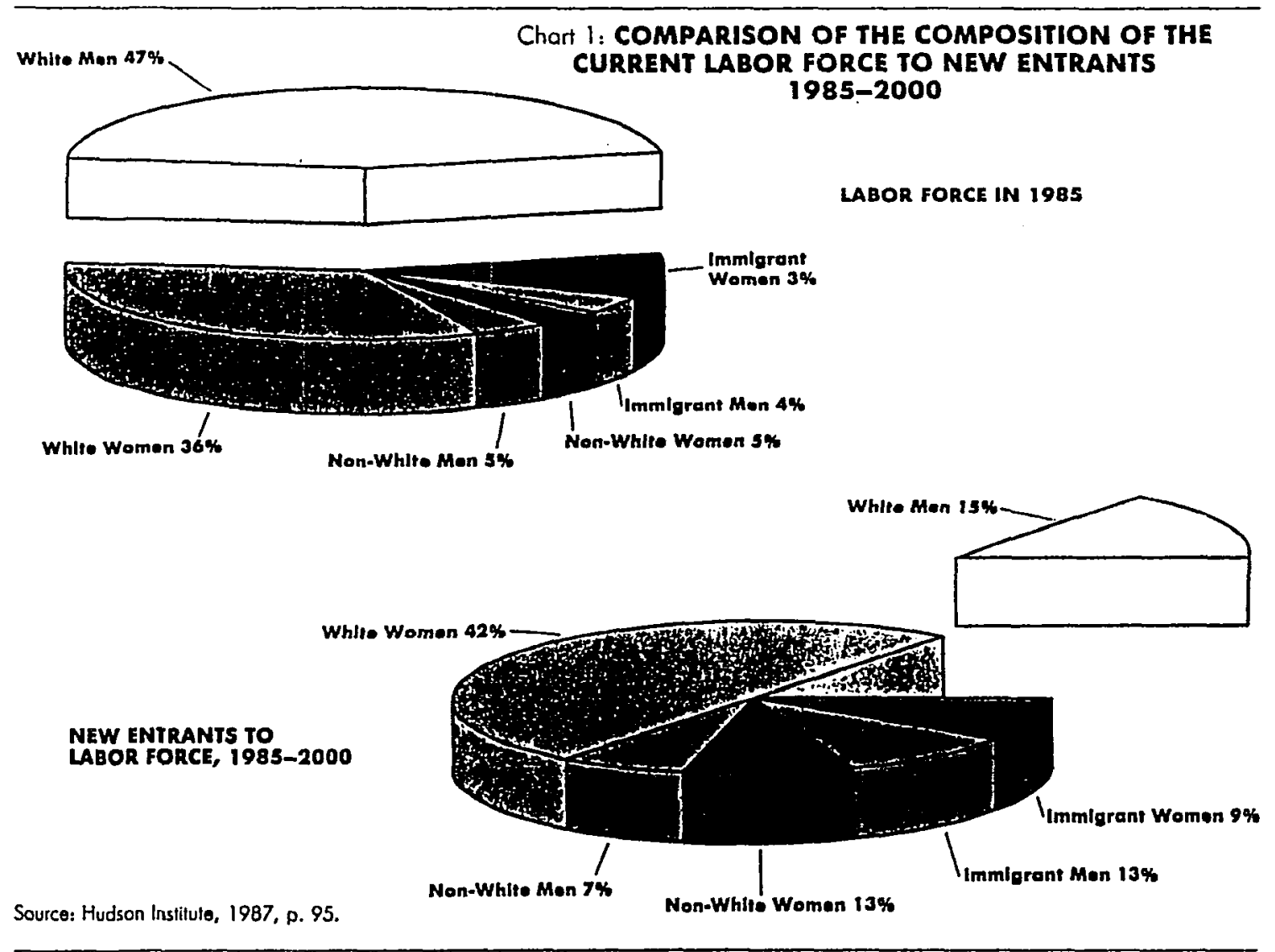


APPENDIX C PROBLEM-SOLVING STYLES:

SYSTEMATIC AND INTUITIVE THINKERS 


\section{PLEASE NOTE:}

Copyrighted materials in this document have not been filmed at the request of the author. They are available for consultation, however, in the author's university library.

\section{These consist of pages:}

126 Appendix C

128 Appendix D

132 Appendix F

150-152 Appendix O

156-158 Appendix Q

178-179 Appendix X

The Leadership Practices Inventory is copyrighted by Kouzes Posner international, Inc. and is available from University Associates, 8517 Production Avenue, San Diego, California 92121.

\section{$\mathrm{U} \cdot \mathrm{M} \cdot \mathrm{I}$}


APPENDIX D

A COMPARISON OF LEFT-MODE AND RIGHT-MODE CHARACTERISTICS 
APPENDIX E

LETTER TO PRESIDENTS 


\author{
Appendix E \\ Letter to Presidents
}

5722 San Miguel Road
Bonita, California 92002
December 6,1988

Dear

As a doctoral student at the University of San Diego, I am requesting your help in my dissertation study. It is based on two survey tools, one on Human Information Processing (Brain Hemispherscity) and one on Ieadership Effectiveness.

I am asking that you, as a california community college president, nominate two persons from your college, either administrative or full-time faculty, who are regarded by the college community as leaders. Leadership as described in this study is defined by the characteristics identified on the attached page.

In addition, will you list five close observers of each of these individuals, observers including both administrators and faculty. Upon receiving these, I will forward the survey tools to the designated leaders and their recommended observers. Will you please forward your responses to me by December $22 \mathrm{nd}$.

I will provide feedback on the final results of the study to you and to the two main participants as well as information about the use of these tools for staff development or other such activity on your campus, if you so desire.

Thank you for your time and cooperation. It is deeply appreciated.

Sincerely,

Mary E. (Betty) scott 
APPENDIX F .

LEADERSHIP CRITERIA 
APPENDIX G

PRESIDENTS' NOMINATIONS FORMS 
APPENDIX G

PRESIDENTS' NOMTNATIONS FORM

Please return by January $25 \mathrm{th}$.

President's Nominee I:

\section{Position:}

Five (5) Observers of Nominee 1 for Leadership Survey:

1.

$\underline{2 .}$

$\underline{3}$.

4.

$\underline{5 .}$

President's Nominee 2:

\section{Position:}

Five (5) Observers of Nominee 2 for Leadership Survey: 1.

2.

3.

4.

5.

Name of President

Name of Community College 
APPENDIX $\mathrm{H}$

REASONS FOR NON-PARTICIPATION 


\author{
APPENDIX H \\ Reasons for Non-Participation
}

1. In nomination of leaders/others by presidents:

presidents)
a. Too new in presidency
b. Insufficient project information
c. Current heavy job demands
d. Survey saturation e. Bad experience with doctoral
studies
f. No staff interest
g. Too many persons required
h. In process of presidential search 2
i. Uncomfortable providing nominees 2
$j$. Unfamiliarity with staff 2
$k$. No reason
Total: $\quad 3 \frac{2}{8}(36 \%$ of

2. In response to surveys by nominees, leaders and others:
a. Insufficient survey information
b. Current heavy job demands
c. Unfaniliarity with nominee
d. Conflict of interest
e. Unwilling to evaluate superior
f. Uncomfortable providing response
g. No recollection of nomination (president)
h. Death in family/illness
1. No desire
j. No reason

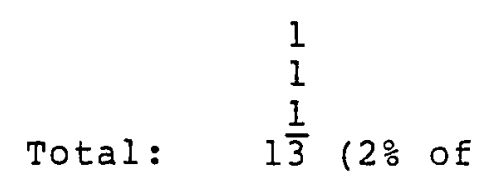

nominees)

Grand Total: 51

* One of two answers given. 
APPENDIX I

FOLIOW-UP LETTER TO PRESIDENTS 


\author{
Appendix I \\ Eollow-up Ietter to Presidents
}

5722 San Miguel Road

Bonita, California 92002

January 6, 1989

Dear

A few weeks ago I sent a request that you may have been unable to complete at that time. I do need your assistance, if at all possible, in my work as a Doctoral student at the university of San Diego. My work is based on two survey tools, one on Euman Information Processing (Brain Hemisphericity) and one on Leadership Effectiveness.

I am asking that you, as a California commuity college president, nominate two persons from your college, either administrative or full-time faculty, who are regarded by the college commnity as leaders. Leadership as described in this study is defined by the characteristics identified on the attached page.

In addition, will you list five close observers of each of these individuals, observers including both administrators and faculty. upon receiving these, I will forward the survey tools to the designated leaders and their recommended observers. I would very much appreciate your responses by January 25 th.

I will provide feedback on the final results of the study to you and to the two main participants as well as information about the use of these tools for staff development or other such activity on your campus, if you so desire.

Thank you for your time and cooperation. It is deeply appreciated.

Sincerely,

Betty Scott 


\section{APPENDIX J \\ REQUESTS FOR PRESIDENTS' REASONS FOR NON-PARTICIPATION}




\author{
Appendix $J$ \\ Requests for Presidents' Reasons for \\ Non-Participation
}

If you are unable to participate at the current tine, please complete and return by January 25th.

I would like to participate but, unfortunately I cannot at this time:

Too new in presidency.

Insufficient information about the study.

Current heavi job demands.

Name of President

Name of Community College 
APPENDIX $\bar{K}$

IETTER TO NOMINATED LEADER 
Appendix $k$

Letter to Nominated Ieader

Eebruary 18,1989
5722 San Miguel Road
Bonit3, California 92002

You have been selected by your superintendent/president as one of two nominees who are regarded as significant leaders within your campus community. As such you are being asked to participate in a doctoral dissertation survey assessing Leadership Effectiveness and Human Information Processing in California community colleges. Five persons who work closely with you were also designated by your superintendent/president to Eill out a similar survey regarding their perception of your leadership (Leadership Practices Inventory only).

Your willingness to participate will be a great help! will you ploase complete the enclosed consent form. demographic guestionnaire, and two surveys - I think you will find the short time spent worth it! For coordination of your responses with those of the observers, it is important that your name be on them. All individual responses will be held in the strictest confidence.

iill you please return everytining to me by March 6,1989 in the enclosed envelope. I will provide you with feediack on the final results of the study. Thank you very much for your time and assistance. It is deeply appreciatad.

sincerely.

$\Xi \Xi t \pm y \operatorname{scot} t$

Reproduced with permission of the copyright owner. Further reproduction prohibited without permission. 
APPENDIX I RESEARCH SUBJECTS' CONSENT FORM 


\author{
Appendix I \\ Research Subjects' Consent Eorm
}

\title{
Purpose os the Research
}

The purpose of your participation in this study is twofold: to assess the thinking styles and the behavioral practices of selected individuals regarded as leaders and to examine the interrelationship of these styles and practices. You will be asked to complete two survey instruments $130-45$ minutes each in lengthl and a very short demographic questionnaire.

\section{Risks and Benefits}

There is no anticipated risk to the subject in this stuay. All information received will be kept confidential or used for statistical purposes only. No data will be identified by name. As a benefit for participating in the study, the researcher will provide each subject with feedbaci on his/her own survey results as well as those of the study in general.

\section{Participation}

Participation in the study is voluntary and you may withdraw at any time. By signing this form, you are indicating that you were given the opportunity to ask questions about the research and procedures, and that they were answered prior to your agreement to participate in the study.

There is no agreement, written or verbal, between the subject and the researcher other than that expressed in this consent form.

I, the undersigned, understand the above explanations and, on that basis, I give consent to my voluntary participation in this research.

\begin{tabular}{l}
\hline Signature of Subject \\
\hline College Location \\
\hline Signature of Researcher \\
\hline Signature of wizaess
\end{tabular}

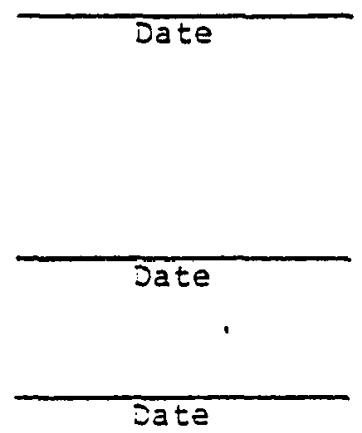


APPENDIX M

DEMOGRAPHIC QUESTIONNAIRE 


\author{
Appendix $M$ \\ Demographic Questionnaire
}

Use a No. 2 lead pexil, mark the rexponse that best describes you on the enclosed scantion sooring sheat.

1. Age:
a. 26-30
b. 31-35
c. 36-40
d. 41-45
e. $\quad$ 66-50

3. Highest Earned Degree:
a. Bachelor
b. Master
c. Etreation Specialist
d. Doctorate

4. Number of Years in Elucation:
a. 1-5
b. 6-10
c. 17-15
d. 16-20
e. over 20

5. Number of Years in Atmiristration:
a. 1-5
b. $6-10$
c. 11-15
d. 16-20
e. over 20

6. Nimber of Years at arrent commity college:
a. 1-5
b. 6-10
c. 11-15
d. $16-20$
e. over 20

7. Doninant hardeciess:
a. Lett
b. Right
c. Both

a. Fense 
APPENDIX N

IETTER FROM SCHOLASTIC TESTING SERVICE, INC. 
Appendix N

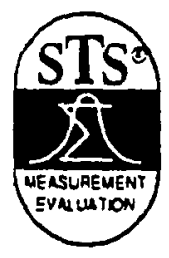

Letter from Scholastic Testing Service, Inc.

\section{SCHOLASTIC TESTING SERVICE, INC. 480 MEYER ROAD \\ P.O. BOX 1056 \\ BENSENVILLE, ILLINOIS 60106-8056 \\ Tolephone: 766-7150 (Area Code 312)}

October 21,1988

Mary E. Scott

6661 Silverstream Avenue

Apartment 2091

Las Vegas, NV 89107

Dear Ms. Scott:

I received your letter requesting permission for you to include the Human Information Processingo Survey in your dissertation.

We do not grant permission for anyone to copy any of our tests. We do not grant permission to include a copy or photocopy of the test in your dissertation. Instead, we suggest that you add the following statement:

"The instrument used for data collection in this study was the Human Information Processing@ Survey, by E. Paul Torrance, Ph.D., William Taggart, Ph.D., and Barbara Taggart, M.S., copyright 1984, published by Scholastic Testing Service, Inc., Bensenville, IL 60106-8056. The original data are available from the authors. The tests may be purchased from the publisher."

I have enciosed a brochure and price list so that you may order the material that you need. For faster service, I suggest that you enclose a check or money order with your order form and formal request to use the test material. Remeinber to allow $15 \%$ for shipping and handling.

Sincerely,

Brian O'Donnell

Editor 
APPENDIX R

FOLLOW-UP LETTER TO LEADERS 
Appendix R

Follow-up Letter to Leaders

March 31, 1989

5722 San Miguel Road

Bonita, California 92002

Dear

:

Recently I mailed out a survey related to my doctoral work. The response has been very positive--both heartening and exciting. With a few more additions, I would be able to boost my return rate substantially because of the way they will be used and clustered in the research.

An adequate cluster of persons on your campus, persons who know you and work with you, has already responded to their opportunity to participate. Won't you please round out your college's involvement by completing the enclosed materials? It would be a great help to me--and to the study!

Then will you please return everything to me by April 14, 1989 in the enclosed envelope. I will provide you feedback on the final results of the study. Thank you so much for your time and assistance. It is deeply appreciated!

sincerely,

Betty scott 
APPENDIX S

FOLLOW-UP LETTER TO OBSERVERS 


\author{
Appendix S \\ Follow-up Letter to Observers
}

March 31, 1989

5722 San Miguel Road

Bonita, CA 92002

Dear

Recently I mailed out a survey related to my doctoral work. The response has been very positive--both heartening and exciting. With a few more additions, I would be able to boost my return rate substantially because of the way the surveys will be used and clustered in the research.

A majority of persons on your campus has already responded. But it would be that much more fruitful if I could hear from you also. Won't you please help round out your college's involvement by completing the enclosed materials? It would be a great help to me-and to the study!

Then will you please return the consent form and the survey in the enclosed envelope by April 14, 1989. Thank you so much for your time and help. It is deeply appreciated.

Sincerely,

Betty Scott 


\section{APPENDIX T \\ HIPS HISTOGRAMS}




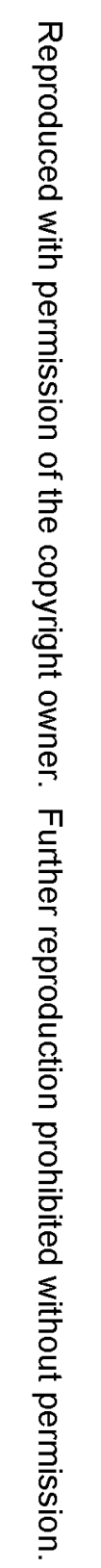

Appendix $T$

HIIPS Histograns

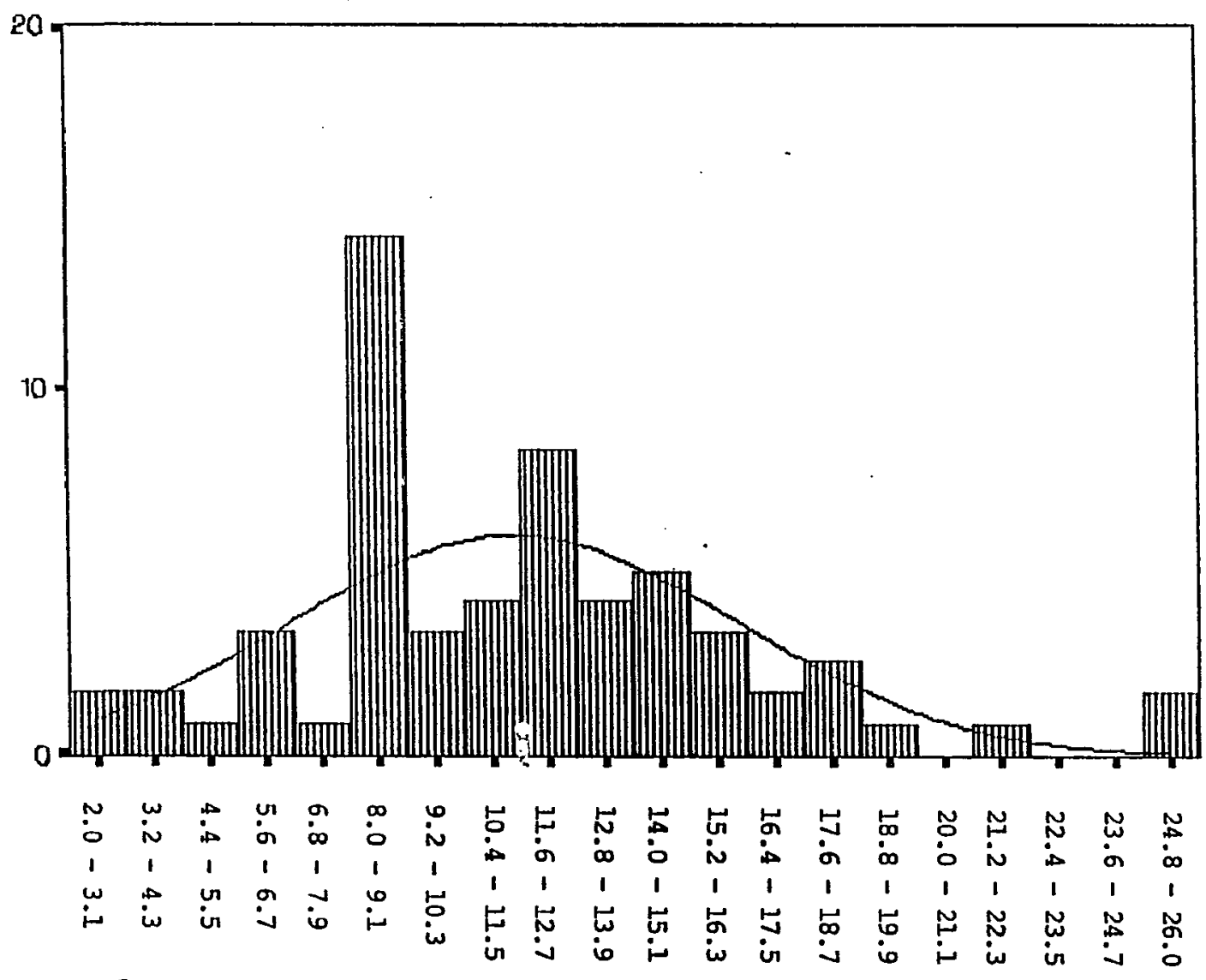

LEGEND

Sid. Cev. -400 Meann $=115$ $M=70$

Sumiary: Left 


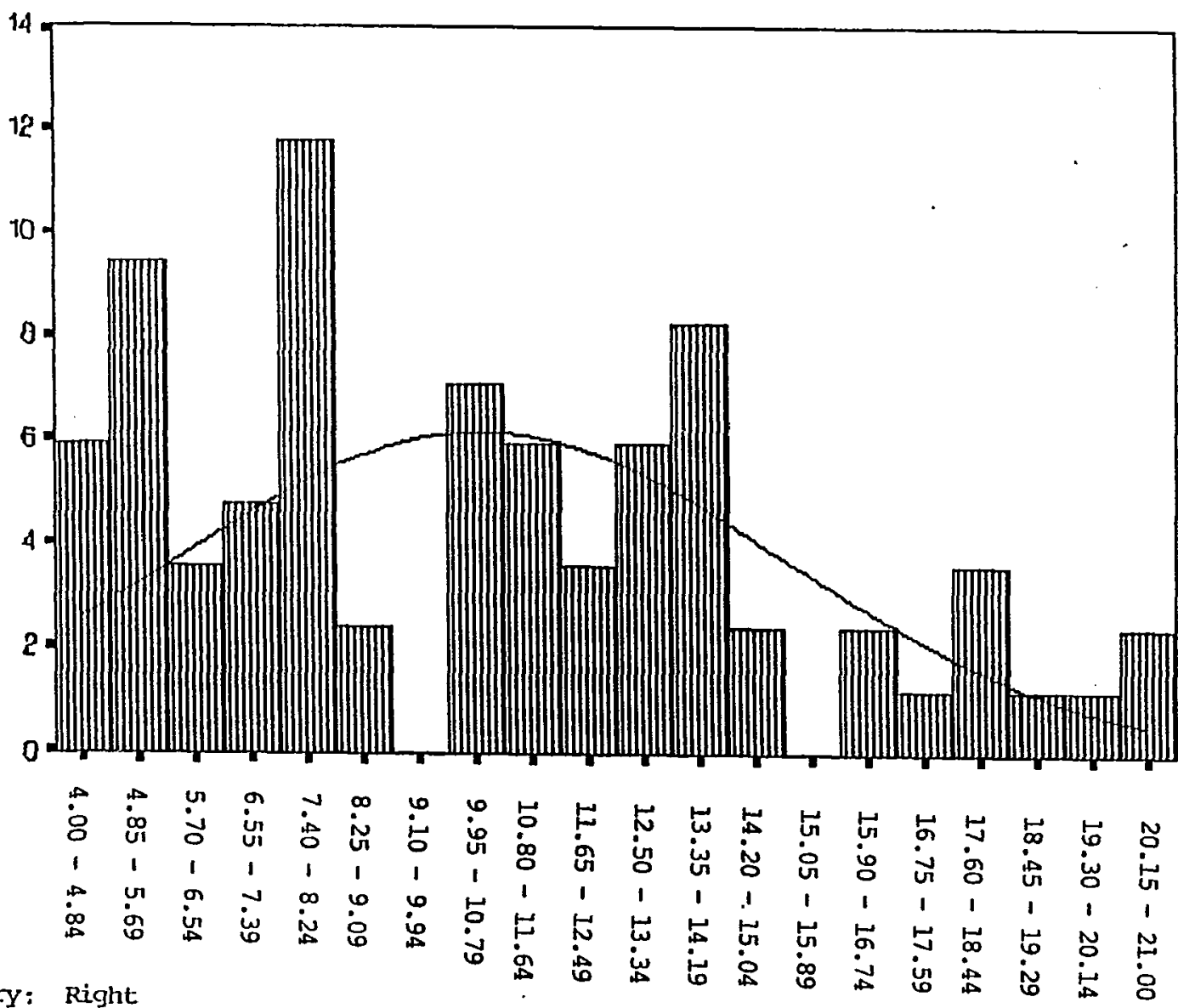

LEGEND

Std. Dev. -455 $\begin{aligned} \text { Nean } & =10.46 \\ N & =70\end{aligned}$

Summary: Right 


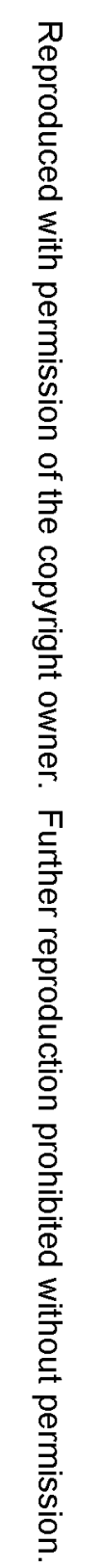

Appendix T (continued)

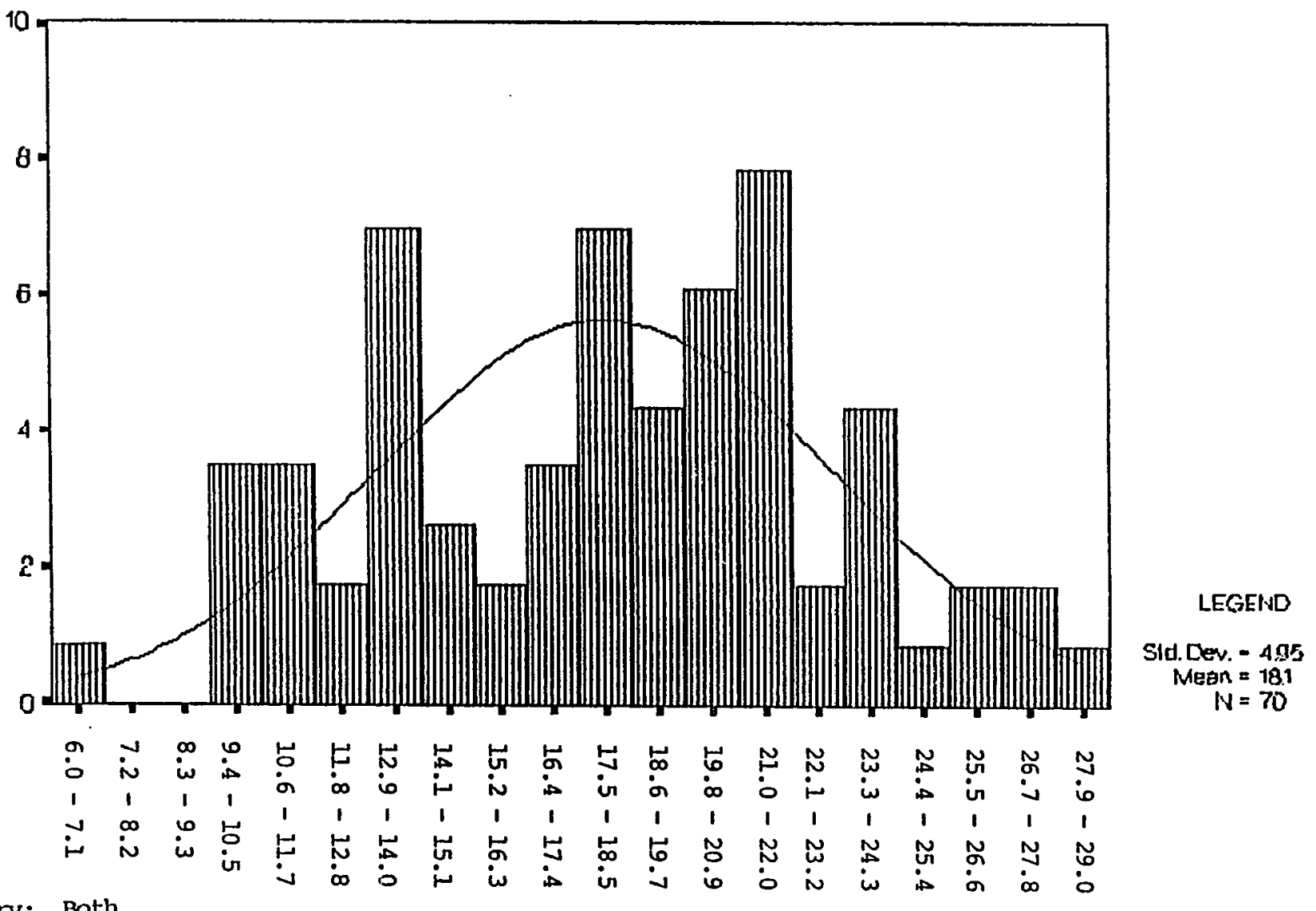


APPENDIX U

LPI-S PERCENTILE RANKINGS FOR LINEAR AVERAGES 
Appendix $U$

LPI-S Percentile Rankings for Linear Averages

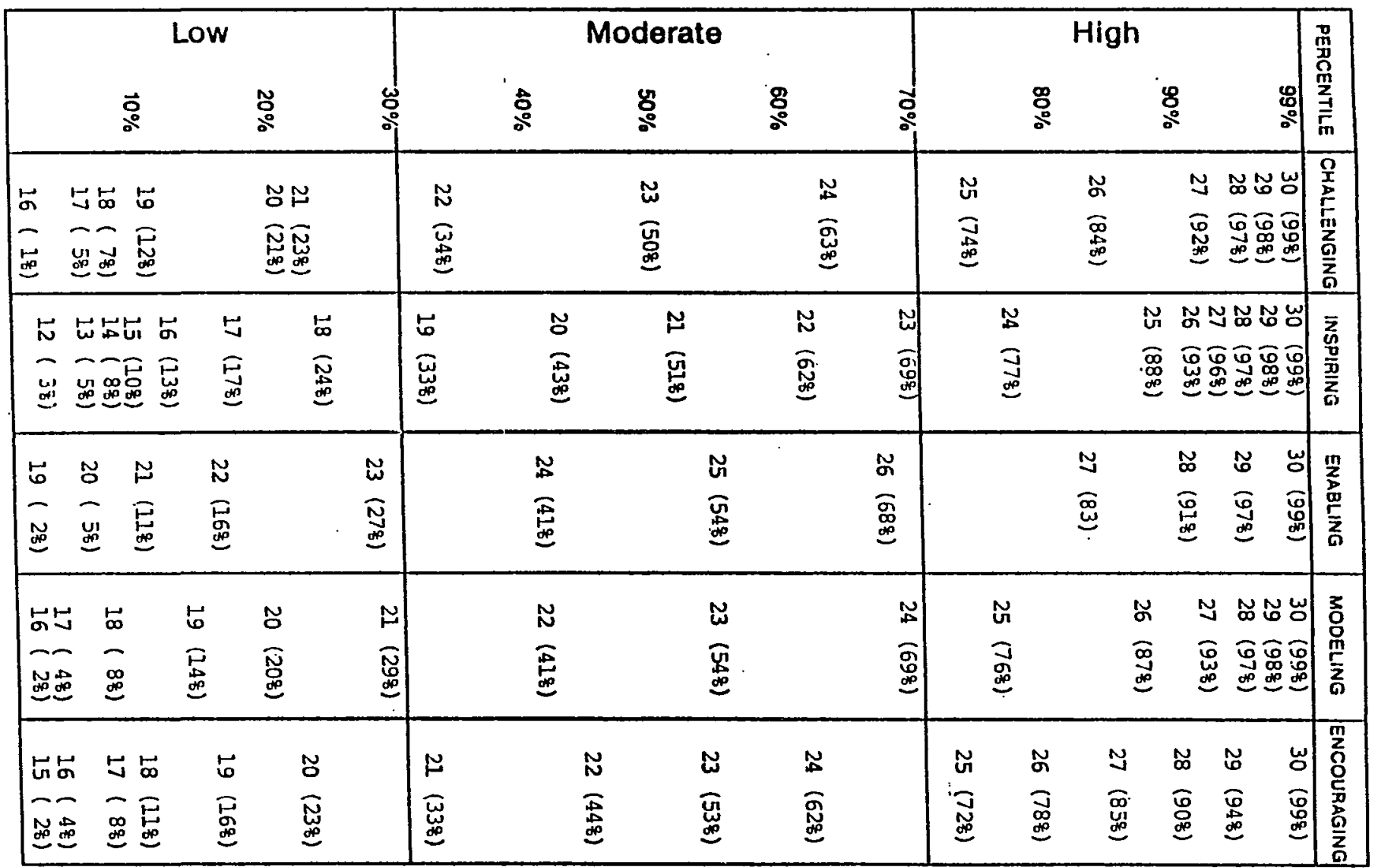




\section{APPENDIX V}

LPI-S PERCENTILE RANKINGS 
Appendix $\mathrm{V}$

LPI-S Percentile Ranking




171

APPENDIX W

IPI-S HISTOGRAMS

Reproduced with permission of the copyright owner. Further reproduction prohibited without permission. 


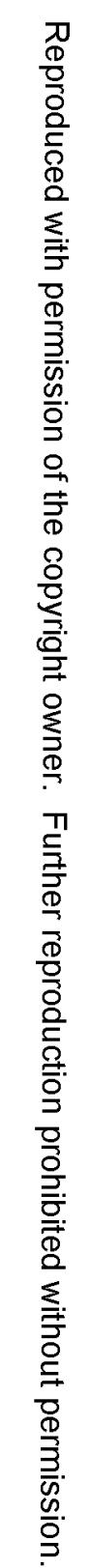

Appendix $W$

LPI-S Histograms

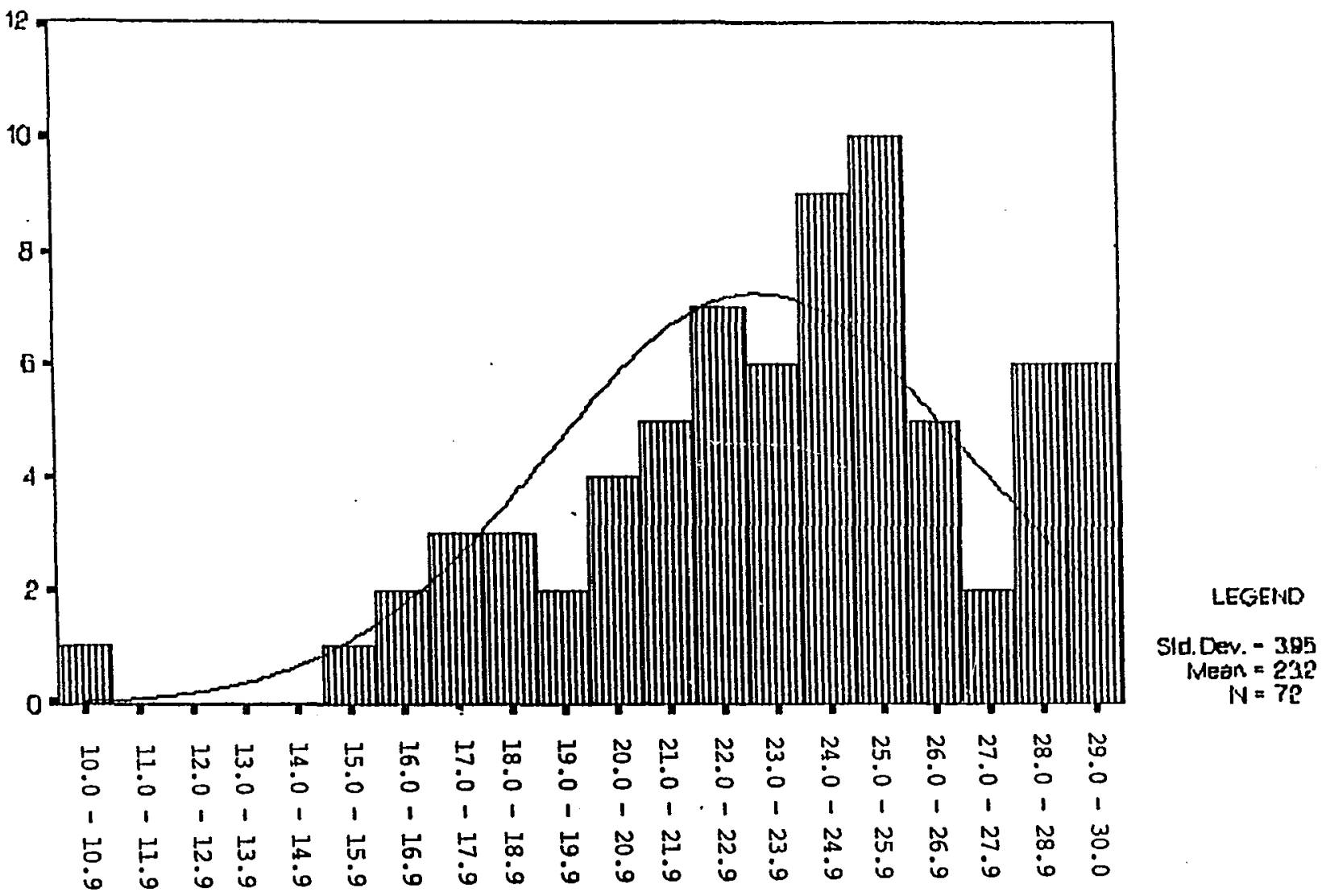

Summary: Challenging 


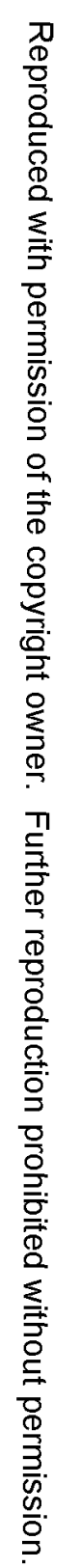

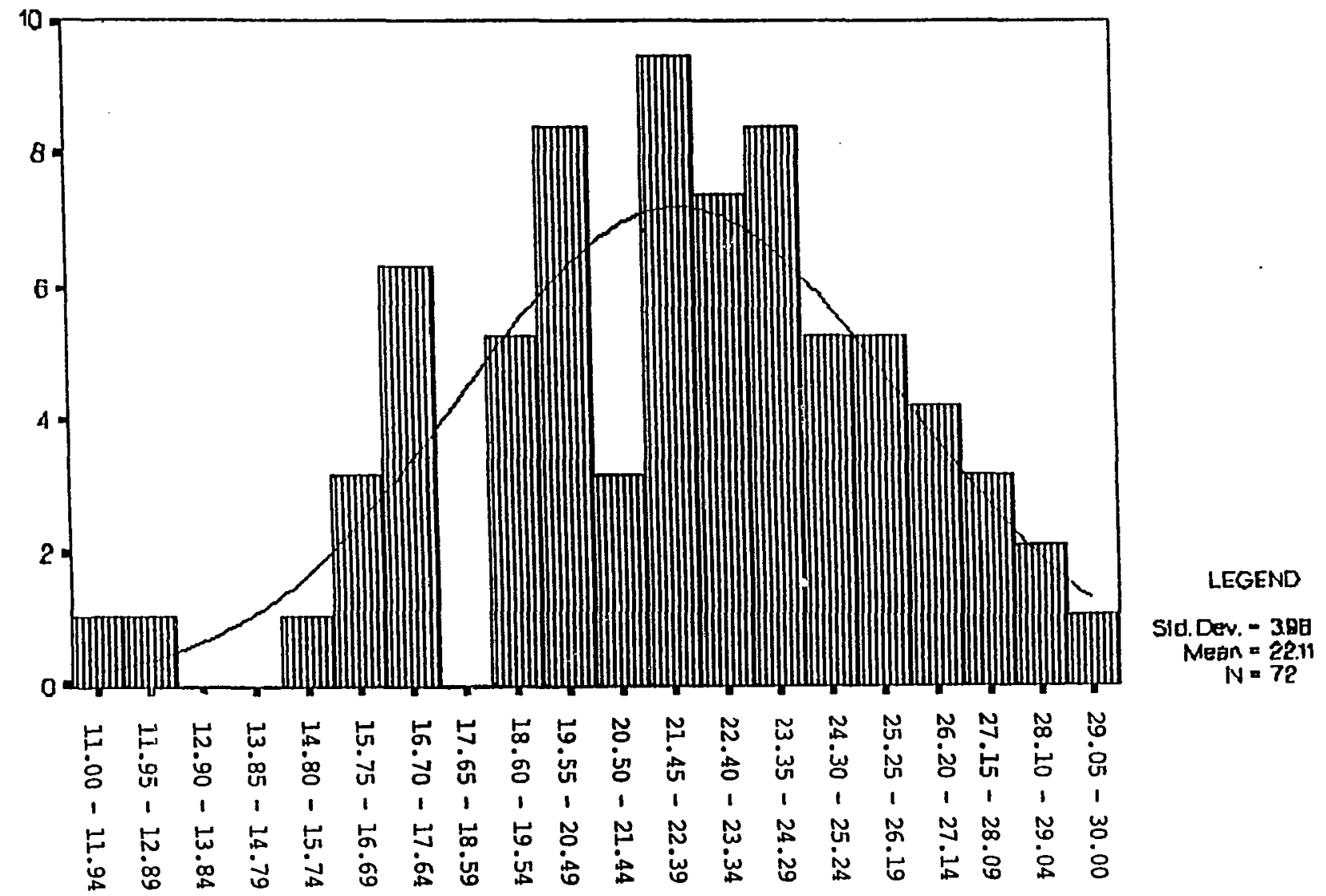

Summary: Inspiring 


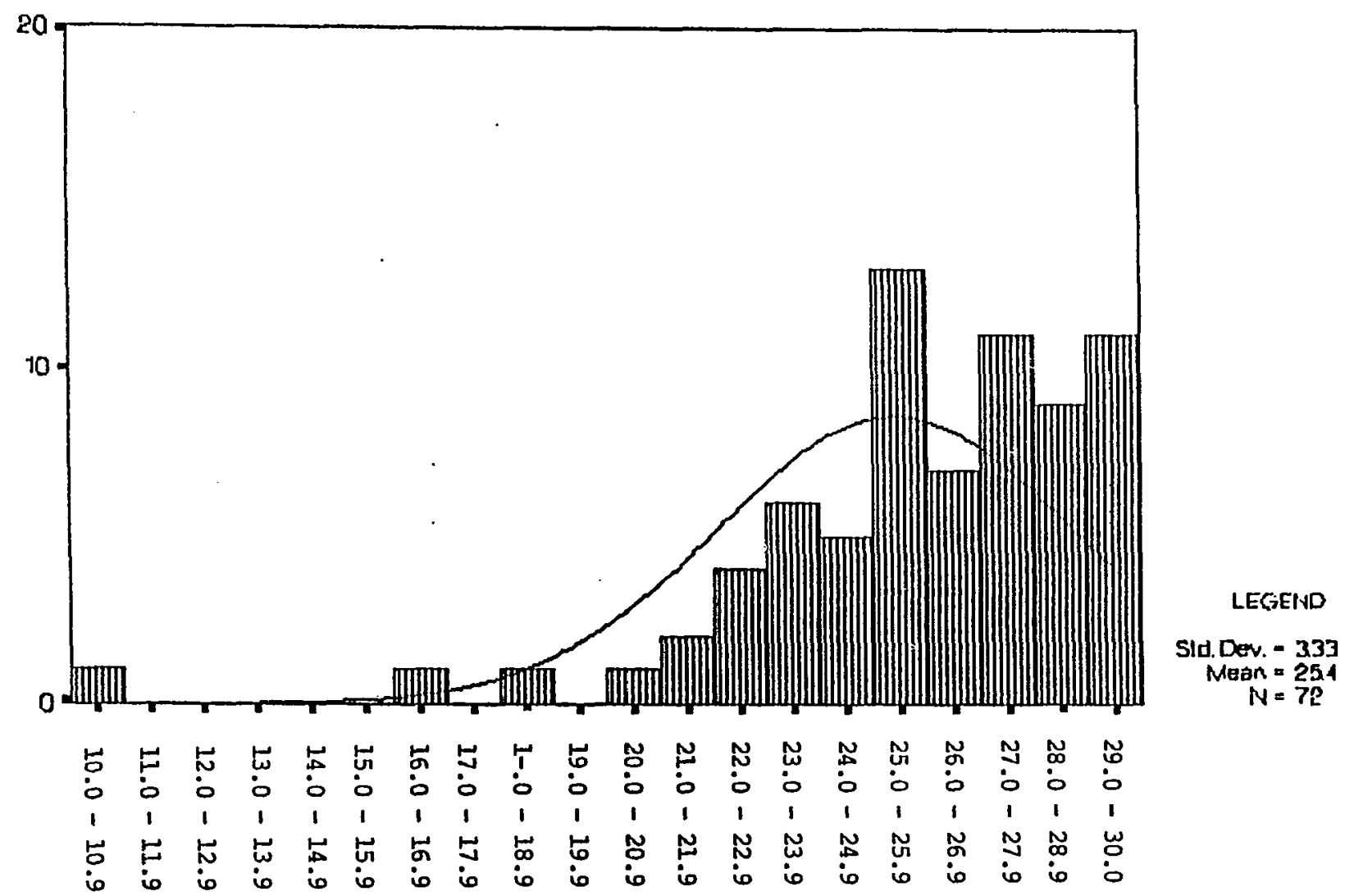

Summary: Enabling 


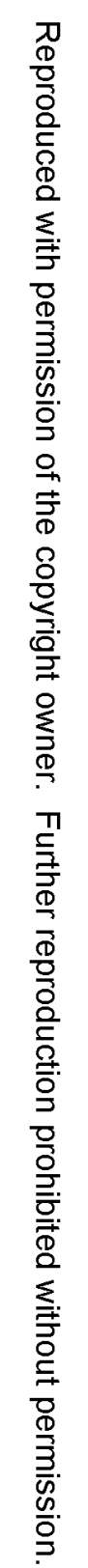

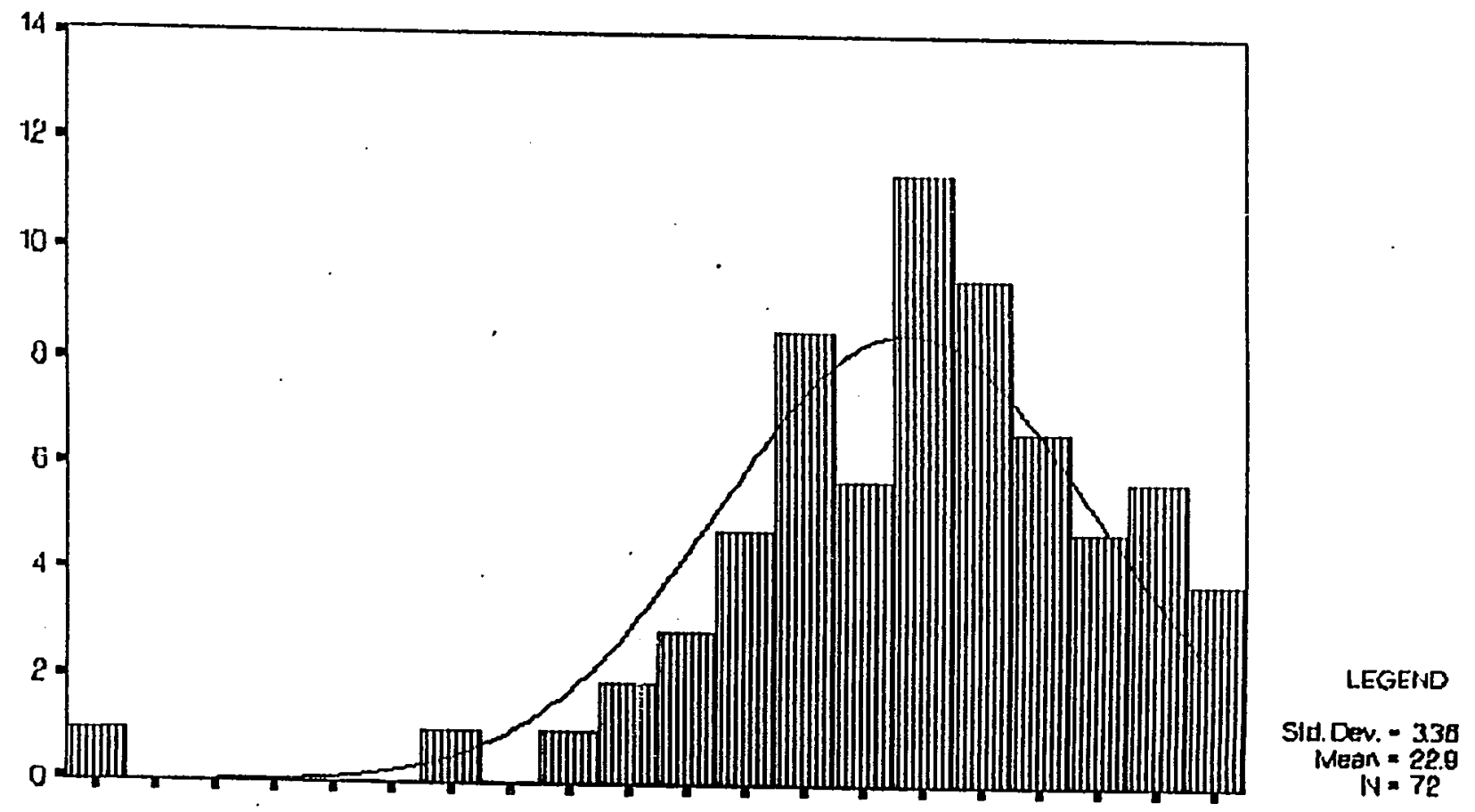

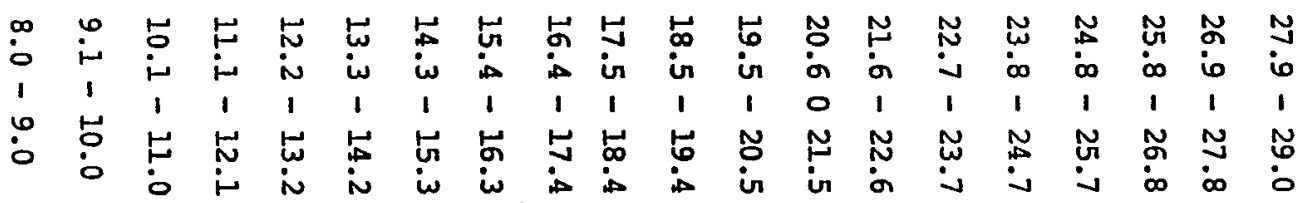

Summary: Modeling 


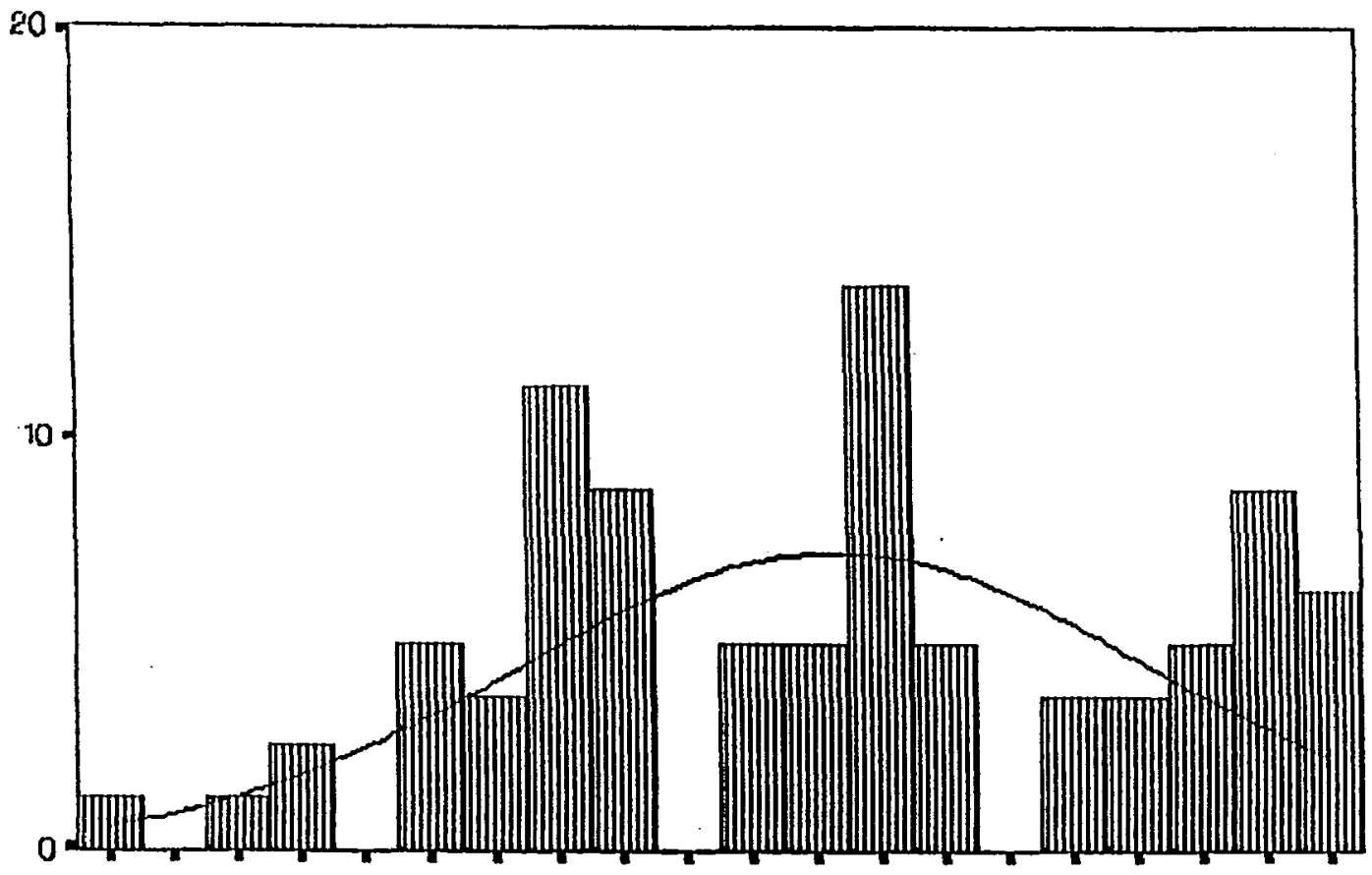

LEGEND

Sid. Cev. -399 $N=72$
$N=234$

占

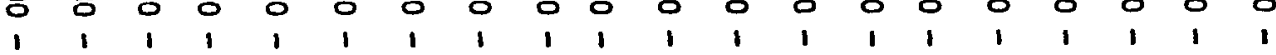

占

Summary: Encouraging 
APPENDIX X

CLUSTERING OF QUESTIONS FOR LPI-S BEHAVIORAL PRACTICES 
APPENDIX Y

SELECTED EXAMPLES OF IPI-S AND LPI-O DIFFERENCES 
Appendix $Y$

Selected Examples of LPI-S and LPI-0 Differences

LPI DIFFERENCES 20004

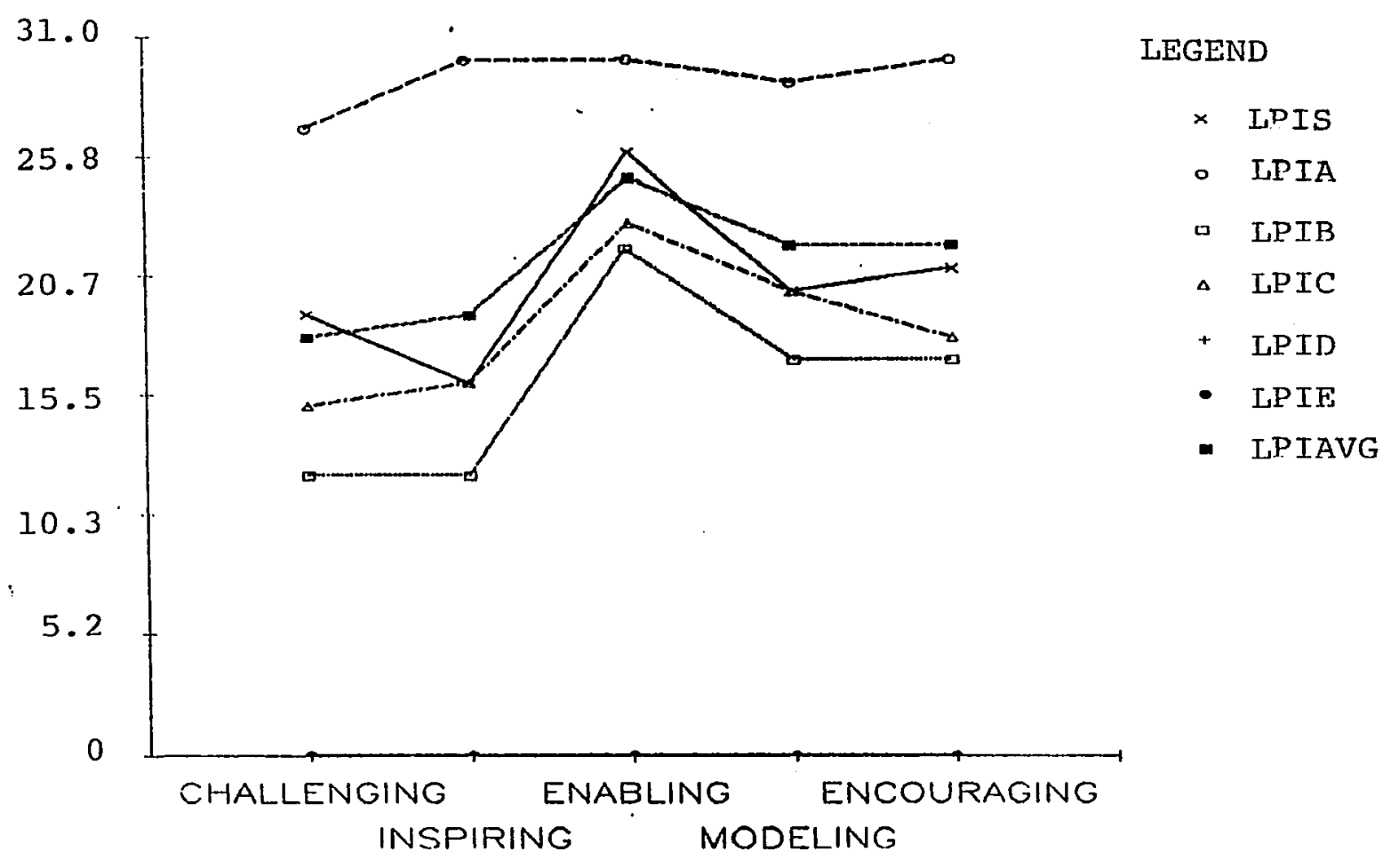


L.PI DIFFERENCES 20006

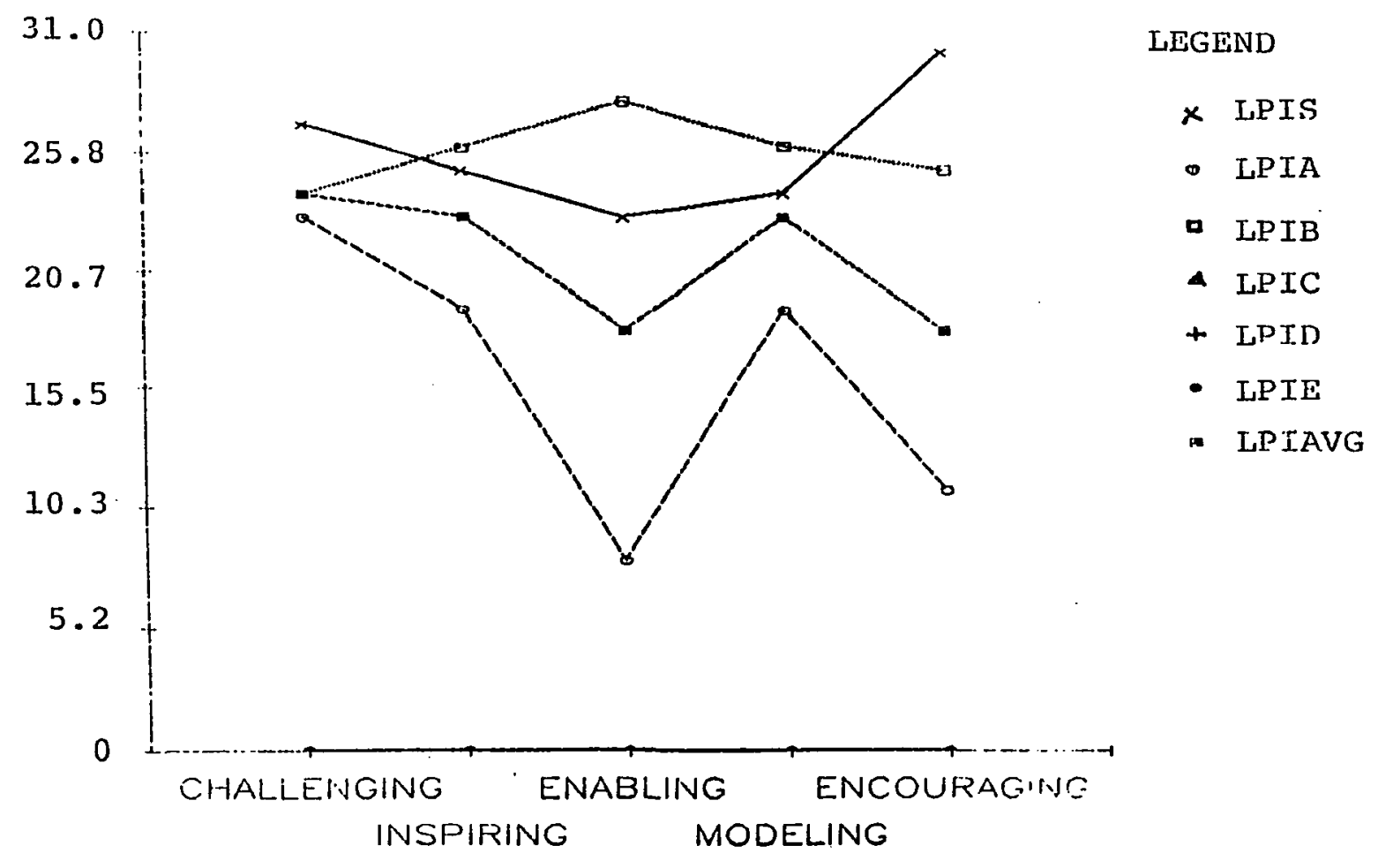




\section{LPI DIFFERENCES} 20011

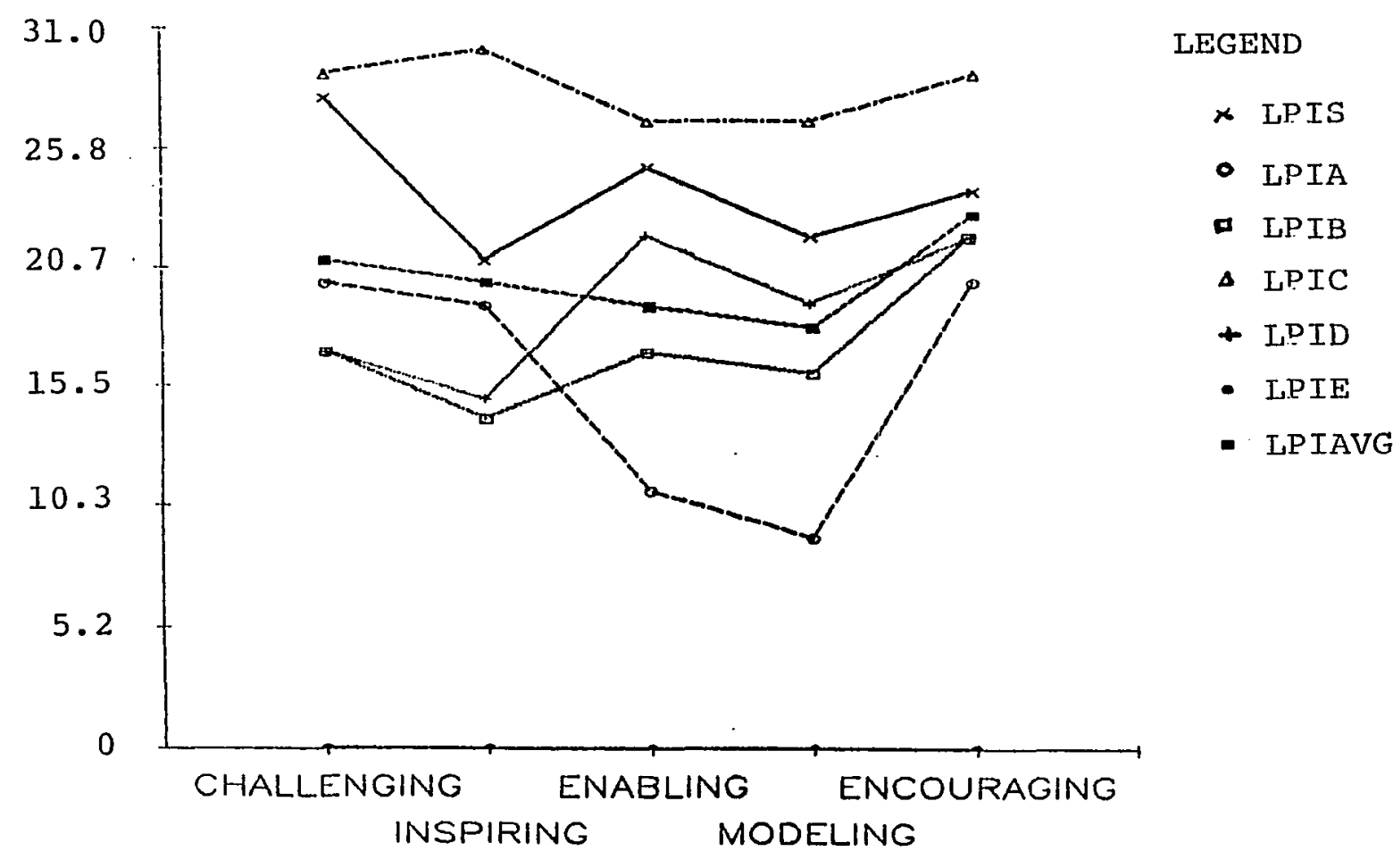


LPI DIFFERENCES 20019

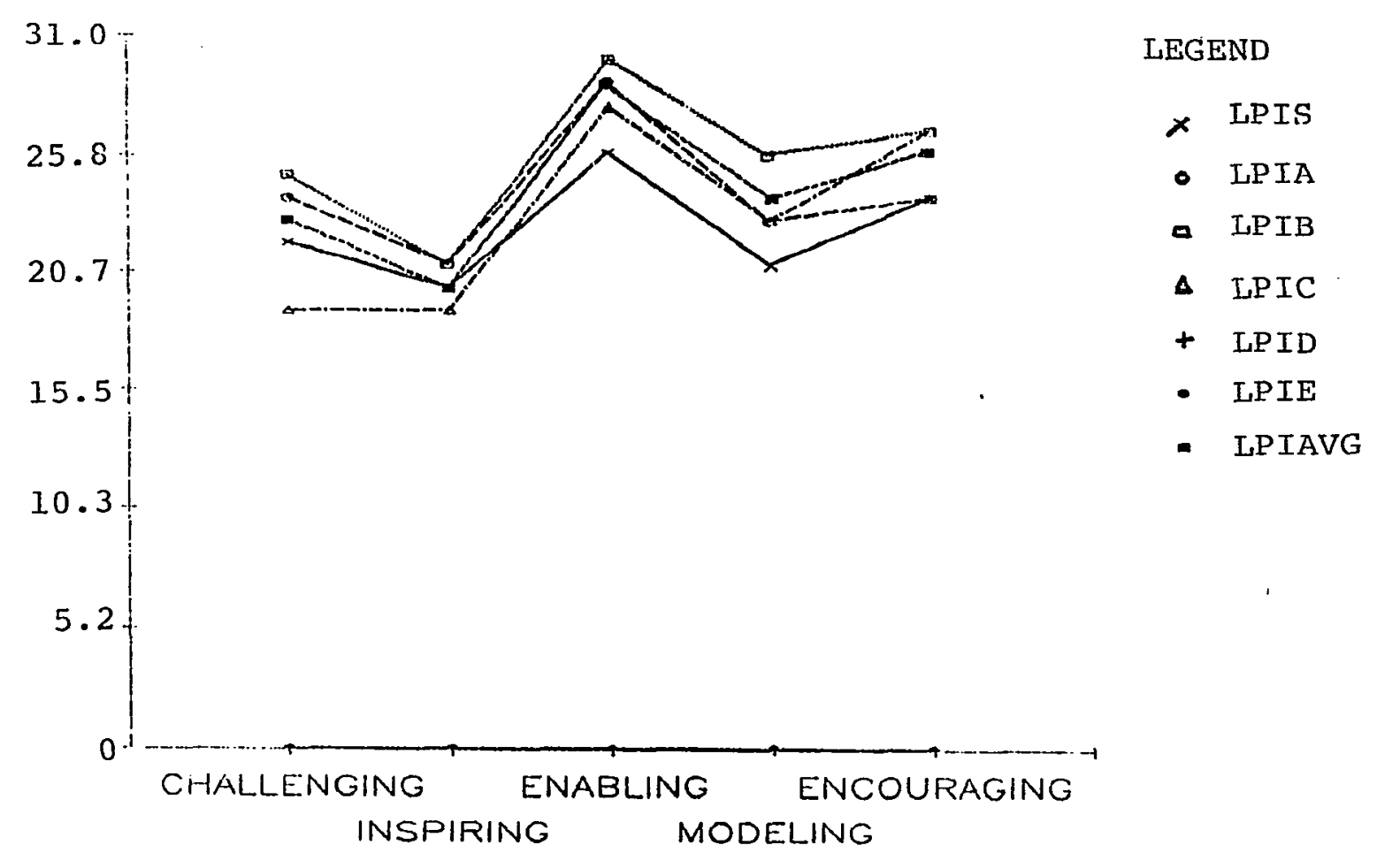




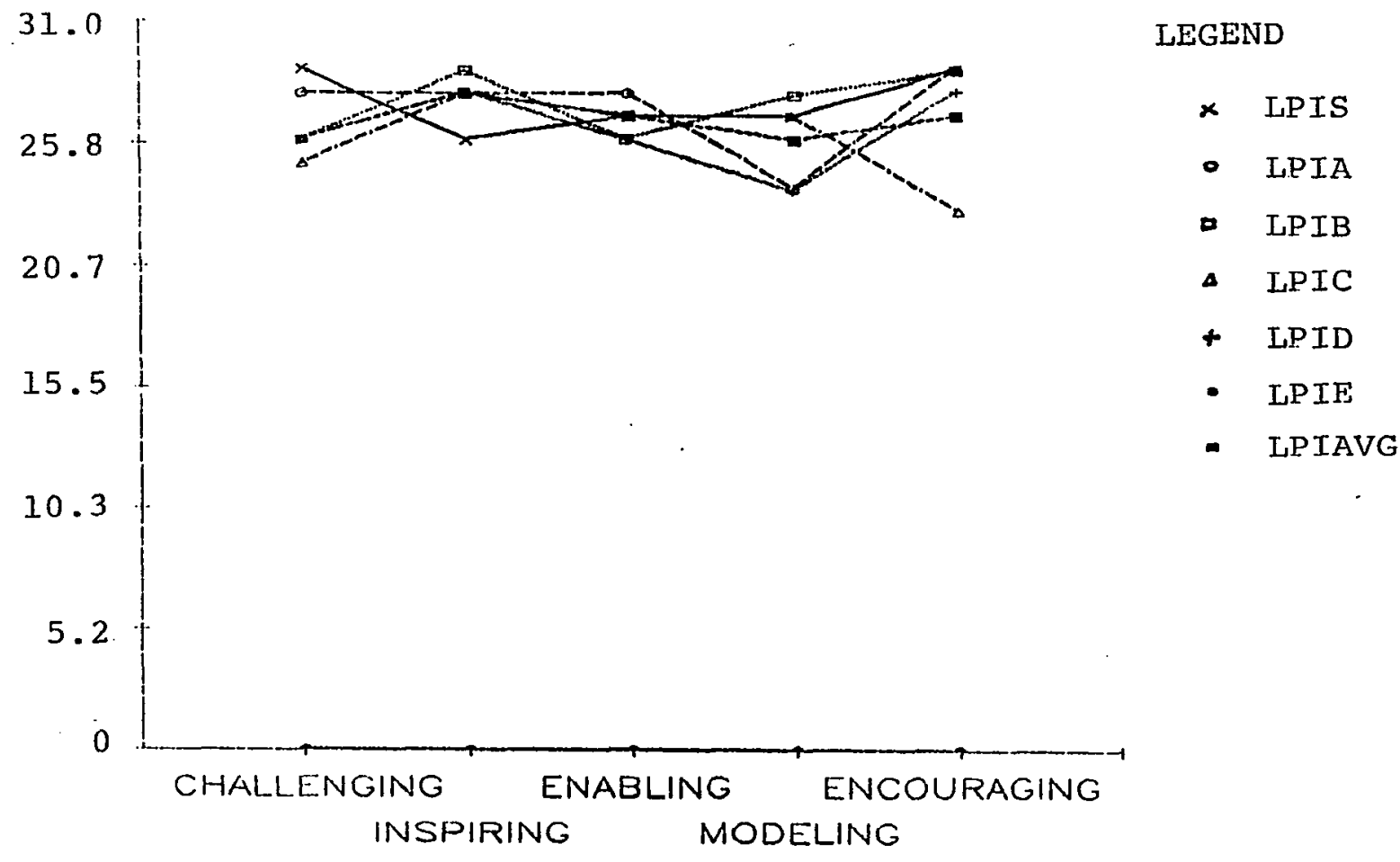




\section{LPI DIFFERENCES} 20026

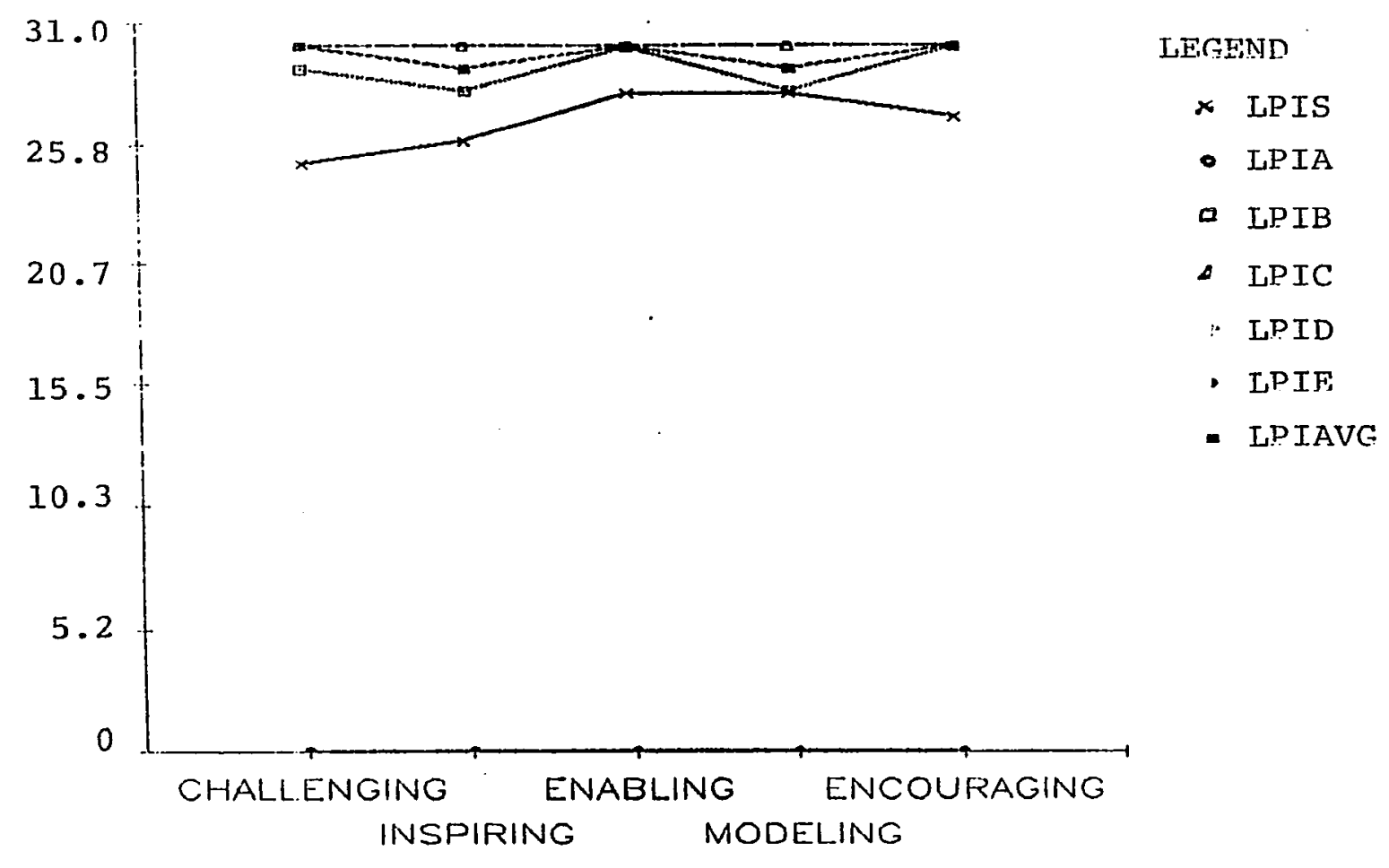


LPI DIFFERENCES 20028



